\title{
Lucas Spada
}

ASPECTOS METABÓLICOS DO CICLO REPRODUTIVO DE FÊMEAS DE Potamotrygon amandae (Chondrichthyes: Myliobatiformes: Potamotrygonidae), EM ÁREA DE OCORRÊNCIA NÃO-NATURAL (RESERVATÓRIO DE JUPIÁ, ILHA SOLTEIRA/SP)

REPRODUCTIVE METABOLIC ASPECTS OF THE FEMALE FRESHWATER STINGRAYS Potamotrygon amandae (Chondrichthyes: Myliobatiformes:

Potamotrygonidae) FROM A NON-NATURAL OCCURRENCE AREA (JUPIA RESERVOIR, ILHA SOLTEIRA/SP)

São Paulo 
ASPECTOS METABÓLICOS DO CICLO REPRODUTIVO DE FÊMEAS DE Potamotrygon amandae (Chondrichthyes: Myliobatiformes: Potamotrygonidae), EM ÁREA DE OCORRÊNCIA NÃO-NATURAL (RESERVATÓRIO DE JUPIÁ, ILHA SOLTEIRA/SP)

\section{REPRODUCTIVE METABOLIC ASPECTS OF THE FEMALE FRESHWATER STINGRAYS Potamotrygon amandae (Chondrichthyes: Myliobatiformes: Potamotrygonidae) FROM A NON-NATURAL OCCURRENCE AREA (JUPIA RESERVOIR, ILHA SOLTEIRA/ SP)}

Exemplar corrigido

Dissertação apresentada ao Instituto de Biociências da Universidade de São Paulo, para obtenção do Título de Mestre em Ciências, na área de Fisiologia Geral.

Orientadora: Profa. Dra. Cristiéle da Silva Ribeiro 
FICHA CATALOGRÁFICA

Spada, Lucas

Aspectos metabólicos do ciclo reprodutivo de fêmeas de Potamotrygon amandae (Chondrichthyes: Myliobatiformes: Potamotrygonidae), em área de ocorrência não-natural (Reservatório de Jupiá, Ilha Solteira/SP). / Lucas Spada; Orientadora Profa. Dra. Cristiéle da Silva Ribeiro -- São Paulo, 2021. $64 \mathrm{p}$.

Dissertação (Mestrado) -- Instituto de Biociências da Universidade de São Paulo. Programade Pós-Graduação em Ciências (Fisiologia).

1. Metabolismo. 2. Histotrofia lipídica. 3. Arraias dulcícolas. 4. Perfil de ácidos graxos. 5.Vitelogênese. I. Universidade de São Paulo. Instituto de Biociências. Departamento de Fisiologia.

Gistiele 5. Ribino

Assinatura do orientador(a) 


\section{Dedico este trabalho:}

À minha mãe Marylza e ao meu pai Cícero, por todo amor, apoio e carinho e por me incentivarem e me encorajarem ao longo dessa jornada.

À minha querida irmã Maisa e aos meus verdadeiros amigos, que me auxiliaram e me apoiaram em todos os momentos.

E também aos animais eutanasiados, pois sem eles essa pesquisa seria impossível de ser realizada. 
"A tarefa não é tanto ver aquilo que ninguém viu, mas pensar o que ninguém ainda pensou sobre aquilo que todo mundo vê" Arthur Schopenhauer 


\section{Agradecimentos}

Primeiramente a Deus, por todas as oportunidades e portas abertas em meu caminho e por guiar toda minha trajetória até chegar aqui. A ele agradeço por todos os dias da minha vida!

À minha querida orientadora, Cristiéle da Silva Ribeiro, por despertar em mim o interesse e a paixão pela Ciência e por me fazer acreditar que no final tudo dá certo, mesmo que não seja como planejamos. Obrigado pela orientação, amizade, dedicação, presença constante, paciência em todos os momentos, além da confiança que depositou em mim todos esses anos. Agradeço imensamente por todo carinho, conhecimento compartilhado, pelas conversas, reuniões, comemorações e por você ser essa pessoa tão querida e por me mostrar como a fisiologia é ainda mais encantadora e apaixonante do que eu imaginava inicialmente. Cris, deixo expresso aqui toda a minha admiração e respeito pela profissional e pessoa que é. Muito obrigado!

À minha colaboradora, profa. Dra. Renata Guimarães Moreira Whitton, por inicialmente ter disposto uma vaga em seu grupo de pesquisa e laboratório para que eu pudesse ingressar na pós-graduação e por toda ajuda neste processo e conhecimento compartilhado. Por todas as revisões, conversas e paciência nestes momentos. Obrigado pela sempre alegria e alto astral.

Aos professores do Departamento de Fisiologia do IB-USP pelos conhecimentos compartilhados, pelas disciplinas ministradas e inspiração para o estudo da fisiologia. Um agradecimento em especial ao meu orientador acadêmico Prof. Dr. Fernando Ribeiro Gomes, que desde o início do projeto auxiliou muito com conselhos e sugestões.

A todos os funcionários do Instituto de Biociências pelos serviços prestados de forma competente, bem-humorada, por toda a ajuda. Agradeço principalmente à Roseli secretária no Depto. de Fisiologia e Érika secretária do Programa de Pós-Graduação do IB.

A doutoranda Jumma Miranda Araújo Chagas e doutorando Douglas C. Ribeiro pelo auxílio na coleta dos animais no campo e laboratório.

À Guarda Municipal da cidade de Ilha solteira, especialmente ao Luiz e Fabiano, pelo auxílio durante as coletas dos animais no campo. 
Aos integrantes/companheiros do LEFISA (Laboratório de Estudos em Fisiologia Animal - Unesp, Campus II), Dirceu, Ariadyne, Bárbara, Emanuelle, César e Agatha, por estarem sempre presentes me auxiliando no laboratório; dando dicas, sugestões e ótimas críticas; além de broncas e risadas; viagens, festas, ou simplesmente uma boa conversa. Vocês todos tiveram grande importância na minha caminhada, nada seria igual sem vocês.

Aos integrantes do LAMEROA (Laboratório de Metabolismo e Reprodução de Organismo Aquáticos), em especial à Bianca e à Aline pela ajuda com as análises e processos realizados no laboratório, além de todo conhecimento compartilhado ao longo deste trabalho. Agradeço também aos integrantes do Laboratório Pirá (Laboratório de Ecologia de Peixes), especialmente a Bruna, Cibele e José Daniel, pela ajuda oferecida durante os procedimentos laboratoriais e análises, além do conhecimento compartilhando ao longo deste percurso.

À CAPES (Coordenação de Aperfeiçoamento de Pessoal de Nível Superior) pela bolsa (processo 88882.377384/2019-01) concedida durante o período desta pesquisa.

Aos meus colegas e amigos Ingrid, Aline, Laís, Stella, Bruna, Cibele, Caio e José Daniel pelo companheirismo, compartilhamento de conhecimentos, grupos de estudos, críticas construtivas, risadas, brincadeiras, broncas, festas e por estarem a todo tempo ao meu lado tornando esses anos maravilhosos e desbravando esse mundo gigante de possibilidades que é a pós-graduação. A vocês que agradeço de coração e é lá que vocês ficaram guardados para sempre.

Aos meus pais, Cícero Jesus Spada e Marylza de Fátima Fracassio Spada, que sempre me apoiaram em minhas decisões e me incentivaram a sempre correr atrás dos meus sonhos e me encorajaram em toda minha jornada. À minha irmã Maisa, que sempre me aconselhou que por mais difícil que seja nossa caminhada nunca sejamos fracos pra desistir e que devemos continuar sempre em frente e de cabeça erguida.

A todos aqueles que não foram mencionados, mas que contribuíram direta ou indiretamente para a realização deste trabalho e que contribuíram para minha formação profissional e intelectual.

Enfim, minha sincera gratidão a todas as pessoas que, com amizade e seriedade, colaboraram para a realização desse trabalho. 


\section{Sumário}

Lista de Abreviações ..................................................................................................................................................i

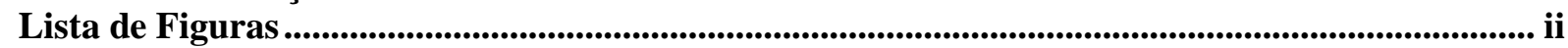

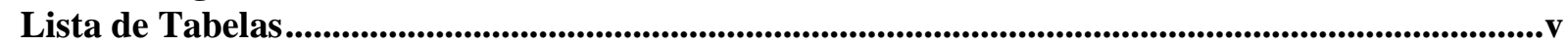

Lista de Apêndices ................................................................................................................................................vi

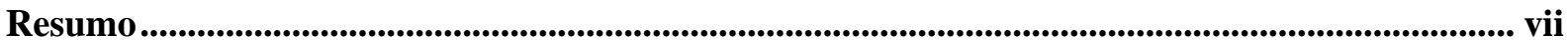

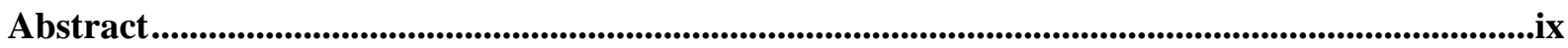

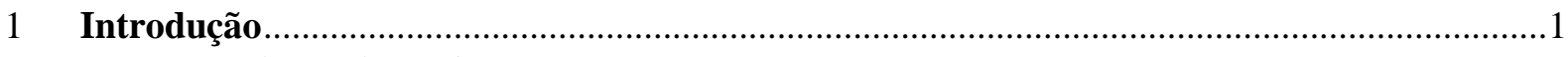

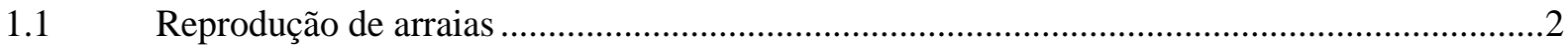

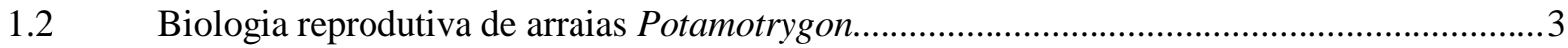

1.3 Metabolismo de substratos energético em elasmobrânquios...................................................

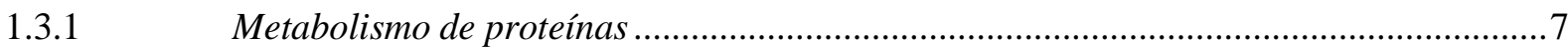

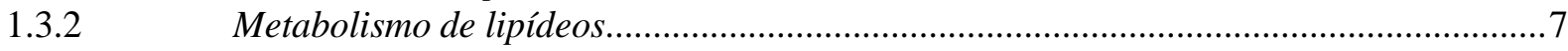

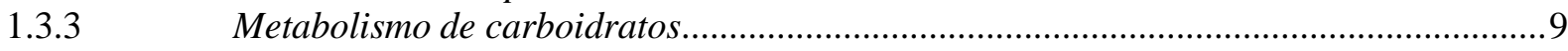

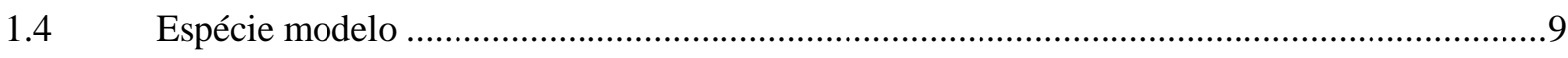

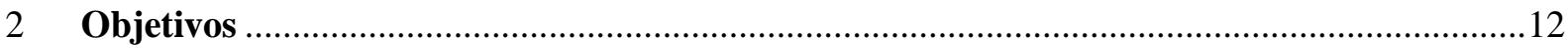

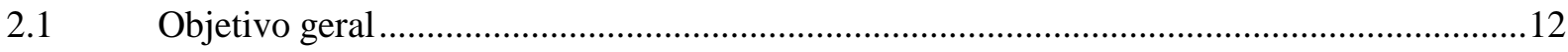

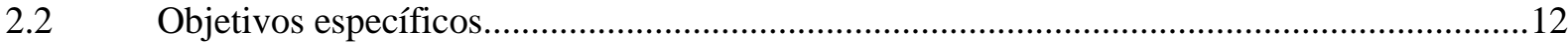

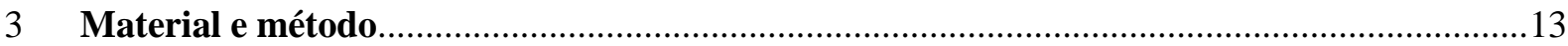

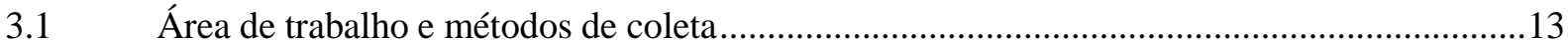

3.2 Classificação do estágio reprodutivo da espécie .................................................................15

3.3 Análise de substratos metabólicos....................................................................................16

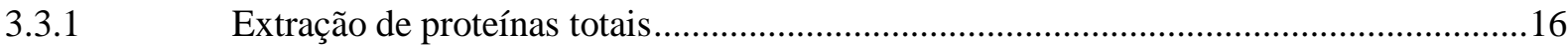

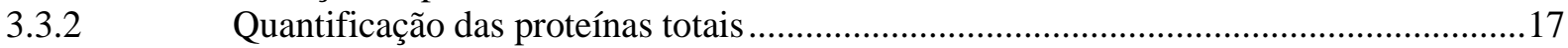

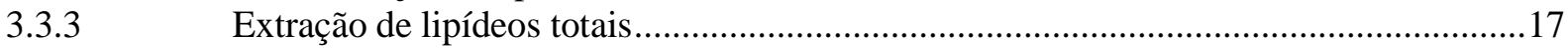

3.3.4 Quantificação de lipídeos totais............................................................................17

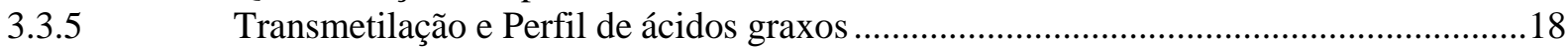

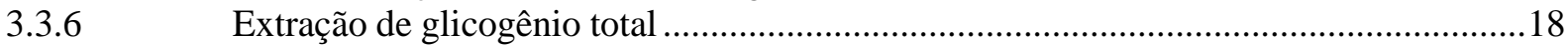

3.3.7 Quantificação de glicogênio total ...............................................................................19

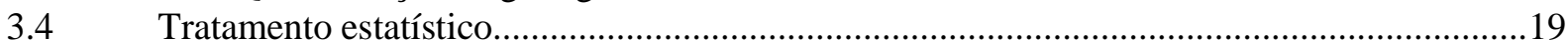

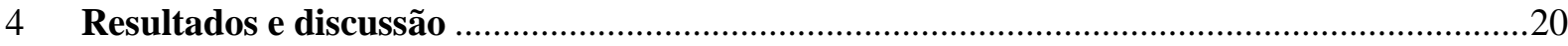

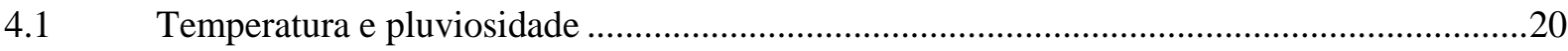

4.2 Classificaçãa do estágio reprodutivo das fêmeas ………........................................................20

4.3 Índice Hepatossomático (IHS) e Gonadossomático (IGS) ......................................................21

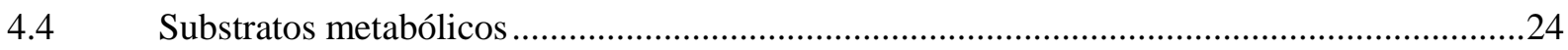

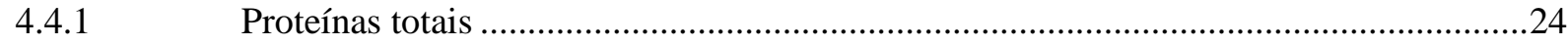

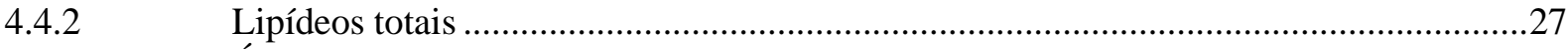

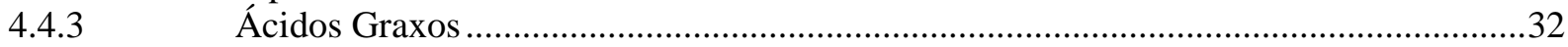

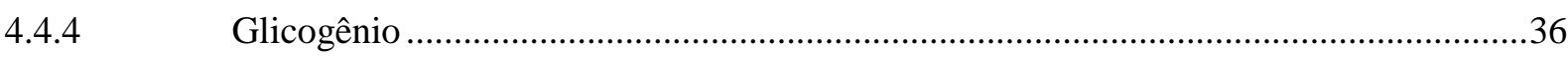

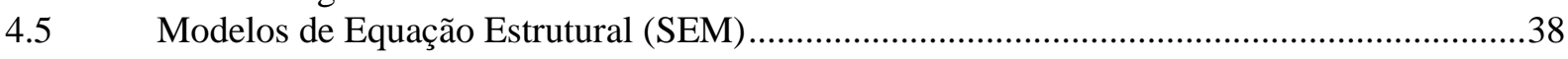

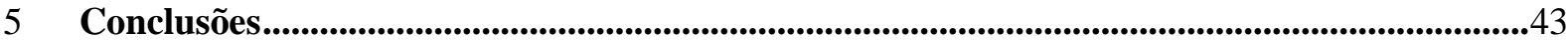

6 Referências bibliográficas..................................................................................................44

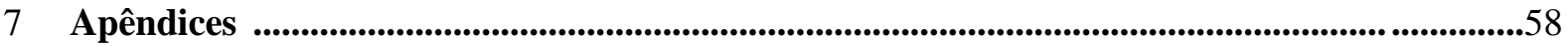





\section{Lista de Abreviações}

AGL - Ácidos graxos livres

$\mathrm{CD}$ - Comprimento do disco

CITES - Comercio Internacional de Espécies Ameaçadas de Fauna e Flora Silvestre CPT - Carnitina palmitoiltransferase

$\mathrm{CT}$ - Comprimento total

$\mathrm{GC}$ - Cromatografia gasosa

GDH - Glutamato desidrogenase

GS - Glutamina sintetase

HOAD - 3-Hidroxiacil CoA Desidrogenase

IAVH - Instituto de Pesquisa de Recursos Biológicos Alexander von Humboldt

IGS - Índice gonadossomático

IHS - Índice hepatossomático

IUCN - União Internacional para a Conservação da Natureza

K2SO4 - Sulfato de potássio

$\mathrm{KOH}$ - Hidróxido de potássio

LD - Largura do disco

LEFISA - Laboratório de Estudos em Fisiologia Animal

PCA - Ácido perclórico

PK - Piruvato quinase

SEM - Modelo de equação estrutural

VTG - Vitelogenina

$\beta$-HB - $\beta$-Hidroxibutirato

$\beta$-HBDH $-\beta$-hidroxibutirato desidrogenase 


\section{Lista de Figuras}

Figura 1. Potamotrygon amandae Loboda \& Carvalho, 2013. Fêmea adulta, coletada em fevereiro /2018, traço representa escala de $1 \mathrm{~cm}$.

Figura 2. Localização geográfica da área de coleta de exemplares de Potamotrygon amandae no Alto Rio Paraná (reservatório de Jupiá, Ilha Solteira/SP). Marcador vermelho: local de amostragem. Fonte da imagem: Bruno Silva.

Figura 3. Dados de temperatura e pluviosidade anual da região de coleta: município de Ilha Solteira, SP. Fonte: Rede Agrometeorológica do Noroeste Paulista.

Figura 4. Aferição de dados biométricos de Potamotrygon amandae: comprimento do disco (CD), largura do disco (LD) e comprimento total (CT).

Figura 5. Análise macroscópica das gônadas de Potamotrygon amandae no estágio de repouso: Ovário esquerdo bem irrigado, úteros vazios, menos irrigados e mais retraídos. Escala de $1 \mathrm{~cm}$.

Figura 6. Análise macroscópica das gônadas de Potamotrygon amandae no estágio de vitelogênese: Ovário esquerdo bem desenvolvido e irrigado. Setas indicam folículos ovarianos em desenvolvimento e bem desenvolvidos. Escala de $1 \mathrm{~cm}$.

Figura 7. Análise macroscópica das gônadas de Potamotrygon amandae no estágio de gravidez: Ovário esquerdo bem irrigado; úteros com presença de trofonemas em abundância. A- Trofonema. B- Leite Uterino. C- Oócitos em desenvolvimento. Escala de $1 \mathrm{~cm}$.

Figura 8. Classificação de estágios reprodutivos de fêmeas de Potamotrygon amandae com base nas análises macroscópicas dos ovários e presença de embriões no útero, coletadas no Alto Rio Paraná (reservatório de Jupiá, Ilha Solteira/SP). Cor azul indica estágio Imatura, cor laranja Repouso, cor cinza Vitelogênese e cor amarela Grávida.

Figura 9. Índice Hepatossomático de fêmeas de Potamotrygon amandae coletadas no Alto Rio Paraná (reservatório de Jupiá, Ilha Solteira/SP): ${ }^{a}, \mathrm{~b}$ mostram diferença estatística significativa $(\mathrm{P}<0,05)$ entre os meses de coleta.

Figura 10. Índice Gonadossomático de fêmeas de Potamotrygon amandae coletadas no Alto Rio Paraná (reservatório de Jupiá, Ilha Solteira/SP): ${ }^{a}$, mostram diferença estatística significativa $(\mathrm{P}<0,05)$ entre os meses de coleta. 
Figura 11. Correlação de Spearman entre o Índice Hepatossomático (IHS) e Índice Gonadossomático (IGS) de fêmeas de Potamotrygon amandae coletadas no Alto Rio Paraná (reservatório de Jupiá, Ilha Solteira/SP). A intensidade das cores indica maior índice de correlação, próximas de $1 \mathrm{ou}-1$. A cor azul indica correlação positiva e vermelha correlação negativa entre as variáveis testadas.

Figura 12. Concentração de proteínas totais teciduais de fêmeas de Potamotrygon amandae coletadas no Alto Rio Paraná (reservatório de Jupiá, Ilha Solteira/SP). ${ }^{\text {a,b }}$ letras acima das barras mostram diferença estatística significativa $(\mathrm{P}<0,05)$ entre os meses de coleta.

Figura 13. Concentração de lipídeos totais teciduais de fêmeas de Potamotrygon amandae coletadas no Alto Rio Paraná (reservatório de Jupiá, Ilha Solteira/SP). ${ }^{\text {a,b }}$ letras acima das barras mostram diferença estatística significativa $(\mathrm{P}<0,05)$ entre os meses de coleta.

Figura 14. Concentração de glicogênio em fêmeas de Potamotrygon amandae coletadas no Alto Rio Paraná (reservatório de Jupiá, Ilha Solteira/SP. A) Glicogênio hepático. B) Glicogênio muscular. C) Glicogênio ovariano. D) Glicogênio uterino. Média \pm Desvio: a,b mostram diferença estatística significativa $(\mathrm{P}<0,05)$ entre os meses de coleta.

Figura 15. Modelo de equação estrutural (SEM) mostrando conexões diretas entre o estágio reprodutivo e os substratos proteicos e lipídicos teciduais. Os números associados às relações entre as variáveis são coeficientes apresentados como valores padronizados pelos desviospadrão das variáveis. Os números dentro das caixas são os valores de $R^{2}$ de cada uma das variáveis de saída do modelo. Setas sólidas mostram conexões significativas $(\mathrm{P}<0,05)$, setas tracejadas mostram conexões não significativas $(\mathrm{P}>0,05)$. Qualidade do ajuste do $\operatorname{SEM}: \mathrm{P}\left(\chi^{2}\right)$ $=0,386$ (um bom ajuste do modelo indicando que o modelo claramente não é significativamente diferente do modelo teórico). PM- Proteína muscular; PF- Proteína hepática; PO- Proteína ovariana; PUProteína uterina; LM- Lipídeo muscular; LF- Lipídeo hepático; LO- Lipídeo ovariana; LU- Lipídeo uterina.

Figura 16. Modelo de equação estrutural (SEM) mostrando conexões diretas entre o estágio reprodutivo e os substratos hepáticos e indiretas entre estágio reprodutivo e substratos hepáticos via índice hepatossomático. Os números associados às relações entre as variáveis são coeficientes apresentados como valores padronizados pelos desvios- padrão das variáveis. Os números dentro das caixas são os valores de $\mathrm{R}^{2}$ de cada uma das variáveis de saída do modelo. Setas sólidas mostram conexões significativas $(\mathrm{P}<0,05)$, setas tracejadas mostram conexões não significativas $(\mathrm{P}>0,05)$. Qualidade do ajuste do SEM: $\mathrm{P}\left(\chi^{2}\right)=0,477$ (um bom ajuste do modelo 
indicando que o modelo claramente não é significativamente diferente do modelo teórico). PFProteína hepática; LF- Lipídeo hepático; GF- Glicogênio hepático.

Figura 17. Modelo de equação estrutural (SEM) mostrando conexões diretas entre o estágio reprodutivo, substratos hepáticos, ovarianos e uterinos e indiretas entre estágio reprodutivo e substratos ovarianos e uterinos via substratos hepáticos. Os números associados às relações entre as variáveis são coeficientes apresentados como valores padronizados pelos desviospadrão das variáveis. Os números dentro das caixas são os valores de $R^{2}$ de cada uma das variáveis de saída do modelo. Setas sólidas mostram conexões significativas $(\mathrm{P}<0,05)$, setas tracejadas mostram conexões não significativas $(\mathrm{P}>0,05)$. Qualidade do ajuste do SEM: $\mathrm{P}\left(\chi^{2}\right)$ $=0,128$ (um bom ajuste do modelo indicando que o modelo claramente não é significativamente diferente do modelo teórico). PF- Proteína hepática; LF- Lipídeo hepático; GF- Glicogênio hepático; POProteína ovariana; LO- Lipídeo ovariano; GF- Glicogênio ovariano; PU- Proteína uterina; LF- Lipídeo uterino; GF- Glicogênio uterino. 


\section{Lista de Tabelas}

Tabela 1. Valores de Correlação $\mathrm{R}^{2}$ e $\mathrm{P}$ estatístico entre o Índice Hepatossomático (IHS) e Índice Gonadossomático (IGS) de fêmeas de Potamotrygon amandae coletadas no Alto Rio Paraná (reservatório de Jupiá, Ilha Solteira/SP).

Tabela 2. Lipídeos totais hepáticos em elasmobrânquios e teleósteos. 


\section{Apêndices}

Apêndice 1. Dados dos substratos metabólicos (proteínas, lipídeos e glicogênio) em fêmeas de Potamotrygon amandae coletadas noAlto Rio Paraná (reservatório de Jupiá, Ilha Solteira/SP) (Média \pm Desvio padrão).

Apêndice 2. Perfil de ácidos graxos (\%) do tecido hepático de fêmeas de Potamotrygon amandae coletadas no Alto Rio Paraná (reservatório de Jupiá, Ilha Solteira/SP) ao longo do ciclo reprodutivo (Média \pm EPM).

Apêndice 3. Perfil de ácidos graxos (\%) do tecido muscular de fêmeas de Potamotrygon amandae coletadas no Alto Rio Paraná (reservatório de Jupiá, Ilha Solteira/SP) ao longo do ciclo reprodutivo (Média \pm EPM).

Apêndice 4. Perfil de ácidos graxos (\%) do tecido ovariano de fêmeas de Potamotrygon amandae coletadas no Alto Rio Paraná (reservatório de Jupiá, IlhaSolteira/SP) ao longo do ciclo reprodutivo (Média \pm EPM).

Apêndice 5. Perfil de ácidos graxos (\%) do tecido uterino de fêmeas de Potamotrygon amandae coletadas no Alto Rio Paraná (reservatório de Jupiá, Ilha Solteira/SP) ao longo do ciclo reprodutivo (Média \pm EPM). 


\section{Resumo}

As arraias da Ordem Myliobatiformes são consideradas vivíparas, não placentárias, histotróficas. Na fase intermediária da gestação os embriões recebem nutrientes do saco vitelino e histotrofo, sendo nutridos inicialmente pelo vitelo (lecitrofia) e, posteriormente, são alimentados por uma secreção da mucosa viliforme do útero da mãe, conhecido como trofonema, que é rica em lipídeos e proteínas de grande peso molecular. Este fluido uterino é conhecido como "leite uterino", ainda pouco estudado. O objetivo deste trabalho foi investigar a dinâmica de armazenamento e alocação de substratos metabólicos ao longo do ciclo reprodutivo da espécie vivípara histotrófica Potamotrygon amandae em área de ocorrência nãonatural, no reservatório de Jupiá, Ilha Solteira, SP. As coletas dos exemplares foram realizadas no reservatório da Usina Hidrelétrica Engenheiro Souza Dias - “Jupiá”, Ilha Solteira-SP, entre os meses de janeiro a dezembro de 2018, com aferição de dados biométricos e ponderais das fêmeas. A análise dos dados ambientais permitiu a classificação do local de coleta em dois períodos bem marcados (chuvoso e seca). Os animais coletados foram anestesiados e eutanasiados, com posterior extração do tecido hepático, muscular, ovariano e uterino, e foram classificados de acordo com análise macroscópica dos ovários e presença de filhotes, em três estágios reprodutivos: repouso, vitelogênese e grávidas. Posteriormente foram realizados cálculos dos índices hepatossomático e gonadossomático e mensuração da concentração de proteínas, lipídeos e glicogênio dos tecidos. A espécie apresenta estágio de repouso ocorrendo entre os meses de fevereiro a maio, vitelogênese nos meses de maio a novembro e gravidez entre os meses de novembro a março. O IHS mostrou maiores valores naseca, correspondendo à vitelogênese da espécie, mesmo padrão observado para IGS, que mostrou um pico no mês de agosto. Uma correlação positiva foi observada entre os dois índices, o que inviabiliza a hipótese de alocação entre os dois tecidos durante a vitelogênese. As proteínas hepáticas mostraram padrão de alocação tecidual, com aumento durante a vitelogênese e diminuição durante o período de gravidez, com útero e ovário mantendo concentrações estáveis deste substrato. O ápice da seca em julho parece ser um mês de prejuízo deste substrato, com menores valores para fígado, músculo e ovários, aparentemente fruto de escassez de recursos alimentares. Potamotrygon amandae, assim como outros elasmobrânquios, apresentaram altas concentrações de lipídeos hepáticos; enquanto o tecido muscular apresenta valores ínfimos deste substrato, fruto da ausência de oxidação muscular deste substrato. A histotrofia lipídica foi demostrada pelas maiores concentrações de lipídeos nos meses correspondentes ao período de gravidez no tecido uterino, além das maiores porcentagens de saturado (SAT) e monoinsaturado (MUFA) neste período; nos meses de gravidez cerca de $90 \%$ da composição do tecido uterino (reflexo para a composição do leite 
uterino) são representados por SAT e MUFA; e a gliconeogênese e armazenamento de glicogênio parece ocorrer nos tecidos hepático e ovariano, enquanto o tecido muscular aparentemente realiza glicólise mais ativamente.

Palavras-chave: Metabolismo. Histotrofia lipídica; Arraias dulciaquícolas; Perfil de ácidos graxos. Vitelogênese. 


\begin{abstract}
The rays of the Order Myliobatiformes are considered viviparous, non-placental, histotrophic. In the intermediate stage of gestation, embryos receive nutrients from the yolk sac and histotrophic tissue, being initially nourished by yolk (lecitrophy) and later fed by a secretion from the villiform mucosa of the mother's uterus, known as trophonema, which is rich in lipids and high molecular weight proteins. This uterine fluid is known as "uterine milk", which has not yet been studied. The objective of this work was to investigate the dynamics of storage and allocation of metabolic substrates along the reproductive cycle of the histotrophic viviparous
\end{abstract} species Potamotrygon amandae in an unnaturally occurring area, in the Jupiá reservoir, Ilha Solteira, SP. The collections of the specimens were carried out in the reservoir of the Engenheiro Souza Dias Hydroelectric Plant - "Jupiá", Ilha Solteira-SP, between the months of January to December 2018, with measurement of biometric and weight data of the females. The analysis of environmental data allowed the classification of the collection site in two wellmarked periods (rainy and dry). The animals collected were anesthetized and euthanized, with subsequent extraction of liver, muscle, ovarian and uterine tissue, and were classified according to macroscopic analysis of the ovaries and the presence of puppies, in three reproductive stages:rest, vitellogenesis and pregnant. Subsequently, calculations of the hepatosomatic and gonadosomatic indexes and measurement of the concentration of proteins, lipids and glycogen in the tissues were performed. The species presents a resting stage occurring between the months of February to May, vitellogenesis in the months of May to November and pregnancy between the months of November to March. The IHS showed higher values in the drought, corresponding to the vitellogenesis of the species, the same pattern observed for IGS, which showed a peak in the month of August. A positive correlation was observed between thetwo indexes, which precludes the hypothesis of allocation between the two tissues during vitellogenesis. Liver proteins showed a pattern of tissue allocation, with an increase during vitellogenesis and a decrease during the pregnancy period, with uterus and ovary maintaining stable concentrations of this substrate. The peak of drought in July seems to be a month of damage to this substrate, with lower values for liver, muscle and ovaries, apparently the result of a scarcity of resources. Potamotrygon amandae, as well as other elasmobranchs, showed high concentrations of hepatic lipids; while the muscle tissue has very low values for this substrate, due to the absence of muscle oxidation of this substrate. Lipid histotrophy was demonstrated by the highest concentrations of lipids in the months corresponding to the period of pregnancy in the uterine tissue, in addition to the highest percentages of SAT and MUFA in this period; in the months of pregnancy about $90 \%$ of the composition of the uterine tissue (reflex to the 
composition of the uterine milk) is represented by SAT and MUFA; and gluconeogenesis and glycogen storage appear to occur in hepatic and ovarian tissues, while muscle tissue apparently performs glycolysis more actively.

Keyword: Metabolism. Lipid histotrophy. Freshwater stingrays. Fatty acid profile. Vitellogenesis. 


\section{Introdução}

As arraias pertencem à Classe Chondrichthyes que compreende a classe dos peixes com esqueleto cartilaginoso, separada por duas subclasses: Subterbranchialia (Holocephali), que abrange as quimeras e Elasmobranchii, que inclui os tubarões e as arraias (RICHTER et al., 2000). Estão ainda classificadas na Subdivisão Batoidea e na Ordem Myliobatiformes (LOVEJOY, 1996), que contém a família Potamotrygonidae, de arraias de água doce (LESSA et al., 1999; CARVALHO et al., 2003, NELSON, 2006; COMPAGNO; COOK, 1995). São descritas 1154 espécies de Elasmobranchii, e somente 56 são exclusivamente adaptadas à água doce, dessas, 30 pertencem à família Potamotrygonidae (LUCIFORA et al., 2015; CARVALHO, 2016).

Grupo monofilético que compartilha especializações morfológicas e fisiológicas únicas, as quais incluem: baixa concentração de ureia no sangue, redução da glândula retal e captação ativa de eletrólitos pelos rins e brânquias, que fazem com estas espécies apresentem controle iono- regulatório comparado a de peixes teleósteos de água doce, caráter estenoalino e hiperosmótico em relação ao ambiente (DUNCAN, 2008; POUGH; HEISER; JANIS, 2008; SPEERS-ROESCH e TREBERG, 2010; TREBERG, et al., 2006, LUCIFORA et al., 2015), além de adaptações nas ampolas de Lorenzini, suportando alterações importantes em sensores ambientais (RASCHI; MACKANOS, 1989). Adicionalmente, a presença de um processo pré-pélvico longo é sinapomorfia deste grupo (THORSON et al., 1983, ROSA, 1985; CARVALHO et al., 2003).

A família Potamotrygonidae atualmente compreende 30 espécies e pelo menos sete espécies conhecidas mas ainda não descritas (LUCIFORA et al., 2015; CARVALHO, 2016), encontra-se dividida em duas subfamílias, sendo a subfamília Potamorygoninae dividida em quatro gêneros: Paratrygon, Plesiotrygon, Heliotrygon e Potamotrygon (CARVALHO; LOVEJOY; ROSA, 2003; CARVALHO e RAGNO 2011; CARVALHO; LOVEJOY, 2011; CARVALHO, 2016). Representantes dessa família são encontradas apenas na América do Sul, local onde estão presentes nos principais sistemas fluviais (ROSA, 1985), sendo presentes em vários habitats de água doce, os quais incluem a calha de grandes rios, praia, igapós, riachos com fundo argiloso ou pedregoso e lagos.

No entanto, o entendimento da diversidade de Potamotrigonídeos está longe de ser completo e continuará a aumentar substancialmente, já que muitas novas espécies foram descobertas como resultado de revisões mais abrangentes, como é o caso do trabalho publicado por Fontenelle e Carvalho (2017), em que a espécie Potamotrygon scobina foi revisada taxonomicamente, e redescrita como três novas espécies: Potamotrygon adamastor, 
Potamotrygon amazona e Potamotrygon garmani, com características morfológicas e distribuição geográfica distintas.

Na região do alto rio Paraná, após a inundação do Salto de Sete Quedas para a construção da Usina Hidrelétrica de Itaipu, muitas espécies antes existentes apenas na parte baixa da bacia hidrográfica, iniciaram um processo de dispersão e colonizaram o Alto Paraná, incluindo as arraias da família Potamotrygonidae, as quais passaram a desempenhar o papel de espécies invasoras. Atualmente, as arraias estão estabelecidas até a região de Ilha Solteira-SP (alto Paraná), com possibilidade de já terem atingido pontos mais superiores nesta bacia (LOVEJOY, 1996; CARVALHO et al., 2003, ARAÚJO et al., 2004, LASSO et al., 2014).

Apesar da biologia reprodutiva do gênero Potamotrygon ter sido investigada em muitos trabalhos, a fisiologia deste processo ainda é pouco explorada, com apenas um trabalho encontrado em nossa busca bibliográfica, abordando os níveis hormonais e variáveis bioquímicas do plasma e leite uterino de Potamotrygon wallacei (AMAZONAS, 2019). Para entender os aspectos metabólicos e outros pontos da biologia do grupo, é preciso investigar os detalhes de sua organização metabólica, incomum na comparação com outros vertebrados.

\subsection{Reprodução de arraias}

Do ponto de vista reprodutivo, o sucesso da Classe Chondrichthyes está associado ao seu sofisticado mecanismo de reprodução, a fecundação interna. Neste tipo de fecundação os machos apresentam cláspers pélvicos, uma estrutura esquelética sólida que ao ser inserido na cloaca da fêmea e fixo a ela por meio de um conjunto de estruturas (farpas, ganchos e espinhos) próximos à extremidade do clásper, aumenta a sua eficiência (CONRATH e MUSICK, 2012). Além da fertilização, apresentam estratégias diversificadas, como o armazenamento de espermatozoides(RÊGO, 2014). Com a evolução da fecundação interna, os elasmobrânquios adotaram uma estratégia reprodutiva que favorece a produção de pequeno número de descendentes, que são retidos, protegidos e cuidado por períodos variáveis, dentro do corpo da fêmea. Este modo de reprodução requer um investimento significativo de energia pela fêmea (POUGH; JANIS; HEISER, 2008).

No grupo das arraias são encontrados representantes ovíparos e vivíparos, característica plesiomórfica do grupo (MARUSKA e GELSLEICHTER, 2011). As arraias da Ordem Myliobatiformes são consideradas vivíparas, aplacentárias e histotróficas, com embriões nutridos por secreção da mucosa viliforme do útero da mãe, conhecido como trofonema, que é 
rica em lipídeos e proteínas de grande peso molecular, esta secreção, ou fluido uterino é conhecido como "leite uterino", ainda pouco estudado (HAMLETT et al., 1993; MARUSKA e GELSLEICHTER, 2011; TOBERGTE e CURTIS, 2013). Um estudo com a espécie Dasyatis americana, raia vivípara histotrófica, traçou um padrão de manutenção de filhotes no útero materno, com a retenção dos embriões durante a gestação, inicialmente nutridos pelo conteúdo do saco vitelínico, com posterior nutrição de secreção de nutrientes advindos do trofonema, que nutrirão o embrião até o momento do parto (HAMLETT et al., 1996).

Levando-se em conta a viviparidade histotrófica das arraias é possível conjecturar sobre dois períodos de organização metabólica reprodutiva em fêmeas adultas, a primeira ligada à vitelogênese ovariana e a segunda ao desenvolvimento de fluido advindo do trofonema uterino (histotrofia lipídica). A vitelogênese, termo utilizado para denotar as fases de um processo complexo, inclui a síntese de compostos orgânicos dentro do folículo ovariano (JALABERT, 2005). Mudanças sazonais na composição corporal (de armazenamento de água, carboidratos, lipídeos e proteínas) têm sido observada em várias espécies, e estas alterações parecem estar relacionadas com o crescimento e desenvolvimento das gônadas, bem como outros processos associados com a desova (SHAHJAHAN et al., 2014). A histotrofia lipídica, por sua vez, envolve a produção e secreção de um fluido rico em lipídeos, proteínas e carboidratos, que é então ingerido e/ou absorvido pelo embrião por filamentos branquiais externos, espiráculo e boca (AMAZONAS, 2019; RANGEL, 2018; TOBERGTE e CURTIS, 2013; TRICAS et al., 2000).

\subsection{Biologia reprodutiva de arraias Potamotrygon}

A reprodução dos Potamotrigonídeos está relacionada ao ciclo hidrológico, respondendo a uma sequência de eventos, com variação temporal espécie-especifica, sendo a maturação gonadal a primeira de todas as etapas, levando de dois a quatro meses para ser completada; o período de cópula pode ocorrer durante a estação seca ou chuvosa; a fecundidade ovariana pode variar de um a 11 oócitos por período reprodutivo; a fecundidade uterina de um a oito embriões e a época do nascimento pode durar de três a quatro meses (CHARVETALMEIDA; GÓES DE ARAÚJO; DE ALMEIDA, 2005; GARRONE NETO et al., 2007; GAMA, 2013). A maior parte da história de vida deste gênero ainda corresponde a dos ancestrais marinhos: baixa taxa de crescimento populacional, maturação lenta, baixa fecundidade e longo período de gestação (CARRIER et al., 2004; CHARVET-ALMEIDA et al., 2005). 
De acordo com Charvet-Almeida et al. (2005), os machos amadurecem com largura de disco menor que o das fêmeas, como observado para Potamotrygon orbignyi com 390mm macho /440mm fêmea; Potamotrygon schroederi com 420mm macho/440 mm fêmea. Esse padrão também é relatado no trabalho de Rincon Filho (2006), com a espécie $P$. orbignyi em que foi observado $251 \mathrm{~mm}$ macho/260mm fêmea. O estudo de Garrone Neto (2010), com duas espécies de Potamotrygon na região do Alto Rio Paraná, mostrou que a maturação foi atingida com largura de disco de $271 \mathrm{~mm}$ macho/334mm fêmea para Potamotrygon motoro e de $262 \mathrm{~mm}$ macho/326mm para Potamotrygon falkneri. A idade de maturidade sexual foi estimada apenas para duas espécies até o momento, sendo para Paratrygon aiereba de aproximadamente 35 anos e para a pequena arraia de água doce "cururu" (Potamotrygon wallacei), com idade estimada de 2 anos (CHARVET- ALMEIDA; GÓES DE ARAÚJO; ALMEIDA, 2005). Rincon Filho (2006), trabalhando com a espécie $P$. orbignyi estimou que a idade de maturação foi de 5 anos com longevidade máxima de 10 anos.

A maioria dos Potamotrigonídeos estudados até o momento parece ter apenas um ovário funcional, o esquerdo, descrito em $P$. motoro (CASTEX, 1963; ACHENBACH; ACHENBACH, 1976; THORSON et al., 1983; PRATT, 1988), Potamotrygon brachyura (CASTEX; MACIEL, 1965), Potamotrygon constellata (THORSON et al. 1983), P. orbignyi (LASSO et al. 1996) e Potamotrygon sp. (ARAÚJO, 1998). Silva (2017), avaliou a morfologia dos ovários da raia cururu, $P$. wallacei, e verificou que o ovário esquerdo é volumetricamente 55 vezes maior que o direito. No lado direito, o volume tecidual (ovário/ órgão epigonal) é constituído por 7,3\% de ovário e 92,7\% de órgão epigonal, enquanto o ovário esquerdo ocupa $51,2 \%$, e o órgão epigonal apenas $48,8 \%$ do volume tecidual total. Em contraponto, o estudo de Teshima e Takeshita (1992) mencionou que ambos os ovários de Potamotrygon magdalenae são funcionais e o trabalho de Rincon Filho (2006), relata a funcionalidade do ovário direito, com desenvolvimento de folículos vitelogênicos, embora menos frequente que o ovário esquerdo, além de não apresentar diferenças estatísticas na largura e comprimento médios entre os ovários.

Charvet-Almeida et al. (2005), mostrou que a fecundidade ovariana variou entre as espécies, sendo o valor mais baixo observado de um a cinco oócitos em $P$. iwamae e o maior de seis a onze oócitos em P. motoro. Adicionalmente, a fecundidade uterina apresentou um número médio de embriões que variaram de um a oito, para $P$. orbignyi uma média de dois embriões, mesmo achado para esta espécie feito por Rincon Filho (2006) e para P. motoro sete 
embriões. Estudo de Garrone Neto (2010), relata que o número de filhotes oscilou entre um e três para as espécies $P$. motoro e $P$. falkneri.

Os abortos são muito frequentes para espécies do gênero Potamotrygon, e parecem ocorrer quando as fêmeas grávidas são expostas a condições estressantes, os embriões quase nunca sobrevivem nessas circunstâncias, independente do estágio de desenvolvimento (CHARVET- ALMEIDA; GÓES DE ARAÚJO; DE ALMEIDA, 2005). A ocorrência comum de abortos entre fêmeas grávidas também foi indicada por Schomburgk (1843), Achenbach e Achenbach (1976) e Charvet-Almeida (2001). Gama (2013), relata que das 29 fêmeas grávidas estudadas, 20 foram observadas abortando embriões em diferentes fases de desenvolvimento e Garrone Neto (2010), aborda que em todas as ocasiões, apenas filhotes fêmeas foramabortados para as espécies $P$. falkneri e $P$. motoro. Observações sobre o evento de aborto em $P$. amandae foram feitas por nosso grupo de pesquisa e evidenciaram alguns pontos importantes, tais como a relação do tempo para este evento, tamanho da ninhada e o tamanho materno, mostrando que fêmeas maiores e em estágio mais avançado de gravidez são mais susceptíveis ao aborto ou parto induzido (Rangel et al., 2020).

Quanto a composição do fluido uterino, "leite", somente foi descrita para a espécie $P$. wallacei no ano de 2019, mostrando a presença de gonadotrofinas e hormônios esteroides, sinalizando a comunicação entre ovários e úteros na sincronização da gestação, além de altas concentrações de $\mathrm{Ca} 2+$ e $\mathrm{Mg} 2+$ no início da gestação, como mobilização materno fetal de componentes formadores de cartilagem e altas concentrações de colesterol e triglicerídeos ao final do período gestacional, em detrimento da glicose, demostrando a histotrofia lipídica da espécie (AMAZONAS, 2019).

\subsection{Metabolismo de substratos energético em elasmobrânquios}

O metabolismo dos elasmobrânquios difere dos demais vertebrados, apresentando uma organização metabólica incomum, que inclui baixa capacidade de oxidação lipídica extra hepática, dependência de corpos cetônicos, principalmente o $\beta$-hidroxibutirato $(\beta-\mathrm{HB})$, e aminoácidos como combustíveis oxidativos nos tecidos musculares (esquelético e cardíaco) (SPEERS-ROESCH et al., 2006). Unido à baixa capacidade de oxidação de lipídeos nos tecidos, são descritos baixos níveis de ácidos graxos não esterificados no plasma, devido à ausência funcional da albumina, proteína de ligação e transporte deste metabólito (SPEERSROESCH et al., 2006; BALLANTYNE, 2016, RANGEL, 2018). 
Tais características foram exaustivamente analisadas, a partir do que foi postulado de "Hipótese da ureia". Segundo esta hipótese se acreditava que altos níveis de ureia plasmática eram uma restrição à capacidade dos elasmobrânquios marinhos para transportar ácidos graxos na correntesanguínea, e que talvez elasmobrânquios de água doce, com seus menores teores de ureia, novamente priorizariam os lipídeos como um combustível metabólico extra hepático, reduzindoa importância dos corpos de cetônicos e dos aminoácidos (SPEERS- ROESCH et al., 2006).

É amplamente aceito que todos os elasmobrânquios de água doce são derivados de formas marinhas (THORSON e BROOKS, 1983) e que para entender a fisiologia dos elasmobrânquios na água doce então, faz-se necessário compreender os aspectos relevantes da fisiologia das formas marinhas. A fisiologia dos elasmobrânquios marinhos é muito diferente da dos teleósteos marinhos e a característica de distinção do sistema osmorregulador marinho elasmobrânquios é a retenção de altos níveis de ureia (SPEERS- ROESCH et al., 2006; BALLANTYNE e ROBINSON, 2010). Nos elasmobrânquios a principal função da ureia é osmótica, tornando o animal hiperosmótico em relação ao meio (BALLANTYNE e ROBINSON, 2010).

Secundariamente, a ureia interrompe as interações hidrofóbicas necessárias para a estrutura e função adequadas das proteínas, e como as interações hidrofóbicas são as principais responsáveis pela ligação dos ácidos graxos à albumina, o transporte de ácidos graxos estaria comprometido nestes animais (WETLAUFER et al., 1964; YANCEY et al., 1982; PETERS, JR, 1996). A evolução da osmorregulação à base de ureia em elasmobrânquios pode, portanto, ter sido associada ao desenvolvimento de uma organização metabólica extra hepática que não enfatiza os ácidos graxos em favor de corpos cetônicos e aminoácidos altamente solúveis, que não requerem transportadores especiais (BALLANTYNE e MOON, 1986; SPEERS-ROESCH et al., 2006).

Todavia, o trabalho de Speers-Roesch et al. (2006) refuta essa hipótese, mostrando que a oxidação lipídica extra hepática ocorre em elasmobrânquios, principalmente nos rins e na glândula retal; a capacidade para a oxidação e transporte de lipídeos extra hepáticos não é reforçada em elasmobrânquios de água doce com baixo teor de ureia em relação às espécies marinhas; a capacidade de oxidação do corpos cetônicos foi detectada em todos os tecidos de todas as espécies de água doce investigados e nenhuma evidência de diminuição de utilização de corpos cetônicos foi observada em formas de água doce; a capacidade glicolítica, indicado pela atividade da piruvato quinase, forneceu informações sobre a importância de carboidratos como combustível metabólico (SPEERS-ROESCH et al., 2006). A explicação para tais 
resultados estaria ligada à evolução, em que espécies dulciaquícolas apenas mantiveram características de seus ancestrais marinhos, e que a colonização do ambiente de água doce não foi uma força seletiva suficientemente poderosa para causar a adoção de uma organização metabólica semelhante à dos teleósteos.

\subsubsection{Metabolismo de proteínas}

O metabolismo de aminoácidos é uma importante fonte de energia para os elasmobrânquios, especialmente o aminoácido glutamina, como combustível oxidativo (SPEERS-ROESCH e TREBERG, 2010). A glutamina sintetase (GS) é uma enzima essencial nos elasmobrânquios marinhos por seu papel na eliminação de amônia para a síntese de ureia. A atividade de GS é mais baixa em Potamotrygon spp. de água doce do que em outras espécies marinhas e é semelhante ao dos teleósteos de água doce. (SPEERS- ROESCH et al., 2006; BALLANTYNE e ROBINSON, 2010). Alta atividade de glutaminase no músculo vermelho e no coração de elasmobrânquios foram atribuídos ao uso deste aminoácido para oxidação (SHADWICK; FARRELL; BRAUNER, 2015).

A glutamato desidrogenase (GDH) está geralmente associada à oxidação de aminoácidos. Os níveis de GDH no fígado de diferentes espécies de elasmobrânquios variam de acordo com a necessidade de nitrogênio para a síntese de ureia. As atividades mais altas de GDH ocorrem nos potamotrigonídeos de água doce que não acumulam ureia. Os níveis mais baixos ocorrem em espécies marinhas, onde a oxidação reduzida de aminoácidos garante que a maior parte do glutamato esteja disponível para a síntese de glutamina via glutamina sintetase (SHADWICK; FARRELL; BRAUNER, 2015).

\subsubsection{Metabolismo de lipídeos}

Os vertebrados apresentam diferentes estratégias para armazenamento e utilização dos estoques lipídicos, que podem variar com a história de vida de cada espécie (SHERIDAN, 1994; SPEAKE e THOMPSON, 2000). O fígado é o principal sítio de armazenamento de lipídeos em elasmobrânquios marinhos, com níveis muito altos acumulando-se em espécies não-bentônicas para aumentar a flutuabilidade não há evidências de que as animais de água doce sejam diferentes (BALLANTYNE e ROBINSON, 2010; SHADWICK; FARRELL; BRAUNER, 2015). Nenhuma espécie de elasmobrânquio apresenta reserva na forma de tecido adiposo, o que promove importância extra ao tecido hepático como armazenador deste substrato (BALLANTYNE, 1997). 
Os lipídeos constituem um grupo diverso de compostos ricos em carbono, e são a forma mais concentrada de energia nos animais, funcionando como moléculas de armazenamento de energia e como componentes estruturais das células, principalmente devido às suas características bioquímicas de serem combustíveis quimicamente reduzidos, de maior rendimento energético $\left(\sim 38 \mathrm{~kJ} \mathrm{~g}^{-1}\right)$ quando comparados aos carboidratos e proteínas ( $\left.18 \mathrm{~kJ} \mathrm{~g}^{-1}\right)$, e armazenados sem a necessidade de água (NELSON E COX, 2014). Além de serem considerados como a principal fonte de energia metabólica, os lipídios estão estreitamente ligados às condições ambientais, como quantidade e qualidade de presas, ciclos biológicos da reprodução e migração (SPEERS-ROESCH e TREBERG, 2010; PETHYBRIDGE et al., 2014; VALLS et al., 2016; GALLAGHER et al., 2017).

Dentre as classes de lipídios neutros, os triacilgliceróis (TAG), compostos formados por três cadeias de ácidos graxos (FA, do inglês fatty acids), ligados a uma molécula de glicerol, são a principal fonte de energia metabólica e o componente principal de estoques energéticos. Estudos tem revelado a positiva correlação entre as concentrações de TAG e a deposição de gordura em vertebrados (WILLIAMS et al., 1999; GALLAGHER et al., 2014), e acúmulo deste substrato durante o preparo para eventos energeticamente desgastantes, tais como migração e reprodução (JENNI-EIERMANN et al., 2002; McWILLIAMS et al., 2004). Em tubarões, o TAG plasmático tem sido positivamente associado com a condição corpórea (GALLAGHER et al., 2014) e parecem seguir padrões sazonais, com maiores valores encontrados durante a primavera e verão (GALLAGHER et al., 2017).

A enzima carnitina palmitoiltransferase (CPT), responsável pelo transporte de ácidos graxos à mitocôndria, e sinalizadora de oxidação lipídica, foi investigada em 5 espécies de elasmobrânquios no trabalho de Speers-Roesch et al. (2006), sendo três arraias de ambientes distintos: P. motoro- água doce, Himantura signifer- eurialina, Taeniura lymma- água salgada e um tubarão: Chilosccyllium puntatum, e foi detectada em vários tecidos de todas as espécies, demonstrando a capacidade de oxidação de ácidos graxos em elasmobrânquios. Deve-se, porém, ressaltar a alta atividade desta nos rins e glândula retal, e excluir esta atividade nos tecidos musculares (BALLANTYNE e ROBINSON, 2010). Adicionalmente, a HOAD, enzima envolvida na beta oxidação de ácidos graxos, foi facilmente detectável em todos os tecidos, com a maior atividade no fígado em todas as espécies testadas, atividades mais baixas foram observadas nos rins, músculo esquelético, coração e glândula retal (SPEERS-ROESCH et al., 2006). 
Paralelamente ao estudo de mobilização e metabolismo lipídico, conhecer o perfil de ácidos graxos de espécies de elasmobrânquios é relevante, já que tais componentes presentes no vitelo, mobilizados pelos tecidos maternos, suportam o crescimento tecidual dos embriões, além de serem utilizados como reserva energética para o tecido embrionário (PETHYBRIDGE et al., 2010), além da clara ligação da mobilização dos ácidos graxos à embriogênese, o perfil destes está intimamente associado à dieta materna, sendo, portanto, um importante biomarcador trófico (RANGEL et al., 2020).

\subsubsection{Metabolismo de carboidratos}

Com base na atividade da hexoquinase tecidual, no músculo vermelho, coração, cérebro, rim e glândula retal é possível conjecturar sobre a alta capacidade de utilização de glicose como metabólito, sugerindo que a glicose circulante pode ser um combustível oxidativo importante nos tecidos (WALSH et al., 2006, SPEERS-ROESCH e TREBERG, 2010). A dependência de carboidratos como combustíveis aeróbicos parece ser amplamente semelhante em elasmobrânquios e teleósteos carnívoros (DRIEDZIC e HART, 1984; SIDELL et al., 1987; MOYES et al., 1989; CHAMBERLIN et al., 1991).

Assim como nos teleósteos, o glicogênio é uma importante fonte de combustível nos músculos locomotores de elasmobrânquios (SPEERS-ROESCH e TREBERG, 2010). Além disso, a gliconeogênese hepática ocorre em elasmobrânquios, mas a taxa é muito menor do que o encontrado nos teleósteos. Um ponto importante levantado é a importância dos aminoácidos para a gliconeogênese hepática (SPEERS-ROESCH e TREBERG, 2010).

\subsection{Espécie modelo}

Potamotrygon amandae Loboda \& Carvalho 2013 (Fig. 1), conhecida popularmente como raia-comum e raia-de-fogo (LOBODA e CARVALHO, 2013), se encontra distribuída nos sistemas de água doce na América do Sul, incluindo rios da Bolívia, Paraguai, Argentina e Brasil (LASSO et al., 2016; LOBODA e CARVALHO, 2013). Apresenta coloração dorsal predominantemente cinzenta ou castanho escuro, a maioria dos espécimes apresentam ocelos bicolores com uma mancha central branca, cinza clara ou amarela claro, cercado por um anel preto, com a coloração ventral predominantemente cinzenta, cobrindo quase todo o disco ventral. Adicionalmente, apresenta dentículos dérmicos pequenos em forma de estrela, espalhada por toda a região dorsal do disco (LOBODA e CARVALHO, 2013; LASSO et al., 2016; RAMOS, 2017). 


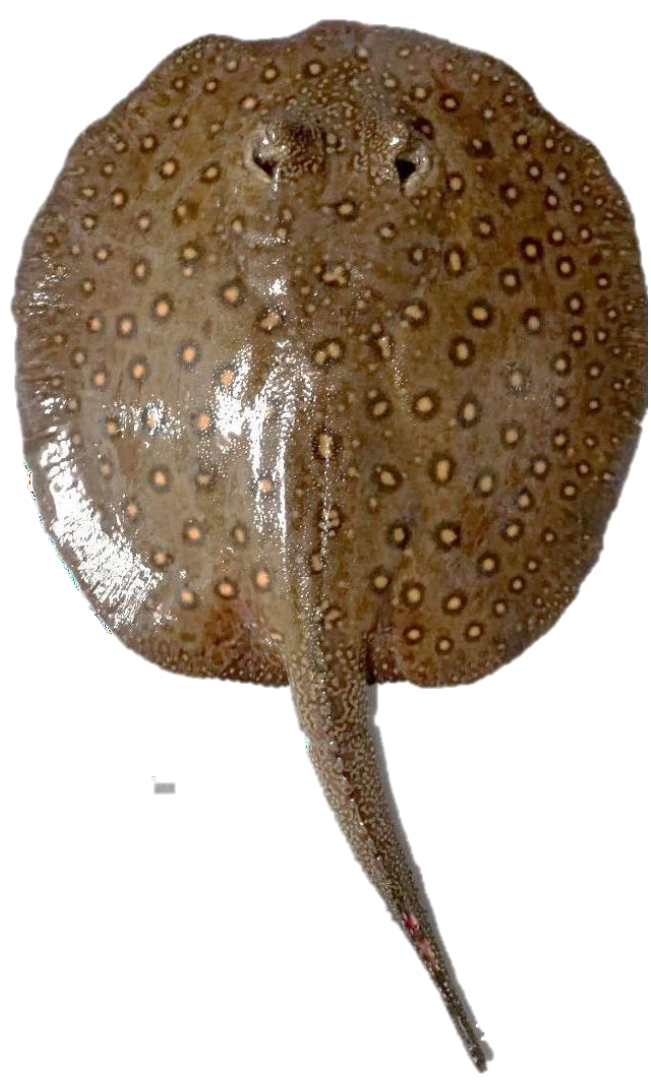

Figura 1. Potamotrygon amandae Loboda \& Carvalho, 2013. Fêmea adulta, coletada em fevereiro $/ 2018$, traço representa escala de $1 \mathrm{~cm}$.

Estudos de Pagliarini et al. (2020), analisando a dieta, posição trófica e valor nutricional da dieta de $P$. amandae classificou a espécie como sendo onívora com tendência a carnivoria, com grande plasticidade alimentar no rio Paraná, SP, com detrito e fragmento de peixe como principais itens encontrados no estomãgo desta espécies. Adicionalmente, os autores descrevem alto consumo de animais bentônicos como larvas e ninfas de insetos aquáticos, que estão relacionados com as táticas de forrageamento, que com o movimento ondulatório do disco, a espécie agita o substrato, escavando-o, proporcionando a formação de nuvens de poeira, que seconstitui num atrativo para quatro espécies de ciclídeos (as mais consumidas). Esses, por sua vez, se aproximam das nuvens de poeiras imediatamente após o forrageio e permanecem nas proximidades das arraias enquanto durar essa atividade (GARRONE NETO; SAZIMA, 2009; OLIVEIRA, 2013), demonstrando que essa espécie apresenta alta capacidade de exploração derecursos no ambiente, como observado por Lonardoni et al. (2006).

Os estudos das arraias de água doce são escassos, fato que fez com que o Programa de Biologia do Instituto de Pesquisa de Recursos Biológicos Alexander von Humboldt (IAvH) propusesse, desde 2012, a inclusão de espécies de arraias dulciaquícolas no status de 
provavelmente em perigo no Apêndice III da CITES (Comercio Internacional de Espécies Ameaçadas de Fauna e Flora Silvestre), como uma tentativa de mitigar uma possível superexploração, havendo a necessidade de regular o comércio e tentar converter a pesca ornamental em uma atividade sustentável, uma vez que o principal impacto das arraias de água doce deriva de sua importância como peixes ornamentais, como alimento e também advindos de impacto na saúde pública (LASSO et al., 2016). A partir da data de inclusão na lista CITES em 2017, para a exportação da arraia do gênero Potamotrygon passou a ser exigida a licença CITES outorgada pelo Instituto Brasileiro de Meio Ambiente e dos Recursos Naturais Renováveis (IBAMA) e a não observância poderá acarretar multa e apreensão dos espécimes.

Esta espécie foi escolhida devido à disponibilidade de captura, pois, já vem sendo estudada por colaboradores do nosso grupo de pesquisa, com trabalhos que abordam aspectos parasitológicos, histomorfológicos e hormonais nestes animais. No entanto, mesmo considerando esta facilidade de captura, a escassez de informações não permite qualquer plano de conservação. Esta espécie é classificada na Lista Vermelha da IUCN (International Union for Conservation of Nature) como "Data Deficient", ou seja, sem dados suficientes para classificação do estado de conservação. Dessa forma, estudos sobre o papel desempenhado por espécies invasoras como as arraias, tornam-se relevantes, pois, as informações obtidas possibilitariam a implantação de sistemas adequados de manejo desses ecossistemas e a própria preservação das espécies originais. Desse modo, é importante o entendimento dos processos fisiológicos ligados à dinâmica reprodutiva, adaptações fisiológicas associadas à relação trófica materno-fetal e os padrões de alocação de substratos energéticos durante o ciclo reprodutivo pré e durante a gestação, que possam refletir particularidades nutricionais e ambientais na espécie escolhida.

Além da indiscutível importância de se descrever aspectos reprodutivos de espécies pouco estudadas, como o caso de arraias de água doce (CHARVET-ALMEIDA et al., 2005), é amplamente discutido na literatura um padrão de alterações reprodutivas em espécies nãonativas, como forma de adaptação a um novo ambiente (WHITNEY e GABLER, 2008). Isto justifica a necessidade de estudos relacionados a alterações de padrões reprodutivos na região do Alto Paraná, que, através de vários inventários realizados, tem uma fauna historicamente alterada, com registros várias espécies alóctones e exóticas, mostrando que cercade 6 a 15\% das espécies referidas são novas (LANGEANI, 2007). 


\section{Objetivos}

\subsection{Objetivo geral}

Investigar a dinâmica de armazenamento e alocação de substratos metabólicos ao longo do ciclo reprodutivo de fêmeas da espécie vivípara histotrófica Potamotrygon amandae em área de ocorrência não- natural, no reservatório de Jupiá, Ilha Solteira, SP.

\subsection{Objetivos específicos}

- Classificar os estágios reprodutivos de fêmeas da espécie Potamotrygon amandae no reservatório de Jupiá, Ilha Solteira, SP, com base nas observações morfológicas e Índices gonadossomático e hepatossomático mensais;

- Avaliar o perfil de substratos metabólicos em fases distintas do ciclo reprodutivo em diferentes tecidos, com vistas a compreender padrões associados ao ciclo reprodutivos destes substratos;

- Descrever o perfil de ácidos graxos que compõem os tecidos desta espécie e suas modificações reprodutivas;

- Testar modelos metabólicos/reprodutivos através de Modelagem de Equações Estruturais, explorando caminhos metabólicos/teciduais no ciclo reprodutivo da espécie. 


\section{Material e método}

\section{1 Área de trabalho e métodos de coleta}

As coletas dos espécimes foram realizadas mensalmente entre janeiro e dezembro de 2018 à montante do reservatório de Jupiá, que se localiza no munícipio de Ilha Solteira/SP, Brasil (20²3'03.9"S 51²1'19.8"W) (Fig. 2). Foram coletados aleatoriamente 10 espécimes por mês, (autorização SISBIO 50019-1 e cadastro SisGen A001CBE).

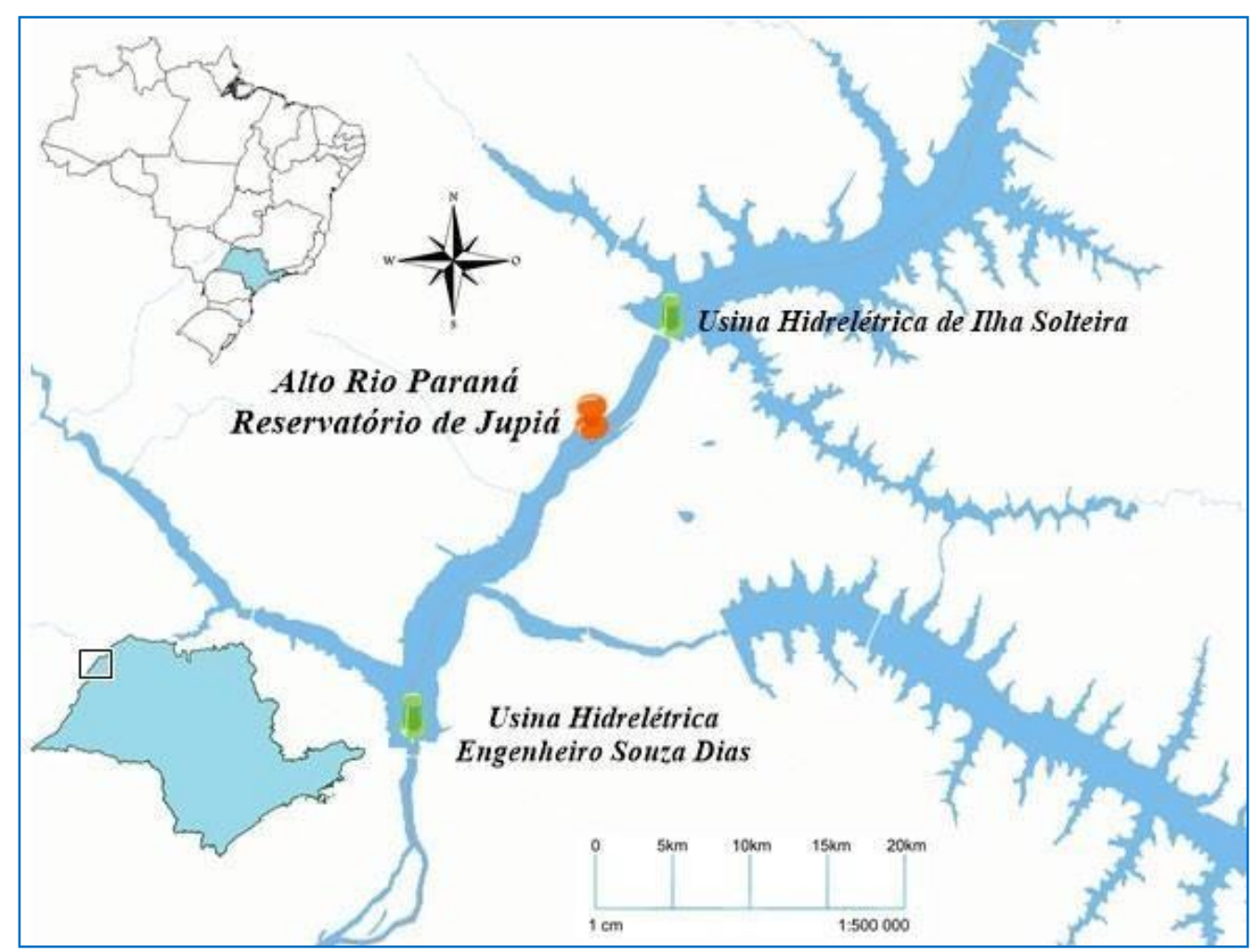

Figura 2. Localização geográfica da área de coleta de exemplares de Potamotrygon amandae no Alto Rio Paraná (reservatório de Jupiá, Ilha Solteira/SP). Marcador vermelho: local de amostragem. Fonte da imagem: Bruno Silva.

Os dados referentes à temperatura e pluviosidade (Fig. 3) foram extraídos da Rede Agrometeorológica do Noroeste Paulista, disponíveis no site https:// http://clima.feis.unesp.br/., e mostram dois períodos bem marcados na região de coleta: cheia, correspondendo aos meses de outubro a fevereiro e seca, correspondendo ao período de março a setembro. 


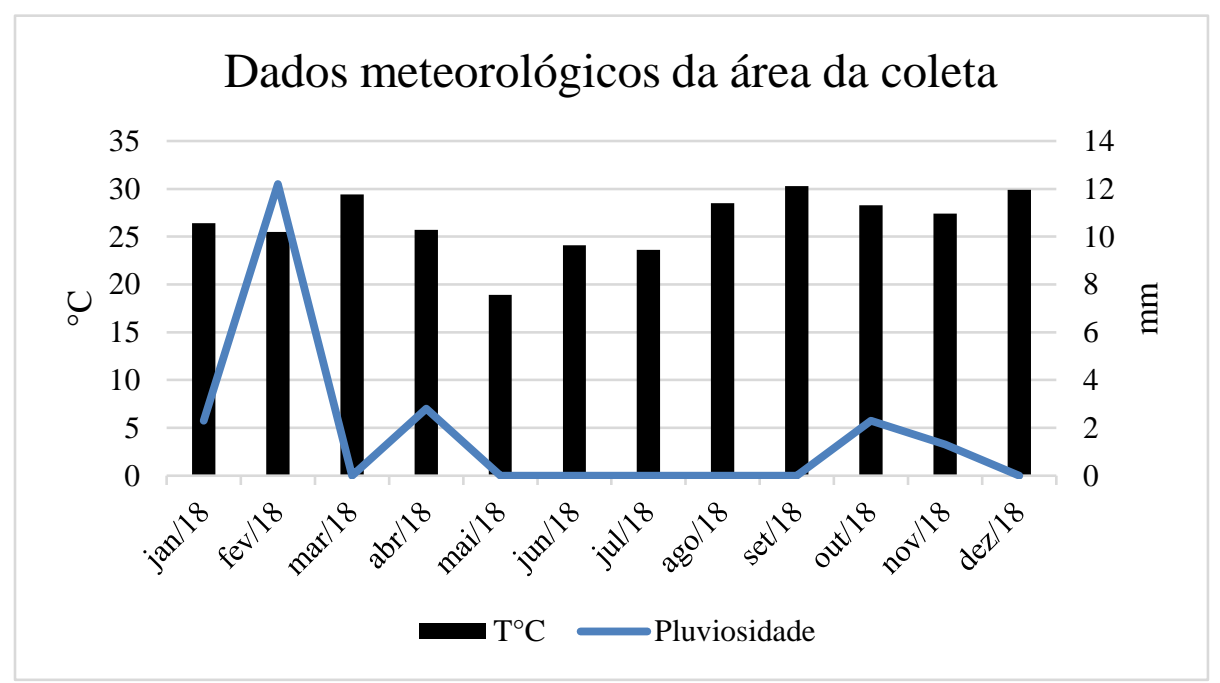

Figura 3. Dados de temperatura e pluviosidade anual da região de coleta: município de Ilha Solteira, SP. Fonte: Rede Agrometeorológica do Noroeste Paulista.

Arpões e tarrafas foram utilizados como método de captura dos animais. Os espécimes foram anestesiados com Eugenol 0,2 g.L $\mathrm{L}^{-1}$ por via respiratória (CEUA FEIS 15/2017), individualizados em caixas de polietileno e transportados vivos para o Laboratório de Estudos em Fisiologia Animal (LEFISA) UNESP/Ilha Solteira, onde foram aferidos os dados biométricos (massa do animal, comprimento de disco (CD), comprimento total (CT) e largura de disco (LD)) (Fig. 4). A massa do tecido hepático e gonadal (ovariana) foi aferida para os cálculos dos índices hepatossomático e gonadossomático:

$$
\text { Índices }=(\text { Massa tecido/Massa corpórea total }) \times 100 .
$$

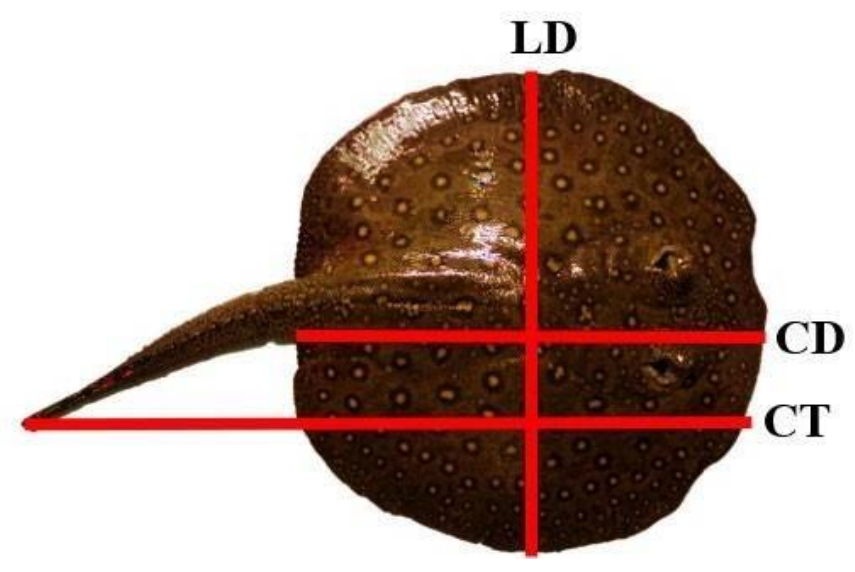

Figura 4. Aferição de dados biométricos de Potamotrygon amandae: comprimento do disco (CD), largura do disco (LD) e comprimento total (CT). 
Após a biometria os animais foram eutanasiados e necropsiados com coleta dos tecidos hepático, muscular, uterino e ovariano (padronizou-se a coleta de tecido do ovário esquerdo, funcional em Potamotrygon) os tecidos foram armazenados em criotubos e mantidos em freezer a $-80^{\circ} \mathrm{C}$ até o momento das análises.

\subsection{Classificação do estágio reprodutivo da espécie}

Os espécimes capturados foram classificados de acordo com análise macroscópica dos ovários e presença de filhotes, em 4 estágios reprodutivos: repouso, vitelogênese, grávidas e imaturas. Esta classificação se baseou no trabalho de Gama (2013), que de acordo com CharvetAlmeida (2006), utilizam os seguintes parâmetros:

Repouso (Fig. 5): Ovário esquerdo bem irrigado; presença de folículos ovarianos em início de desenvolvimento ou em desenvolvimento; útero (ou úteros) vazio; o útero encontrase menos irrigado e mais retraído.

Vitelogênese (Fig. 6): Ovário esquerdo bem desenvolvido e irrigado; presença de folículos ovarianos em desenvolvimento e bem desenvolvidos; útero pouco irrigado e com trofonemas pouco desenvolvidos.

Grávida (Fig. 7): Ovário esquerdo bem irrigado; presença de folículos ovarianos em desenvolvimento; útero (ou úteros) contendo embriões bem desenvolvidos, com paredes distendidas, presença de trofonemas em abundância em seu interior.

Imatura: Fêmeas juvenis.

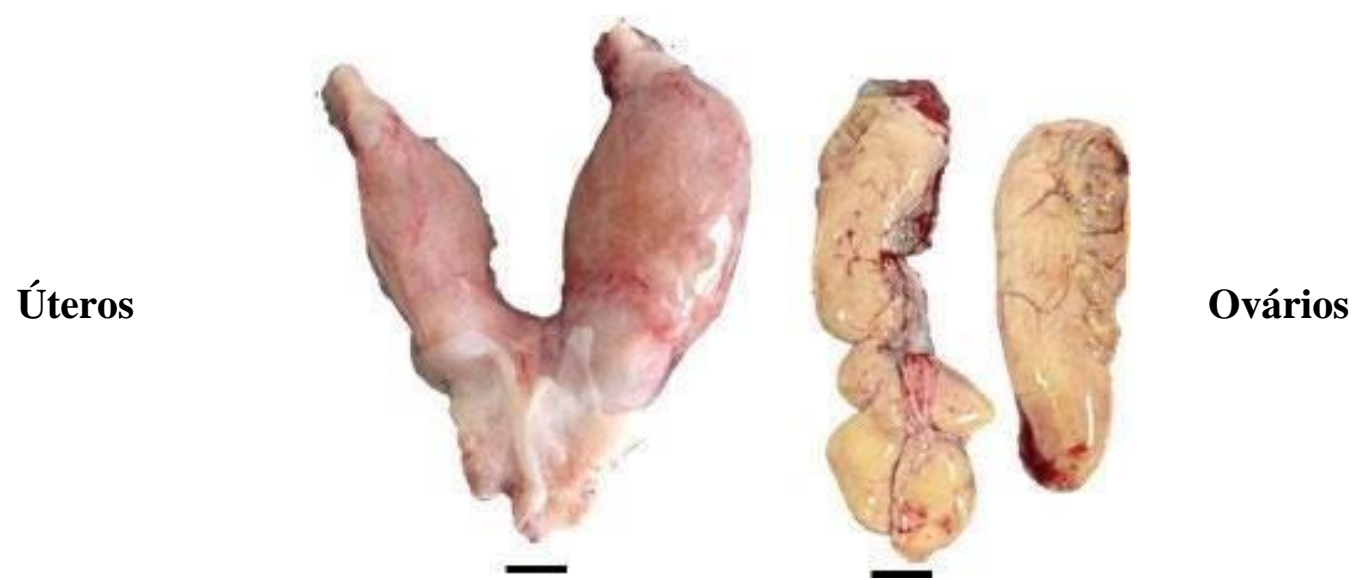

Figura 5. Análise macroscópica das gônadas de Potamotrygon amandae no estágio de repouso: Ovário esquerdo bem irrigado, úteros vazios, menos irrigados e mais retraídos. Escala de $1 \mathrm{~cm}$. 


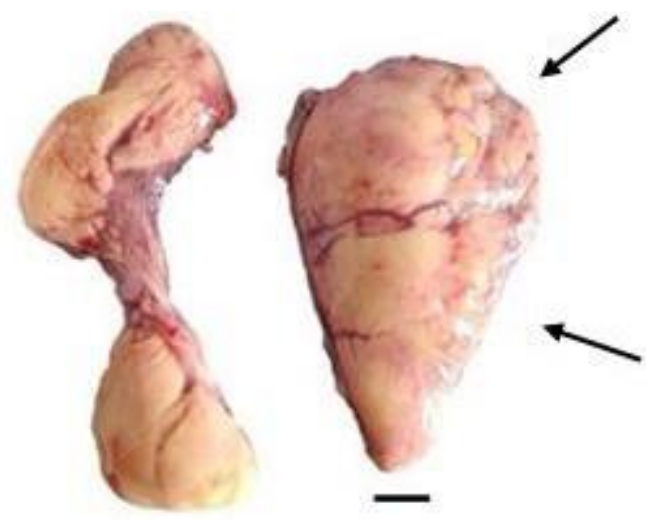

\section{Ovários}

Figura 6. Análise macroscópica das gônadas de Potamotrygon amandae no estágio de vitelogênese: Ovário esquerdo bem desenvolvido e irrigado. Setas indicam folículos ovarianos em desenvolvimento e bem desenvolvidos. Escala de $1 \mathrm{~cm}$

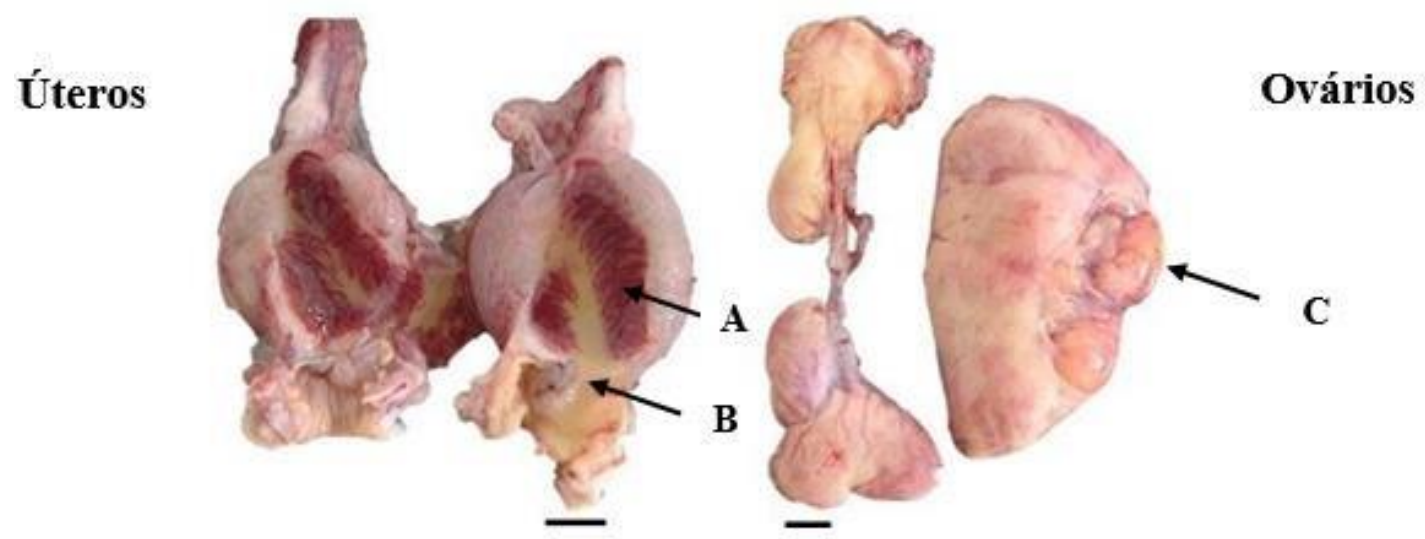

Figura 7. Análise macroscópica das gônadas de Potamotrygon amandae no estágio de gravidez: Ovário esquerdo bem irrigado; úteros com presença de trofonemas em abundância. ATrofonema. B- Leite Uterino. C- Oócitos em desenvolvimento. Escala de $1 \mathrm{~cm}$.

\subsection{Análise de substratos metabólicos}

\subsubsection{Extração de proteínas totais}

As proteínas totais dos tecidos foram extraídas após precipitação e solubilização segundo Milligan \& Girard (1993). As amostras foram pesadas ( $\pm 100 \mathrm{mg}$ de músculo, ovário e útero e $\pm 50 \mathrm{mg}$ de fígado) e homogeneizadas com 5 volumes da solução de PCA (ácido perclórico). Após a homogeneização e centrifugação a 11.000 rpm em centrífuga eppendorf por 5 minutos, o precipitado foi ressuspenso em 4 volumes de PCA e o procedimento de centrifugação foi repetido mais 3 vezes. Em seguida, foram adicionados 14 volumes de $\mathrm{KOH}$ 
(hidróxido de potássio) e o precipitado foi mantido por 24 horas em agitação constante em temperatura ambiente.

\subsubsection{Quantificação das proteínas totais}

A concentração de proteínas totais dos tecidos foi analisada pelo método colorimétrico de Lowry et al. (1951). O solubilizado restante foi diluído 50 e 100 vezes (dependendo do tecido) com água destilada para dosagem protéica. $\mathrm{O}$ volume diluído foi pipetado em tubos eppendorfs e adicionado $1000 \mu \mathrm{L}$ da mistura reativa (hidróxido de sódio + carbonato de sódio + tartarato de sódio e potássio + sulfato de cobre). Posteriormente, adicionou-se $100 \mu \mathrm{L}$ de reagente Folin-Ciocalteu (1:1) e após 30 minutos as amostras foram lidas em espectrofotômetro a um comprimento de onda de $660 \mathrm{~nm}$. A concentração de proteínas totais foi calculada utilizando-se uma curva de albumina sérica bovina (Bovine serum albumin, Sigma Diagnostics) e os resultados foram expressos em $\mathrm{mg} / \mathrm{g}$ para as amostras teciduais.

\subsubsection{Extração de lipídeos totais}

Os lipídeos totais dos tecidos foram extraídos com uma solução de clorofórmio: metanol: água (FOLCH; LEES; SLOANE STANLEY, (1957) adaptada por PARRISH, (1999)). As amostras foram pesadas ( $\pm 10 \mathrm{mg}$ de fígado, $\pm 100 \mathrm{mg}$ de músculo e $\pm 50 \mathrm{mg}$ de ovário e útero) e diluídas em uma solução contendo clorofórmio, methanol e água em uma proporção de 1:0,5:0,5 e, posteriormente homogeneizadas. O homogenado centrifugado a $3000 \mathrm{rpm}$ por 5 minutos e, posteriormente, foi retirada a fase líquida inferior, contendo os lipídeos, através da técnica de dupla pipeta e tranferidos para fracos de vidros. O procedimento foi repetido mais duas vezes adicionando-se clorofórmio para remoção dos lipídeos remanescentes. Posteriormente, o solvente foi evaporado em nitrogênio e os tubos vedados com parafilme e armazenado em geladeira para as posteriores análises.

\subsubsection{Quantificação de lipídeos totais}

A concentração dos lipídeos totais teciduais foi determinada pelo método colorimétrico de FRINGS et al. (1972), utilizando-se como padrão óleo de fígado de bacalhau (Cod liver oil fatty acid methyl esters, SIGMA). A solução padrão e as amostras foram ressuspendidas em clorofórmio e uma alíquota foi pipetada em tubos de ensaio. Os tubos foram mantidos em uma estufa a $100^{\circ} \mathrm{C}$ por 15 minutos para evaporação do solvente. No extrato lipídico seco foi adicionado ácido sulfúrico concentrado e colocado em banho-maria a $100^{\circ} \mathrm{C}$ por 10 minutos. Após o resfriamento, adicionou-se sulfofosfovanilina e os tubos foram mantidos em banho maria a $37^{\circ} \mathrm{C}$ por 15 minutos. Posteriormente, $290 \mu \mathrm{m}$ das amostras foram lidas em espectrofotômetro em comprimento de onda de $540 \mathrm{~nm}$ e a concentração de lipídeos totais foi 
calculada utilizando-se uma curva de óleo de fígado de bacalhau (cod liver oil methyl esters, Sigma Diagnostics). Os resultados foram expressos em $\mathrm{mg} / \mathrm{g}$ para as amostras teciduais e $\mathrm{mg} / \mathrm{dL}$ para as amostras plasmáticas.

\subsubsection{Transmetilação e perfil de ácidos graxos}

Os lipídeos utilizados para realizar o perfil de ácidos graxos foram extraídos a partir do método de transmetilação. As amostras foram pesadas $( \pm 100 \mathrm{mg}$ de músculo e ovário e $\pm 50 \mathrm{mg}$ de fígado e útero) e diluídas em solução de metilação (10:1:1 de metanol: diclorometano: ácido clorídrico) e homogeneizadas em microprocessador. Posteriormente os tubos contendo as amostras foram colocadas sob uma atmosfera de nitrogênio no nitrogênio e colocados em banho maria a $80^{\circ} \mathrm{C}$ por 2 horas. Em seguida foram adicionados $1,5 \mathrm{ml}$ de água destilada, seguido de $1,5 \mathrm{ml}$ de hexano e $0,3 \mathrm{ml}$ de diclorometano e centrifugadas a $2000 \mathrm{rpm}$ por 5 minutos. Posteriormente foi retirada a fase superior e transferidas para tubos vials, os quais foram submetidos a uma atmosfera de nitrogênio para evaporação do solvente sem causar oxidação dos ácidos graxos e os tubos vedados com parafilme e mantidos no freezer até próxima etapa.

O perfil de ácidos graxos foi determinado com o cálculo de tempo de retenção, utilizando-se um padrão de ácidos graxos com tempo de retenção conhecido (Supelco, 37 components). A partir da metilação das amostras (para formação dos metis ésteres) pelo método de de Kitson; Larsen; MCewen (1996), que utiliza o cloreto de acetila e metanol como catalisadores da reação, os metis foram analisados em cromatografia gasosa (GC), acoplada a um ionizador de chama (FID) e auto injetor (VARIAN GC 3900) e o resultados foram expressos emporcentagem $(\%)$.

$\mathrm{Na}$ análise dos ácidos graxos foi utilizada uma programação no cromatógrafo na quala leitura foi iniciada a uma temperatura de $170^{\circ} \mathrm{C}$ mantida por 1 minuto e em seguida por uma rampa de $2.5^{\circ} \mathrm{C} /$ minuto, até atingir a temperatura final de $220^{\circ} \mathrm{C}$, que foi mantida por 5 minutos. $\mathrm{O}$ injetor e o detector foram mantidos a $250^{\circ} \mathrm{C}$, e foi utilizada uma coluna $\mathrm{CP}$ wax $52 \mathrm{CB}$, com espessura de $0,25 \mathrm{~mm}$, diâmetro interno de $0,25 \mu \mathrm{m}$ e $30 \mathrm{~m}$ de comprimento, tendo o hidrogênio como o gás de arraste.

\subsubsection{Extração de glicogênio total}

O glicogênio total dos tecidos foi extraído a partir do método de Bidinotto; Moraes; Souza (1997). As amostras congeladas foram pesadas ( $\pm 50 \mathrm{mg}$ fígado e $\pm 100 \mathrm{mg}$ de músculo, ovário e útero) e rapidamente diluídas em solução de $1 \mathrm{ml}$ de $\mathrm{KOH}$, evitando deixar as amostras descongelarem, e em seguida foram colocadas em banho maria fervente por 4 minutos. 
Posteriormente, os tubos foram agitados em vortex para completa dissolução dos tecidos. Para o isolamento do glicogênio, foi retirada uma alíquota do homogenado $( \pm 250 \mu \mathrm{l})$ e transferidos para tubos de centrifuga, onde forma adicionados $3 \mathrm{ml}$ de álcool $95 \%$ e misturados em vortex. Em seguida foram acrescentados $100 \mu 1$ de solução K2SO4 (sulfato de potássio) e novamente agitados em vortex. O homogenado foi centrifugado a $3000 \mathrm{rpm}$ por 3 minutos e descartado o sobrenadante. Posteriormente adicionou-se 2,5 $\mathrm{ml}$ de água destilada nas amostras de fígado e ovário e $0,5 \mathrm{ml}$ para as amostras de músculo e útero para dissolução.

\subsubsection{Quantificação de glicogênio total}

A determinação de glicogênio dos tecidos foi analisada pelo método colorimétrico de Dubois (1956). Em tubos de ensaio tomou-se $100 \mu 1$ da solução anterior e em seguida adicionouse $700 \mu \mathrm{l}$ de fenol. Posteriormente foi adicionado $2 \mathrm{ml}$ de ácido sulfúrico e aguardou-se aproximadamente 10 minutos. As amostras foram lidas em espectrofotômetro em comprimento de onda de $480 \mathrm{~nm}$ e a concentração do substrato foi calculada utilizando-se uma curva de glicose 100nmoles, e os resultados foram expressos em $\mu$ mol de glicosil-glicose/g de tecido.

\subsection{Tratamento estatístico}

Os valores de cada índice corpóreo, IHS e IGS e variáveis metabólicas proteicas, lipídicas, de ácidos graxos e de glicogênio foram comparados mensalmente ao longo do ano utilizando-se o teste de Análise de Variância (One-Way ANOVA). Os dados que cumpriram os requerimentos de uma análise paramétrica foram comparados utilizado a análise post-hoc Student- NewmannKeuls e os dados que não cumpriram esses requerimentos foram analisados pelo teste de Mann-Whitney pairwise. O nível de significância adotado foi de 0,05.

A correlação entre IHS e IGS foi realizada utilizando o RStudio, em que os índices foram comparados ao longo do ano, considerando-se cada mês, utilizando-se a análise de correlação de Spearman.

Adicionalmente, os dados foram analisados segundo modelo de equações estruturais (SEM) visando verificar relações simultâneas de efeito entre diversas variáveis determinadas, usando o programa STATA. 


\section{Resultados e discussão}

\subsection{Temperatura e pluviosidade}

De acordo com os dados de temperatura e pluviosidade (Fig. 3) foi possível identificar que o período de cheia corresponde aos meses de gravidez dos espécimes coletados (Fig. 8) e o período de seca corresponde aos meses que forma amostrados espécimes em repouso e vitelogênese (Fig. 8). O período de amostragem de espécimes deste trabalho correspondeu a um ano sob influência de La Niña (CPTEC-INPE, 2021). Foi observado para a espécie $P$. motoro a incidência de dois períodos de gestação durante fenômenos de La Niña (Profa Dra Maria Lúcia Góes de Araújo- Comunicação oral durante o II GEEP Week em 2021), o que não se comprovou com $P$. amandae, que somente apresentou um período de gravidez e parto durante o ano de 2018.

\subsection{Classificação do estágio reprodutivo das fêmeas}

De acordo com a figura 8 , foram observados $100 \%$ animais em vitelogênese no mês de julho, setembro e outubro e fêmeas grávidas e em vitelogênese em novembro de 2018, demonstrando claramente o início do período de gestação da espécie e o desenvolvimento reprodutivo dos animais, enfatizando o período de gravidez com a representação de $100 \%$ de fêmeas grávidas no mês de janeiro. Também foram observadas que a maior representação das espécies em repouso está no mês de abrile maio, mostrando o fim do período de gestação e parto dos animais.

\section{ESTÁGIOS REPRODUTIVOS}

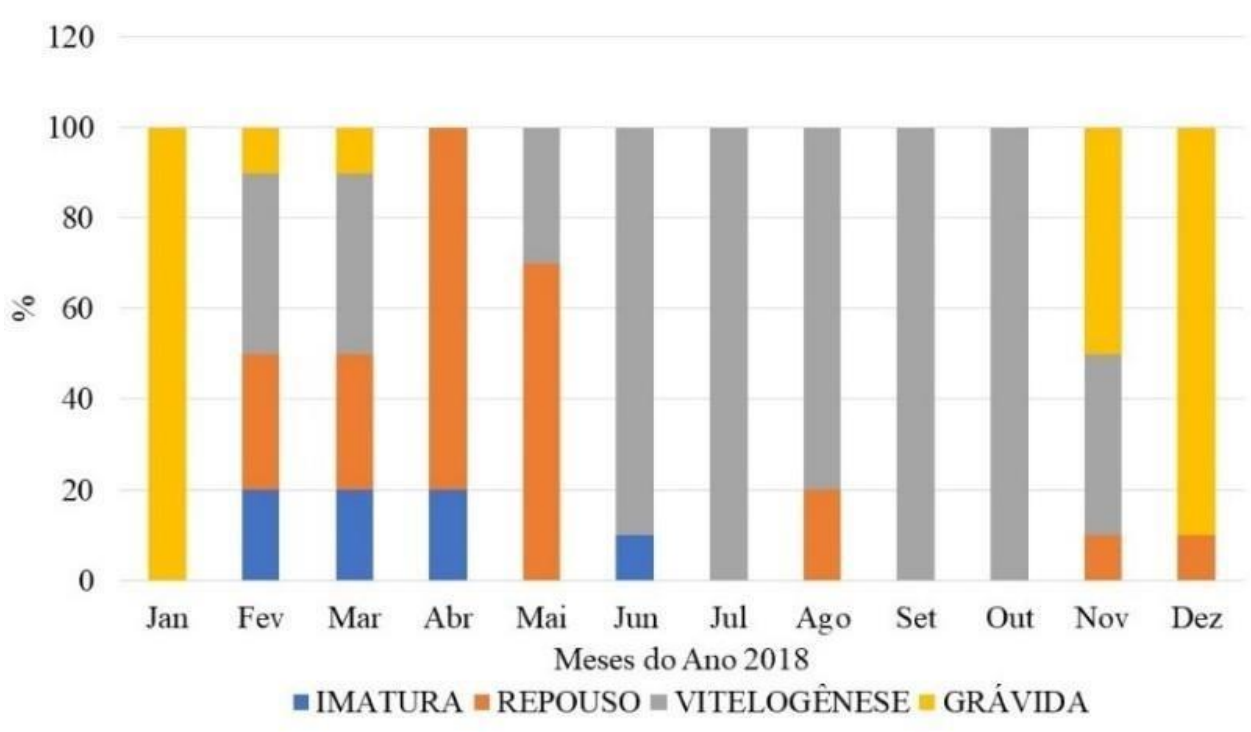

Figura 8. Classificação de estágios reprodutivos de fêmeas de Potamotrygon amandae com base nas análises macroscópicas dos ovários e presença de embriões no útero, coletadas no Alto Rio 
Paraná (reservatório de Jupiá, Ilha Solteira/SP). Cor azul indica estágio Imatura, cor laranja Repouso, cor cinza Vitelogênese e cor amarela Grávida.

\section{3 Índice Hepatossomático (IHS) e Gonadossomático (IGS)}

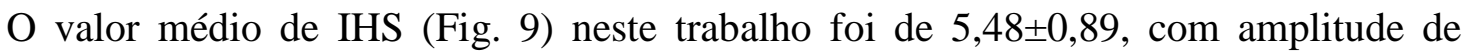
resultados entre 1,42 a 9,52\%, valores superiores aos observados para espécies do mesmo grupo (Potamotrygonidae), P. motoro no reservatório de Itaipu, 3,52\% ( KIRCHHEIM et al., 2013), P. orbignyi no Rio Paranã-Tocantins, 4\% (RINCON FILHO, 2006), P. iwamae na Baía de Marajó, 3,09\% (CHARVET-ALMEIDA, 2001) e P. wallacei, 3,15 (MACEDO, 2019). As maiores porcentagens observadas para $P$. amandae neste trabalho podem ser fruto da dieta desta espécie, que consumiu, além de artrópodes e peixes, itens comuns a Potamotrigonídeos (LONARDONI et al.; 2009; MORO et al., 2012), sementes de soja e milho(com contribuição de $7 \%$ da dieta), o consumo desses itens exógenos não são descritos na literatura (dados obtidos com os mesmos exemplares de nosso trabalho- Pagliarini et al., 2020).

Foi observado que os maiores valores de IHS foram correspondentes aos meses do período de seca, excluindo o mês de janeiro, o que corrobora com os dados de Almeida (2006) para $P$. motoro coletada na região da Ilha de Marajó, e não corrobora com o obtido em dois trabalhos com a espécie $P$. orbignyi (MAUÉS, 2002; RINCON FILHO, 2006), que mostraram os maiores IHS no período chuvoso. As três espécies apresentam vitelogênese nos meses de seca e parto no período chuvoso (CHARVET-ALMEIDA et al., 2005), mostrando que a discrepância de meses com maiores IHS é espécie-específica, e pode estar relacionada a diferentes estratégias de alocação de substratos metabólicos. Neste trabalho foi observado um padrão de diminuição de IHS no início do período de gravidez, mesmo comportamento descrito em P. wallacei (MACEDO, 2019), o que denota para as duas espécies o alto custo energético da reprodução.

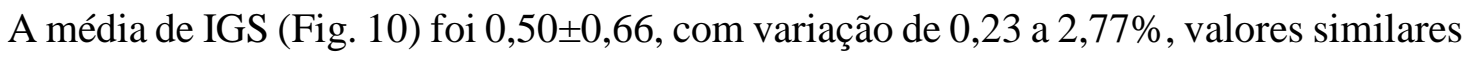
aos observados em P. iwamae (CHARVET-ALMEIDA, 2001), de 0,9\%, e P. motoro, 0,68\% (CHARVET-ALMEIDA, 2006) e bem abaixo do observado para algumas espécies de teleósteos, como é o caso da truta, Oncorhynchus mykiss, que atinge IHS de 12\% nos meses de vitelogênese ativa (GOMES, et al., 2020), o que pode ser explicado pela baixa fecundidade ovariana em arraias na comparação com teleósteos. A distribuição de IGS ao longo do ciclo reprodutivo foi responsiva ao período de vitelogênese, com valores aumentando nos meses de 
julho a setembro, sendo o maior valor observado no mês de agosto, e declínio com o início da gravidez, em dezembro, atingindo os menores valores em abril, mesmo padrão de queda de IHS, coincidindo com o início do estágio de repouso (pós-parto), caracterizando claramente o final do período de parto, e o começo de um novo ciclo reprodutivo para esta espécie.

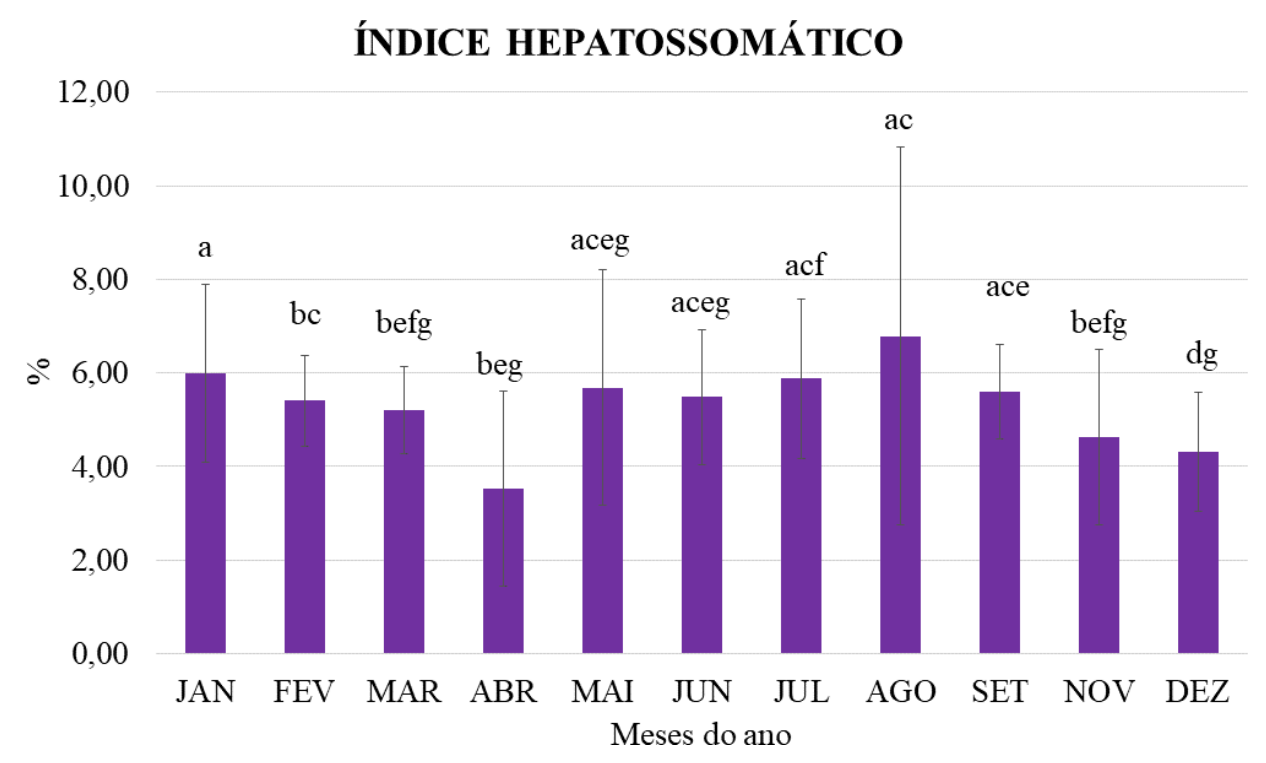

Figura 9. Índice Hepatossomático de fêmeas de Potamotrygon amandae coletadas no Alto Rio Paraná (reservatório de Jupiá, Ilha Solteira/SP): ${ }^{a}, b$ mostram diferença estatística significativa $(\mathrm{P}<0,05)$ entre os meses de coleta.

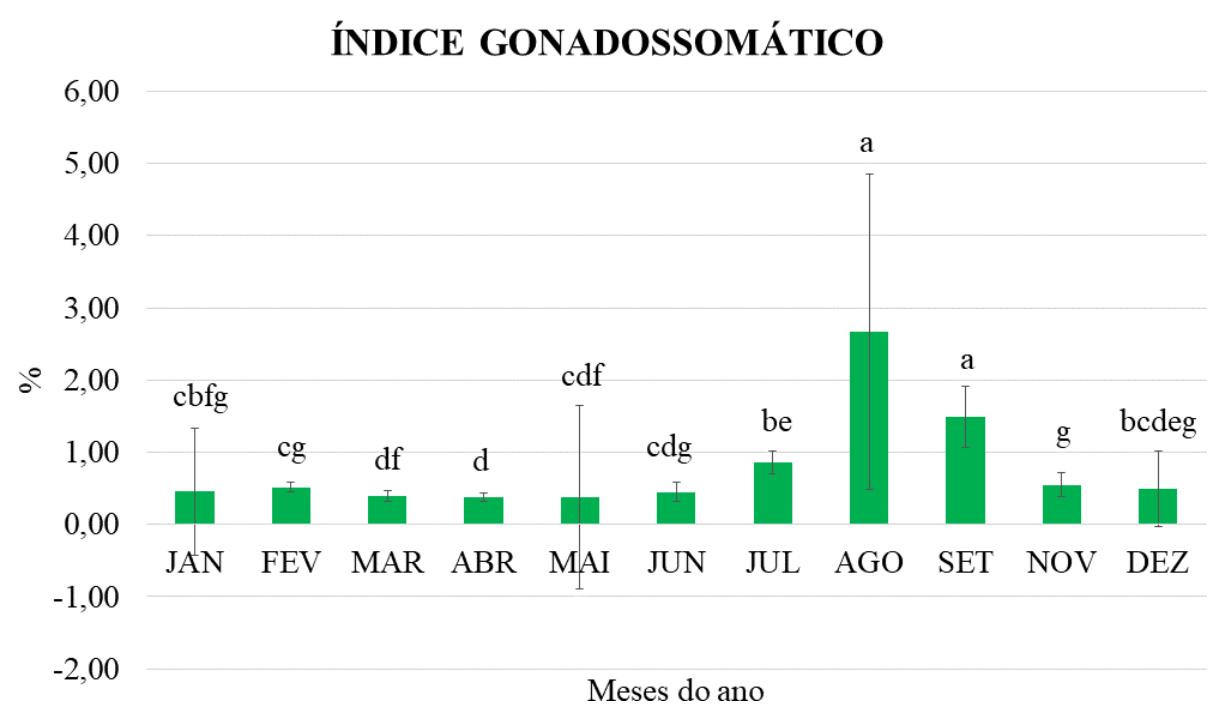

Figura 10. Índice Gonadossomático de fêmeas de Potamotrygon amandae coletadas no Alto Rio Paraná (reservatório de Jupiá, Ilha Solteira/SP): a,b mostram diferença estatística significativa $(\mathrm{P}<0,05)$ entre os meses de coleta. 
Sabendo-se que a vitelogênese está relacionada com a alocação de substratos energéticos do tecido hepático para o gonadal (JALABERT, 2005), optamos por trabalhar os dados de correlação entre os índices. Esta análise revelou correlação positiva entre os índices nos meses de abril, maio, junho, julho, setembro e dezembro (Fig. 11). Os valores de $R^{2}$ e P estatístico estão demonstrados na Tabela 1 , os valores de $R^{2}$ obtidos são altos, acima de 0,78 , demonstrando ajuste do modelo aos dados.

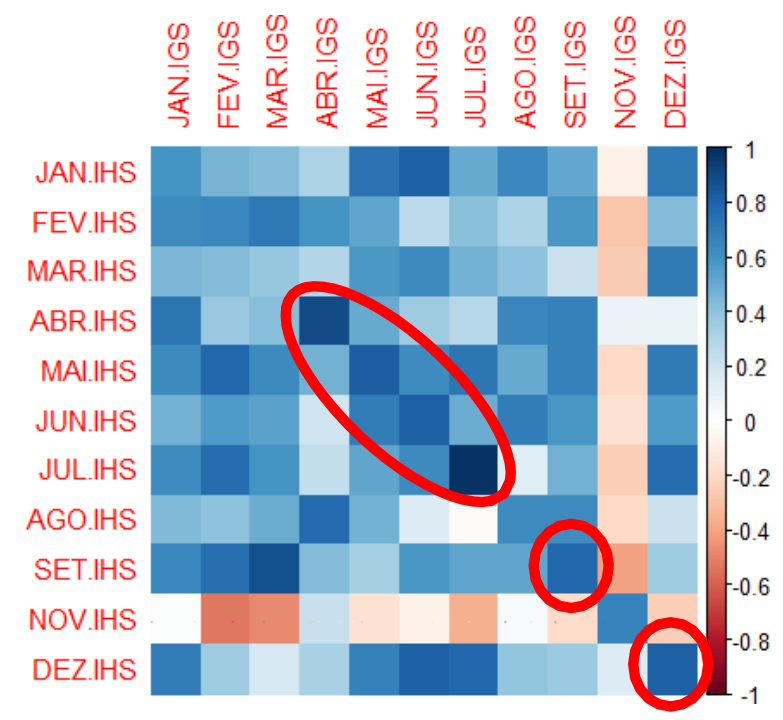

Figura 11. Correlação de Spearman entre o Índice Hepatossomático (IHS) e Índice Gonadossomático (IGS) de fêmeas de Potamotrygon amandae coletadas no Alto Rio Paraná (reservatório de Jupiá, Ilha Solteira/SP). A intensidade das cores indica maior índice de correlação, próximas de $1 \mathrm{ou}-1$. A cor azul indica correlação positiva e vermelha correlação negativa entre as variáveis testadas.

Tabela 1. Valores de Correlação $\mathrm{R}^{2}$ e $\mathrm{P}$ estatístico entre o Índice Hepatossomático (IHS) e Índice Gonadossomático (IGS) de fêmeas de Potamotrygon amandae coletadas no Alto Rio Paraná (reservatório de Jupiá, Ilha Solteira/SP).

\begin{tabular}{|l|l|l|}
\hline Mês & Valor & $\mathrm{P}$ \\
\hline Abril & 0,896 & 0,0008 \\
\hline Maio & 0,827 & 0,0218 \\
\hline Junho & 0,814 & 0,0000 \\
\hline Julho & 0,980 & 0,0000 \\
\hline Setembro & 0,788 & 0,0000 \\
\hline Dezembro & 0,811 & 0,0412 \\
\hline
\end{tabular}

*são apresentados nesta tabela apenas as correlações com significância estatística. 
Nota-se que correlação sempre é positiva, com os dois índices aumentando de modo concomitante, o que refuta a hipótese de alocação de substrato com reflexo na massa tecidual para esta espécie. Almeida (2006), observou um padrão claro de diminuição de IHS e aumento de IGS no período de vitelogênese em $P$. motoro. De acordo com a figura 8 , observa-se que nos meses de abril e maio, os animais estão deixando o período entre ciclos reprodutivos (repouso). Junho, julho e setembro, estão inseridos no período de vitelogênese em que se inicia a mobilização de substrato energéticos armazenados no fígado para as gônadas, dando início a maturação dos oócitos, o que enfatiza o aumento de IGS no mês de julho. Adicionalmente, o mês de dezembro representa o estágio de gravidez, mostrando diminuição expressiva e concomitante dos dois índices.

\subsection{Substratos metabólicos}

\subsubsection{Proteínas totais}

Os resultados de proteínas totais estão apresentados na figura 12 e na tabela do apêndice 1 .

A análise das proteínas totais hepáticas, mostrou um aumento gradual da concentração quando as fêmeas estavam em parte do período de repouso (abril e maio) e vitelogênese (junho, agosto e setembro) e uma posterior queda dessa concentração no final da vitelogênese (outubro), se mantendo baixa durante o período de gravidez, mostrando a mobilização desse substrato para as gônadas e manutenção dos filhotes. Adicionalmente, essa diminuição da concentração de proteínas durante a gravidez está relacionada com o fato dessa espécie não se alimentar neste período, apresentando a válvula espiral sem evidências de alimentos (dados obtidos com os mesmos exemplares de nosso trabalho- Pagliarini et al., (2020)), o que explica a diminuição desse substrato neste tecido.

Perfil muito similar foi observado para os ovários, com valores aumentando no final do repouso, porém, existe uma manutenção de altas concentrações até o mês de dezembro. Adicionalmente, nota-se uma diminuição da concentração de proteínas neste tecido no mês de abril, o que corresponde ao estágio de repouso, mês em que foi observado o menor número de oócitos no ovário dados não apresentados). 
As proteínas totais musculares mostraram-se altas no mês de transição entre ciclos (março), quando há estocagem de substratos metabólicos na vitelogênese (agosto, setembro e outubro) e gravidez (dezembro). Foi observado uma diminuição dessa concentração quando as fêmeas se encontravam no final do estágio de gravidez (janeiro), mostrando que grande parte dessa proteína pode ter sido recrutada pelo fígado e mobilizada para as gônadas (como observado na Fig. 12- fígado e ovários em janeiro).

Os dados de proteínas totais uterinas, não revelam padrão, mostrando que as concentrações se mantêm constantes, exceto no mês de janeiro, quando há uma diminuição dessa concentração, o que é explicado por ser a fase de nascimento dos filhotes, quando a atividade do tecido uterino é esgotada (Fig. 8).

Para todos os tecidos analisados observamos o mesmo padrão de valores diminuídos do substrato proteico no mês de julho, correspondente ao meio do período de seca (Fig. 3), e de vitelogênese ativa, este padrão pode estar ligado a menor oferta de alimento, e menor acesso a proteínas como substrato de armazenamento, já que flutuações sazonais influenciam diretamente na disponibilidade de recursos e consumo de itens alimentares. Lonardoni et al. (2006) observaram, em trabalho investigando a sobreposição trófica de $P$. motoro e $P$. falkneri no alto rio Paraná, diferenças na dieta das duas espécies na seca, o que pode ser resultado de um processo de diferenciação nas estratégias de exploração dos recursos com o intuito de evitar interações competitivas neste período. 


\section{Proteínas totais}
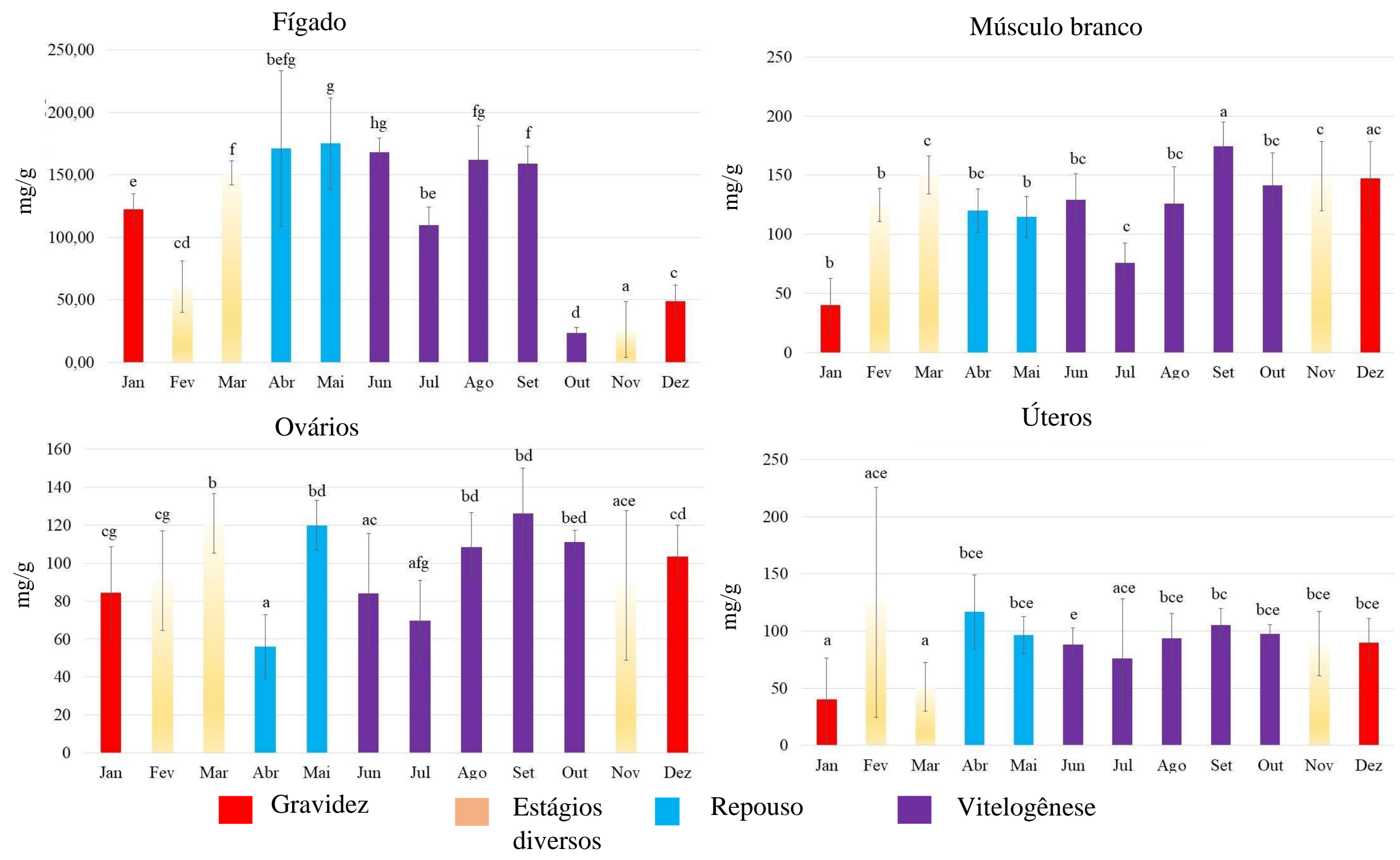

Figura 12. Concentração de proteínas totais teciduais de fêmeas de Potamotrygon amandae coletadas no Alto Rio Paraná (reservatório de Jupiá, Ilha Solteira/SP).

${ }^{a, b}$ letras acima das barras mostram diferença estatística significativa $(\mathrm{P}<0,05)$ entre os meses de coleta. 


\subsubsection{Lipídeos totais}

Os resultados de lipídeos totais estão apresentados na figura 13 e tabela do apêndice 1.

Os resultados serão apresentados de modo distinto neste tópico, já que o metabolismo lipídico do tecido hepático é bastante incomum na comparação com outros grupos de vertebrados, e será destacado, e após este destaque serão trabalhados os dados com vistas a entender o perfil deste substrato no ciclo reprodutivo.

*tecido hepático

A partir da análide dos lipídeos totais hepáticos, pode-se observar que as concentrações se mantêm altas na comparação com os outros tecidos analisados, chegando a ser 100 vezes maiores que a concentração no tecido muscular. Além desta diferença entre os tecidos, podemos observar diferenças marcantes na comparação com teleósteos (tabela 2). Arapaima gigas, Steindachneridion parahybae, Pseudoplatystoma reticulatum, três espécies com hábito alimentar piscívoro, mostraram valores até 20 vezes inferiores a de $P$. amandae Adicionalmente, a comparação com a espécie onívora $O$. niloticus foi ainda mais discrepante, com valores 100 vezes menores. A explicação para tais diferenças pode ser atribuída ao fato de que, ao contrário dos mamíferos e de muitos teleósteos, os elasmobrânquios são desprovidos de tecido adiposo, e o fígado é o principal local de armazenamento de lipídeos (BALLANTYNE, 1997), bem como um importante local de síntese deste substrato, além disso, os elasmobrânquios são famosos por apresentarem fígados grandes, com alto IHS em comparação com os teleósteos e outros vertebrados (BALLANTYNE, 1997; BALLANTYNE e ROBINSON 2010; SPEERS-ROESCH e TREBERG, 2010; BALLANTYNE, 2016).

Comparando-se os resultados de lipídeos hepáticos da espécie analisada neste trabalho e espécies de elasmobrânquios de ambiente marinho é possível observar menores valores totais para animais de água doce. Os valores para animais marinhos alcançam $795 \mathrm{mg} / \mathrm{g}$, ou seja, 79,5\% da massa hepática para a espécie Carcharodon carcharias é lipídica, os autores ressaltaram que os níveis elevados de lipídeos no tecido hepático são indicativos do papel central do órgão no metabolismo e armazenamento lipídico desse grupo (PETHYBRIDGE et al., 2014, DAVIDSON et al., 2014). Além da importância metabólica, os lipídeos têm papel fundamental na flutuabilidade em espécies bentopelágicas (BALLANTYNE e ROBINSON, 2010; 
SHADWICK; FARRELL; BRAUNER, 2015) o que pode explicar os menores valores observados nas espécies dulciaquícolas.

Tabela 2. Lipídeos totais hepáticos em elasmobrânquios e teleósteos.

\begin{tabular}{lcr}
\hline Espécies & $\begin{array}{c}\text { mg/g tecido } \\
\text { hepático }\end{array}$ & Referência \\
\cline { 2 - 3 } Elasmobrânquios & $305,75 \pm 62,15$ & Este trabalho \\
P. amandae & $234.96 \pm 30.59$ & Pagliarini et al. (2020) \\
P. falkneri & 795 & Pethybridge et al. (2014) \\
C. carcharias & 571 & Özyilmaz e OÖzy (2015) \\
Mustelus mustelus & 580 & Özyilmaz e OÖzy (2015) \\
Rhinoptera marginata & 657 & Özyilmaz e OÖzy (2015) \\
Myliobatis aquila & 680 & Özyilmaz e OÖzy (2015) \\
Dasyatis pastinaca & 692 & Özyilmaz e OÖzy (2015) \\
Rhinobatos rhinobatos & 731 & Özyilmaz e OÖzy (2015) \\
Carcharhinus altimus & 280 & Rangel et al. (2020) \\
Rhinoptera brasiliensis & 405 & Kebir et al. (2003) \\
Dasyatis marmorata & 226 & Kebir et al. (2003) \\
Rhinobatos cemiculus & 475 & Kebir et al. (2003) \\
Rhinoptera marginata & & Ribeiro et al. (2014) \\
Teleósteos & $17,57 \pm 3,17$ & Amaral (2009) \\
A. gigas & $15,00 \pm 2,23$ & Tolussi et al. (2018) \\
S. parahybae & $38,63 \pm 6,99$ & Mello (2010) \\
P. reticulatum & $3,3 \pm 0,42$ & niloticus
\end{tabular}

\section{*Lipídeos e ciclo reprodutivo}

Padrões de alocação de substrato lipídico entre tecidos durante o ciclo reprodutivo devem ser tratados com muita cautela para elasmobrânquios, já que a ausência de albumina e a baixa concentração de outras lipoproteínas de transporte (BALLANTYNE e ROBINSON,2010), além de baixos valores de ácidos graxos livres (AGL) no plasma (SPEERS-ROESCH et al., 2006), podem inviabilizar ou tornar ineficiente a tarefa de mobilidade circulatória de tal substrato. 
O tecido hepático mostrou alguma variação anual, com maiores valores amostrados no mês de janeiro, e menores no mês de outubro, delimitando perfeitamente os meses em que todas as fêmeas coletadas estavam grávidas e o mês em que todas estavam em vitelogênese (Fig. 5). Estes achados podem estar relacionados à energia gasta nos processos ligados à reprodução, já que o tecido hepático é o local preferencial de oxidação deste substrato, demonstrado pela atividade da enzima HOAD, comparativamente maior no fígado em comparação com o rim e coração de espécies de elasmobrânquios marinhos e de água doce (SPEERS-ROESCH et al., 2006).

Os menores valores de outubro podem estar diretamente relacionados ao período de cópula da espécie, (relatado por Garrone Neto (2010)), sendo este comportamento custoso energeticamente, enquanto os maiores valores observados em janeiro comprovam a importância deste substrato durante a gravidez, também observado por Macedo (2019) em P. wallacei.

Os lipídeos totais musculares foram extremamente baixos, explicado pela ausência de atividade de enzimas de oxidação deste substrato (CPT e HOAD) na musculatura vermelha e branca dos elasmobrânquios (SPEERS-ROESCH e TREBERG, 2010), e o baixo armazenamento deste substrato entre as fibras musculares. Os baixos níveis de AGL, descrito acima, correlacionam-se à ausência de oxidação lipídica significativa em muitos tecidos, uma vez que estes ácidos graxos plasmáticos são importantes para a oxidação rápida em outros tecidos (SPEERS-ROESCH et al., 2006), o que corrobora as baixas concentrações musculares observadas em $P$. amandae em todos os meses do ano.

Na descrição da oogênese da raia Urolophus jamaicensis realizada por Hamlett, Jezior; Spieler (1999), os autores descrevem no período de vitelogênese ativa o surgimento de células grandes e redondas na parede folicular dos oócitos, contendo gotículas de lipídeos, essas células diminuem de tamanho e número à medida que a foliculogênese prossegue e eventualmente desaparecem antes da ovulação, esta descrição histológica mostra a importância do substrato lipídico para a formação dos oócitos em elasmobrânquios, o que é corroborado diretamente pela alta concentração de lipídeos ovarianos no mês de julho. As menores concentrações de lipídeos estão no último mês de vitelogênese (outubro), mostrando que a maturação desses oócitos está próxima do término, com possível ovulação.

Arraias da ordem Myliobatiformes apresentam histotrofia lipídica, isso é, os filhotes, após o consumo do saco vitelínico, se alimentam do histotrofo, um fluido lipídico produzido e liberado pelo trofonema das mães (HAMLETT e HYSSEL, 1998). Este fluido uterino é produzido logo após a ovulação e continua a ser produzido até o parto (AMESBURY et al., 1999a), para que esta produção ocorra a morfologia do órgão se transforma drasticamente 
durante a gestação, a vascularização aumenta, os capilares hipertrofiaram no início e no meio da gestação e gotas lipídicas se acumulam nas fossas glandulares no meio e no final da gestação (AMESBURY et al., 1999b). Neste trabalho, os lipídeos totais uterinos mostram maiores concentrações no período de gravidez, que vai de dezembro, mês com a maior concentração observada- $10,5 \mathrm{mg} / \mathrm{g}$, até final de fevereiro, quando ocorre o nascimento da maioria dos filhotes. Adicionalmente foi observado que os meses de junho e julho são meses chaves durante a vitelogênese, apresentando altas concentrações de lipídeos no tecido uterino 


\section{Lipídeos totais}

Fígado
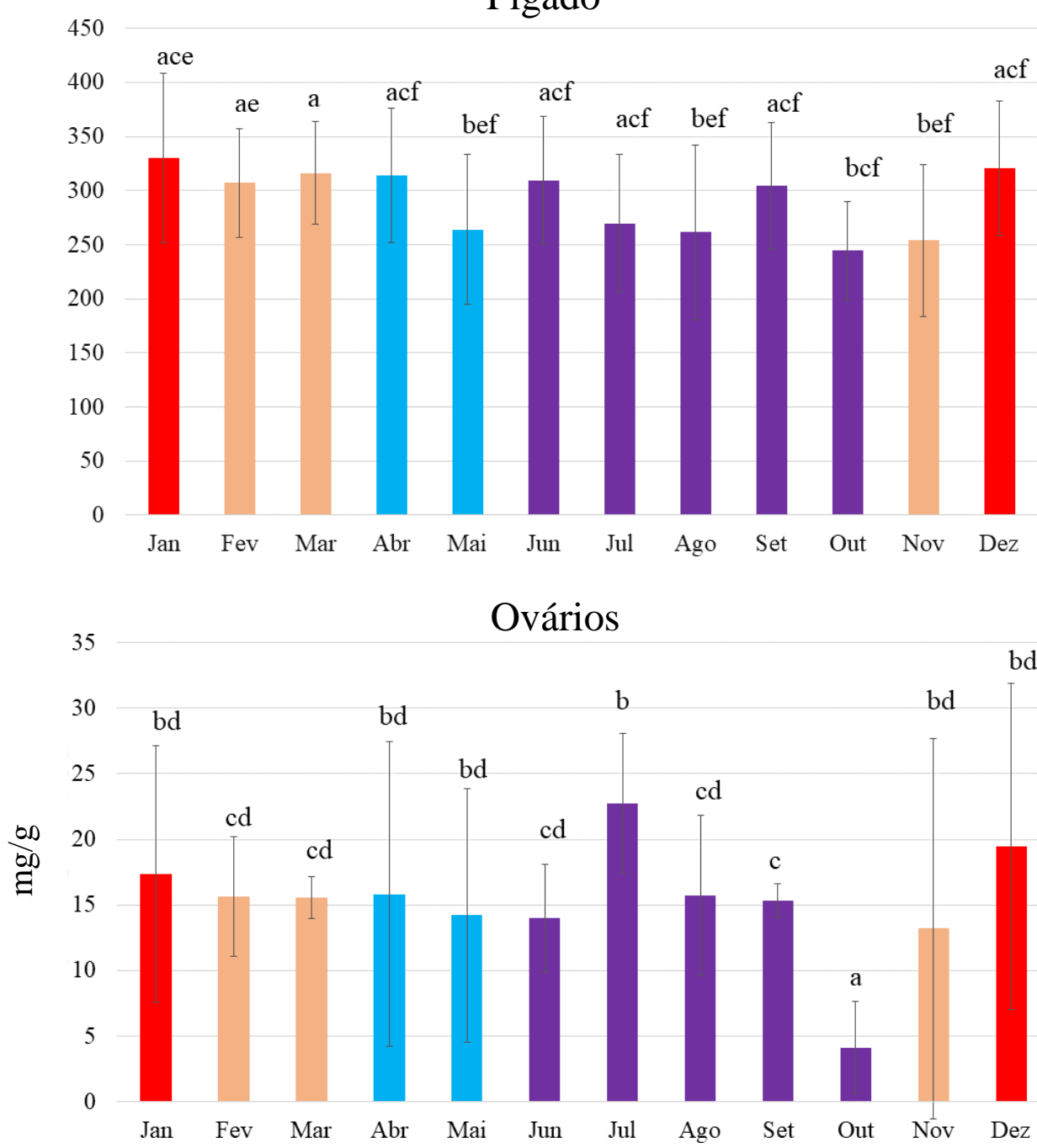

Gravidez

\section{Estágios diversos}

12 Músculo branco

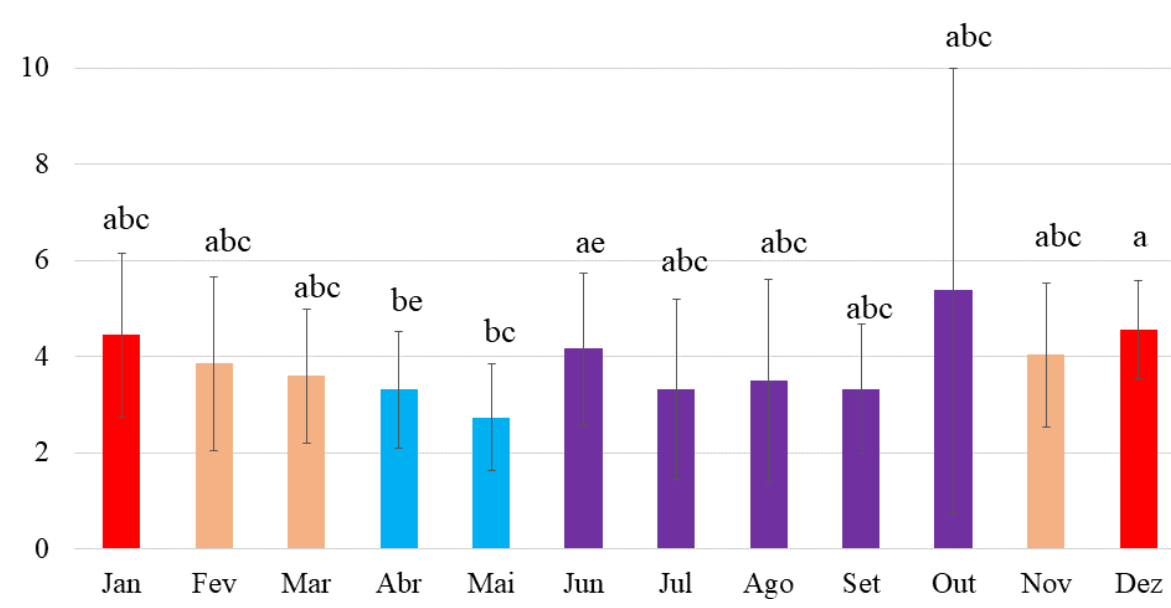

Úteros

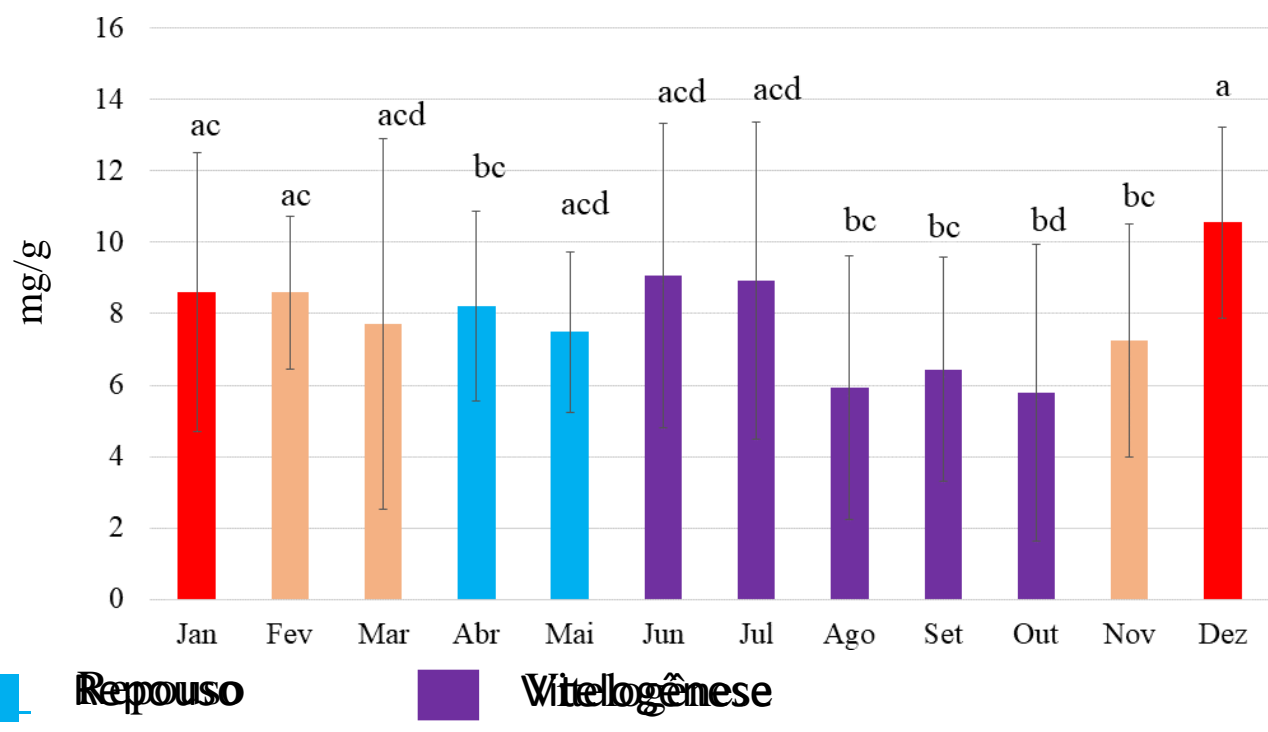

Figura 13. Concentração de lipídeos totais teciduais de fêmeas de Potamotrygon amandae coletadas no Alto Rio Paraná (reservatório de Jupiá, Ilha Solteira/SP).

a,b letras acima das barras mostram diferença estatística significativa $(\mathrm{P}<0,05)$ entre os meses de coleta. 


\subsection{3 Ácidos Graxos}

Nos apêndices (2 a 5) estão apresentados os perfis de ácidos graxos totais dos tecidos hepático, muscular, ovariano e uterino de $P$. amandae durante o ciclo reprodutivo. A nomenclatura de cada ácido graxo e sua classificação de acordo com o número de carbonos, grau de insaturação e posição da primeira insaturação seguiram as regras da IUPAC (International Union of Pure and Applied Chemistry). A análise do perfil de ácidos graxos dos tecidos dos animais permitiu avaliar a porcentagem de cada ácido graxo e consequentemente os principais agrupamentos: ácidos graxos saturados (SAT), monoinsaturados (MUFA) e polinsaturados (PUFA), e dentro destes os ácidos graxos ômega 3 (PUFAn3) e ômega 6 (PUFAn6) dos quatro tecidos analisados, além das somatórias de ácidos graxos de cadeia curta (C18n) e cadeia longa (C20-22n) ômega 3 e ômega 6. Fazendo-se uma análise da diversidade de ácidos graxos foi possível observar alta prevalência de C16:0 e C18:0 como SAT com maior representatividade, C16:1 e C18:1 como MUFA prevalentes e C20:4n6, C20:5n3, C22:5n3, C22:2n6; C22:5n6 e C22:6n3 como principais PUFA.

Os lipídeos armazenados sob a forma de triacilgliceróis são a principal reserva energética rápida na maioria dos vertebrados (SHERIDAN, 1994). Em geral, esses compostos são formados por dois SAT ou MUFAs e uma cadeia central de PUFA. Assim, sabe-se que aproximadamente $80 \%$ da composição dos triacilgliceróis correspondem aos ácidos graxos saturados e monoinsaturados (BELL HENDERSON et al., 1986. A diferença na composição dos tecidos pode ser resultado da especificidade e afinidade de ácidos graxos por estes ou do metabolismoda espécie, bem como da dieta do animal. De uma forma geral, os FAs têm papel diferenciado no metabolismo dos vertebrados, e os fosfolipídeos são importantes constituintes de membranas e funcionam comoo principal precursores de prostaglandinas, tromboxanos e leucotrienos, enquanto os triacilgliceróis servem como depósitos para ácidos graxos que são catabolizados no metabolismo energético celular (NELSON e COX, 2011). Neste trabalho optou-se por analisar o perfil total dos ácidos graxos, sem separação de fosfolipídeos e triacilgliceróis.

Dada a variedade estrutural e diferenças metabólicas, a deposição de FAs específicos pode variar entre os tecidos (BECKMANN et al., 2014). Assim, a análise do perfil de FA tecidual pode ajudar a elucidar padrões de mobilização e explorar mudanças na dieta ao longo 
do tempo (EVERY et al., 2016), além sustentarem demandas energéticas e estruturais ligadas à energética dos parentais e prole e embriogênese (CARVALHO e CARAMUJO, 2018). Estudos com elasmobrânquios têm demonstrado que MUFA são armazenados preferencialmente no fígado, e PUFA e SAT no músculo (DAVIDSON e CLIFF, 2002; PETHYBRIDGE et al., 2010). Os resultados obtidos neste trabalho corroboram com estas informações; observou-se maiores valores de MUFA no tecido hepático (29 - 38\%) em comparação ao tecido muscular $(17-29 \%)$, bem como maiores valores de SAT e PUFA para o tecido muscular (43 - 55\% e 14 - 37\%) na comparação com o tecido hepático (38 - 46\% e $17-29 \%$ ), este mesmo padrão também foi observado por Spada et al. (2020), com a espécie congenérica P. falkneri. No estudo de Rangel (2018), com a espécie marinha Rhinoptera bonasus foram observadas proporções semelhantes dos FAs totais no fígado, plasma e músculo, que apresentou maiores proporções de PUFA (40 - 61\%), seguido de SAT $(28$ - 37\%) e menores proporções de MUFA (10 - 20\%), indicando que os FAs são retidos da dieta em proporções semelhantes nestes tecidos.

A análise do tecido tecido hepático possibilitou detectar intensas diferenças entre o mês de janeiro e os demais, com possibilidade de se traçar um padrão bastante claro, de maiores valores para SAT nos meses de janeiro, fevereiro, março e abril, na comparação com os demais mesesdo ano. Já para MUFA, foi possível observar maiores valores no mês de janeiro, setembro e dezembro, com menor porcentagem no mês de abril. Em contrapartida, os ácidos graxos PUFA apresentaram menores valores para o mês de janeiro em comparação com os demais meses do ano, esta diminuição tem reflexo direto de PUFA n3, e estão intimamente relacionados aos ácidos graxos de cadeia longa e curtas desta classe. O padrão de armazenamento de ácidos graxos energéticos no mês de maior incidência de partos, mostra a necessidade destes ácidos graxos para este processo, com diminuição destas classes no mês de abril, mês com maior representatividade do estágio de repouso (Fig. 8). Um padrão semelhante foi demonstrado por Spada et al. (2020) com a espécie $P$. falkneri, maiores valores de MUFA para os animais no estágio maduro na comparação com os animais em repouso. Em contrapartida, os ácidos graxosPUFA apresentaram menores valores para o mês de janeiro em comparação com os demais meses do ano, e esta diminuição tem reflexo direto em PUFA n3 e n6, e estão intimamente relacionados aos FA de cadeia longa e curtas. Desse modo, observouse maiores valores de PUFA no início da vitelogênese e à medida que a mesma vai progredindo observou-se uma diminuição desses ácidos graxos. Este padrão mostra a clara mobilização de PUFA para o tecido 
ovariano durante o amadurecimento oocitário, estando certamente relacionado ao papel hepático de mobilização de vitelogenina para o tecido ovariano (PATIÑO e SULLIVAN, 2003).

O tecido muscular revelou apenas uma diferença estatística para SAT, maior porcentagem no mês de agosto em comparação ao mês de outubro. Identifica-se nos meses de março, abril e maio menores valores de MUFA na comparação com agosto. Os meses de janeiro, abril e outubro mostraram retenção de PUFA neste tecido, com diminuição de SAT e MUFA, sendo este aumento de PUFA reflexo do PUFA n3 e n6. O músculo tem sido descrito como o melhor tecido para avaliar mudanças na dieta. Estudos com o tubarão da Groelândia (Somniosus microcephalus) encontraram que o perfil de FA do músculo foi proporcional ao encontrado nas presas, sugerindo uma incorporação de FA com pequenas modificações neste tecido (McMEANS et al., 2012). Isso foi encontrado em estudos experimentais com alimentação controlada por Beckmann et al. (2013), em que os FA da dieta foram preferencialmente utilizados e acumulados no tecido muscular do tubarão Heterodontus portusjacksoni. Pagliarini et al. (2020), avaliando o nicho trófico de duas espécies de arraias dulciaquícolas, P. falkneri e P. amandae (mesmos animais amostrados para este trabalho), mostrou consumo preferencial de Baetidae para a primeira e detrito para a segunda, com variação temporal importante; e aumento do consumo de peixes durante os meses com menor pluviosidade, o que explica maior porcentagem de SAT em agosto, e mais diversidade de itens alimentares nos meses com maior pluviosidade, explicando o aumento de PUFA entre outubro e abril.

Identificamos que o tecido ovariano se manteve como tecido mais estável durante o ciclo. Foram observado maiores valores de SAT nos meses de maio e setembro em comparação aos meses de julho e novembro, isto mostra que SAT iniciam altos no final do estágio de repouso e começo da vitelogênese, decaem durante a vitelogênese ativa e voltam a aumentar ao final deste processo, se mantendo altos. Para MUFA identificou-se maiores valores no mês de setembro em comparação aos meses de abril e junho. Já para PUFA, houve apenas uma diferença, maiores porcentagens em junho na comparação com o mês de setembro, com reflexo do C18 n6, e isto comprova o perfil de maiores valores de SAT e MUFA e uma diminuição de PUFA no mês desetembro, de vitelogênese final.

Analisando o tecido uterino foi possível observar que os meses de janeiro, agosto e setembro, apresentaram maiores valores de SAT em comparação com os demais meses do ano. Já para MUFA observou-se que os meses de gravidez (dezembro e janeiro) foram os meses com maiores valores desta classe de ácidos graxos em comparação ao restante do ano. Isto mostra 
que nos meses de gravidez cerca de $90 \%$ da composição do tecido uterino (reflexo para a composição do leite uterino) são representados por SAT e MUFA. O contrário é verdadeiro para os ácidos graxos PUFA, e observou-se que nestes mesmos meses as porcentagens são menores em comparação ao resto do ano, destacando que foram observados maiores valores de PUFA nos meses de repouso (abril e maio), reflexo direto dos PUFA n3 e PUFA n6 de cadeia longa para este tecido.

Este padrão parece refletir a preparação destes tecidos para o cuidado parental, já que o tecido hepático e muscular irá encaminhar suprimentos para o tecido uterino, que é responsável por grande parte do aporte energético dos filhotes, com a liberação do leite uterino (TOCHER, 2003; ARISTIZABAL, 2007; NARVÁEZ et al., 2008; PETHYBRIDGE et al., 2014). Pethybridge et al., (2014) estudando tubarões brancos (Carcharodon carcharias) mostrou que lipídeos musculares e hepáticos são extremamente relacionados ao sucesso reprodutivo em elasmobrânquios. Estes achados não corroboram com o obtido no trabalho com a espécie $P$. falkneri (SPADA et al., 2020), que mostraram um aumento significativo de PUFA e PUFA n6 no período maduro, o que evidencia que essa diferença é espécie-específica, e pode estar relacionada a diferentes estratégias de alocação de substratos metabólicos. 


\subsubsection{Glicogênio}

Os resultados da análise de glicogênio teciduais de fêmeas de $P$. amandae está apresentado na figura 14 (A, B, C e D) e na tabela do apêndice 1. Notou-se que o tecido hepático e ovariano (A e C) apresentam maiores concentrações de glicogênio em relação ao tecido muscular (B) e tecido uterino (D).
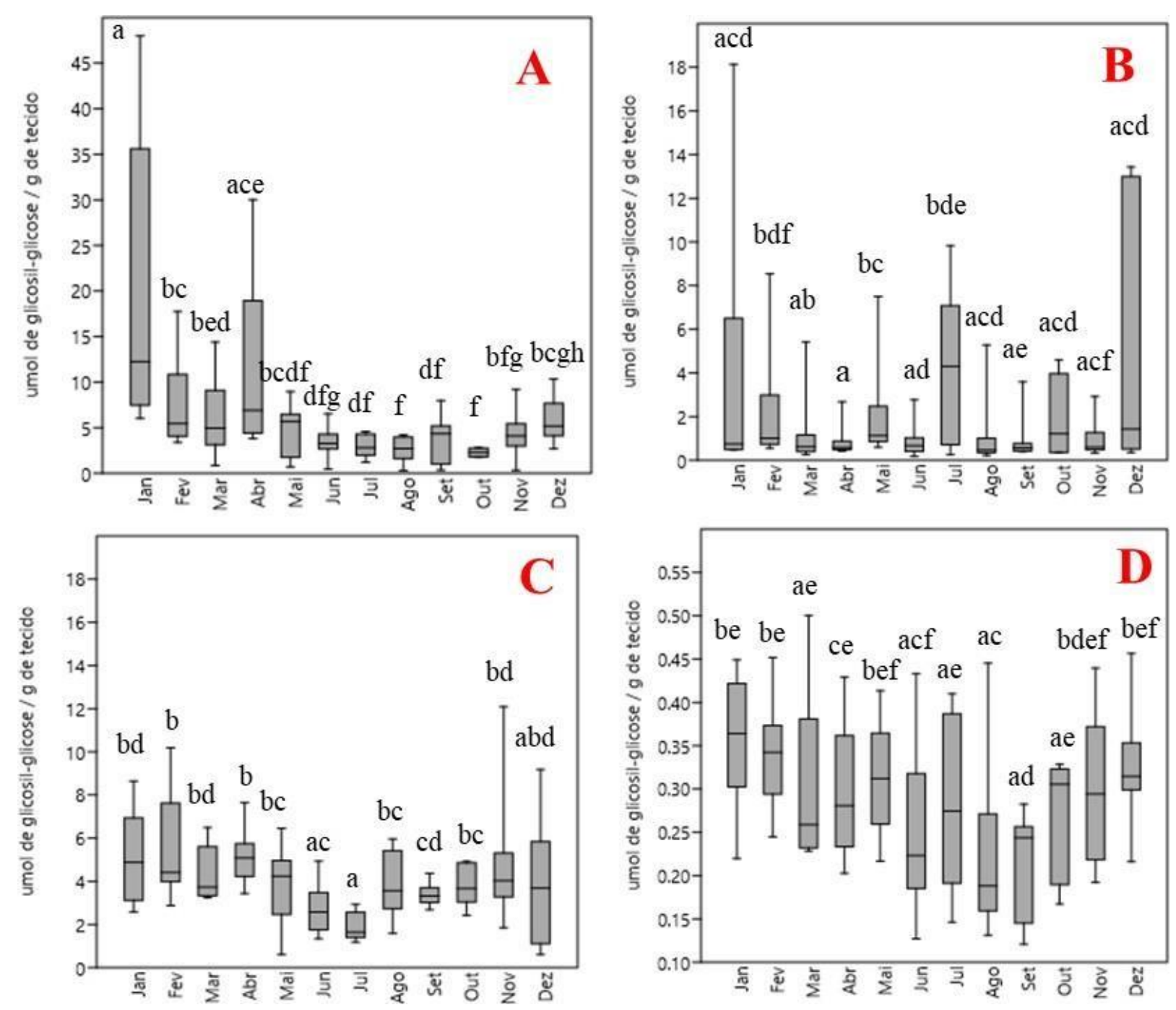

Figura 14. Concentração de glicogênio em fêmeas de Potamotrygon amandae coletadas no Alto Rio Paraná (reservatório de Jupiá, Ilha Solteira/SP. A) Glicogênio hepático. B) Glicogênio muscular. C) Glicogênio ovariano. D) Glicogênio uterino. Média \pm Desvio: a,b mostram diferença estatística significativa $(\mathrm{P}<0,05)$ entre os meses de coleta. 
De acordo com Ballantyne e Robinson (2010), a gliconeogênese pode ocorrer primariamente no fígado e nos rins na espécie de raia dulciaquícola $P$. magdalenae, padrão semelhante à dos elasmobrânquios marinhos e comparável à encontrada em teleósteos carnívoros. Isso explica o fato de a concentração de glicogênio no fígado ser maior que a concentração dos demais tecidos analisados. O mês de janeiro mostrou o maior valor observado para este substrato, este mês corresponde à gravidez dos espécimes, com os maiores filhotes mensurados (dados não publicados), o trabalho de Ahmed-Sorour e Bailey (1981), mostrou uma relação direta do aumento da capacidade de gliconeogênese hepática em ratos tratados com combinação de hormônios estradiol e progesterona, o que corrobora diretamente os resultados deste trabalho quanto à evolução da gravidez.

Surpreendentemente, no tecido ovariano as concentrações de glicogênio são maiores que as concentrações do tecido muscular, podendo sugerir que este tecido apresenta capacidade de gliconeogênese e armazenamento deste substrato aumentada, similar à do tecido hepático, provavelmente resultado da interconversão de substrato proteico em glicogênio (vide a diminuição do primeiro substrato e aumento do segundo no mês de abril- Apêndice 1), pela via aminoacídica/ glicogênio que é preferencial em elasmobrânquios (SPEERS-ROESCH e TREBERG, 2010), o que também pode ser observado no tecido hepáticopara o mesmo mês.

No tecido uterino, nota-se menores concentrações de glicogênio, mostrando que este tecido praticamente não participa da utilização de carboidrato como combustível metabólico no ciclo reprodutivo. Esta incapacidade uterina de realização de gliconeogênese e de alocação deste substrato para a placenta já foi apontada para ratos (PALACIN; LASUNCIÓN; HERRERA, 1987).

Como já levantado anteriormente, a quebra de lipídeos é nula no tecido muscular de elasmobrânquios (SPEERS-ROESCH e TREBERG, 2010), intuitivamente esperávamos maiores valores de glicogênio neste tecido, já que a glicose é combustível preferencial de quebra aeróbica em vertebrados (POLAKOF; MOMMSEN; SOENGAS, 2011) o que não foi confirmado, mas levantou a hipótese de que este substrato pode ser quebrado rapidamente neste tecido, o que não nos permitiu observar altasconcentrações, comparado com o tecido hepático. Esta hipótese encontra base na literatura, a capacidade glicolítica, representada pela enzima piruvato quinase $(\mathrm{PK})$, fornece informações sobre a importância dos carboidratos como combustível metabólico para este grupo, o trabalho de Speers-Roesch et al. (2006), com as espécies de raia $P$. motoro; $H$. signifer, T. lymma; e o tubarão $C$. punctatum, mostrou que a PK 
foi maior no músculo (T. lymma $522 \pm 17 \mu \mathrm{mol} \cdot \mathrm{min}^{-1} \cdot \mathrm{g}^{-1}$ e $C$. punctatum $221.1 \pm 22.3$ $\mu \mathrm{mol} \cdot \mathrm{min}^{-1} \cdot \mathrm{g}^{-1}$ ), e menor no fígado em todas as espécies (P. motoro $16.3 \pm 0.7 \mu \mathrm{mol} \cdot \mathrm{min}^{-1} \cdot \mathrm{g}^{-}$ 1; H. signifer $15.5 \pm 1.2 \mu \mathrm{mol} \cdot \mathrm{min}^{-1} \cdot \mathrm{g}^{-1} ;$. lymma $21.9 \pm 1.1 \mu \mathrm{mol} \cdot \mathrm{min}^{-1} \cdot \mathrm{g}^{-1}$ e C. punctatum $7.31 \pm 1.05 \mu \mathrm{mol} \cdot \mathrm{min}^{-1} \cdot \mathrm{g}^{-1}$ ), isso mostra que o tecido hepático participa mais na gliconeogênese do que da quebra da glicose para produção de energia metabólica.

Adicionalmente, o único valor publicado de concentração de glicose no sangue em uma arraia Potamotrygon sp. (GRIFFITH et al., 1973) é semelhante ao dos elasmobrânquios marinhos, de $22 \mathrm{mg} / \mathrm{dl}$ de glicose, os animais deste trabalho apresentaram uma concentração média de 23,09 $\pm 9,67 \mathrm{mg} / \mathrm{dl}$ de glicose no plasma (dados não publicados), mostrando similaridade entre as espécies, e baixos valores na comparação com outros vertebrados (POLAKOF; MOMMSEN; SOENGAS,2011).

\subsection{Modelos de Equação Estrutural (SEM)}

Com os resultados dos índices corpóreos, substratos metabólicos e estágio de maturação dos espécimes capturados (excluindo-se o estágio imaturo) foram testadas conexões entre as variáveis a fim de possibilitar a verificação de efeitos preditivos ou não dos caminhos de alocação de recursos metabólicos ao longo do ciclo reprodutivo de P. amandae, usando modelos de equação estrutural.

Os modelos serão descritos na seguinte ordem: predição fisiológica, modelo testado e resultados.

Modelo 1: Influência do estágio reprodutivo em substratos metabólicos proteicos e lipídicos.

Predição: as concentrações de substratos metabólicos apresentam mudanças significativas guiadas pelo estágio reprodutivo. 


\section{Modelo testado}

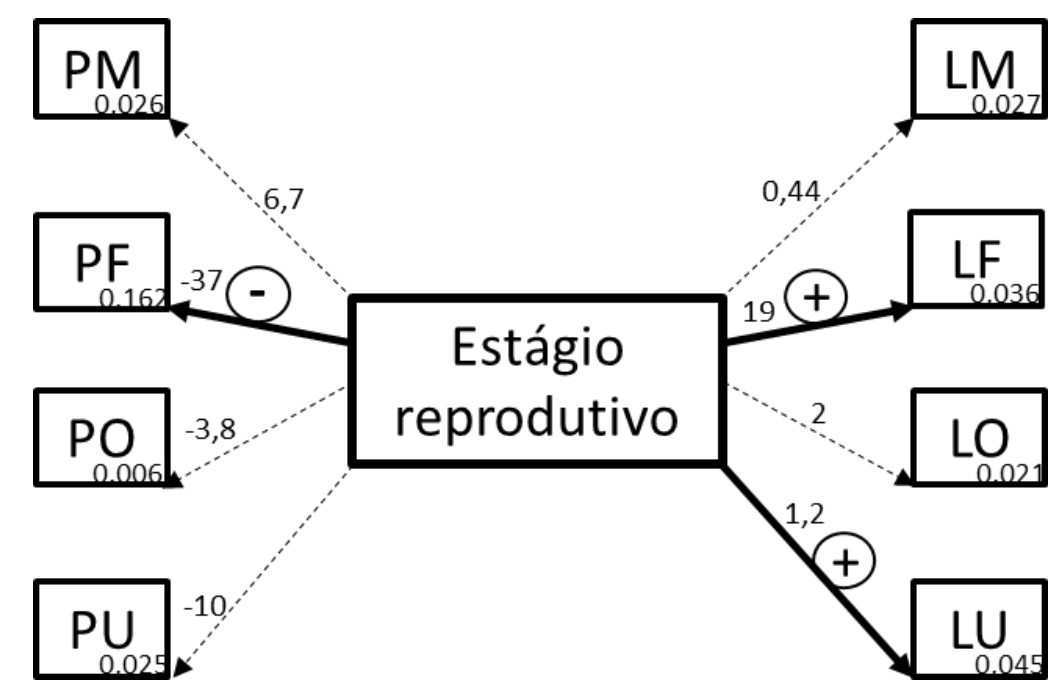

Figura 15. Modelo de equação estrutural (SEM) mostrando conexões diretas entre o estágio reprodutivo e os substratos proteicos e lipídicos teciduais. Os números associados às relações entre as variáveis são coeficientes apresentados como valores padronizados pelos desviospadrão das variáveis. Os números dentro das caixas são os valores de $R^{2}$ de cada uma das variáveis de saída do modelo. Setas sólidas mostram conexões significativas $(\mathrm{P}<0,05)$, setas tracejadas mostram conexões não significativas $(\mathrm{P}>0,05)$. Qualidade do ajuste do SEM: $\mathrm{P}\left(\chi^{2}\right)$ = 0,386 (um bom ajuste do modelo indicando que o modelo claramente não é significativamente diferente do modelo teórico). PM- Proteína muscular; PF- Proteína hepática; PO- Proteína ovariana; PUProteína uterina; LM- Lipídeo muscular; LF- Lipídeo hepático; LO- Lipídeo ovariana; LU- Lipídeo uterina.

Resultados: O modelo mostrou conexões significativas entre o estágio reprodutivo, PF, LF e LU. Estágio reprodutivo afeta negativamente as proteínas hepáticas e positivamente lipídeos hepáticos e uterinos. Este modelo encontra base teórica quando observamos a importância dos lipídeos para a gestação e retenção de filhotes nesta espécie (histotrofia lipídica), enquanto as proteínas tendem a decrescer com o avanço do ciclo reprodutivo, possivelmente para manutenção de tecidos reprodutivos abastecidos durante o período.

Modelo 2: O estágio reprodutivo influencia o IHS e este regula os níveis de substratos hepáticos.

Predição: o fígado, em resposta ao estradiol inicia o processo de vitelogênese, recrutando substratos metabólicos de tecidos de armazenamento, aumentando as concentrações destes em seu tecido. 


\section{Modelo testado:}

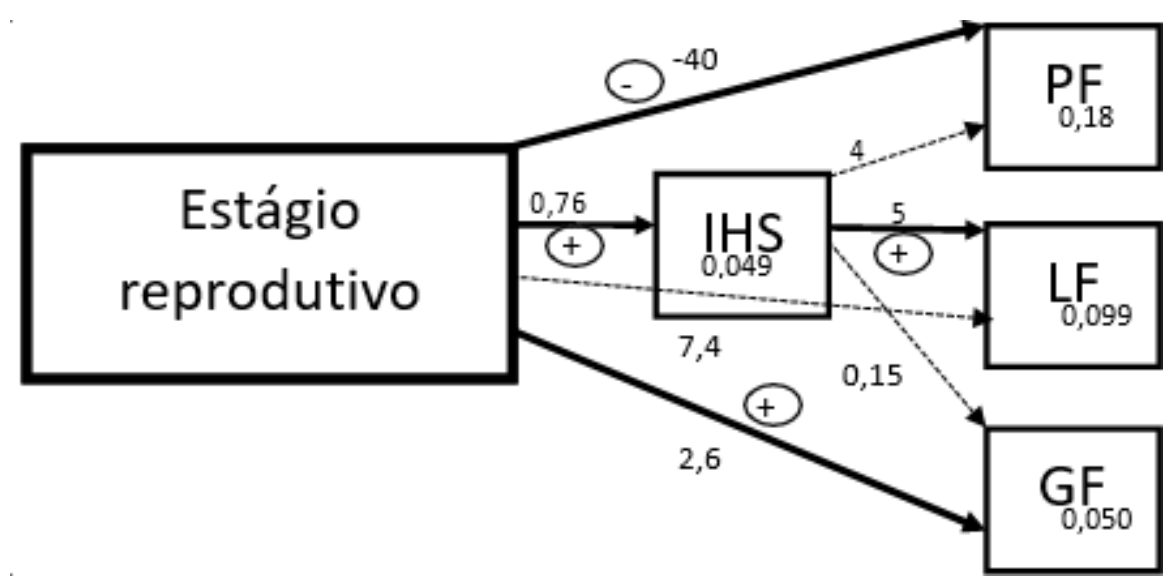

Figura 16. Modelo de equação estrutural (SEM) mostrando conexões diretas entre o estágio reprodutivo e os substratos hepáticos e indiretas entre estágio reprodutivo e substratos hepáticos via índice hepatossomático. Os números associados às relações entre as variáveis são coeficientes apresentados como valores padronizados pelos desvios- padrão das variáveis. Os números dentro das caixas são os valores de $\mathrm{R}^{2}$ de cada uma das variáveis de saída do modelo. Setas sólidas mostram conexões significativas $(\mathrm{P}<0,05)$, setas tracejadas mostram conexões não significativas ( $\mathrm{P}>0,05)$. Qualidade do ajuste do SEM: $\mathrm{P}\left(\chi^{2}\right)=0,477$ (um bom ajuste do modelo indicando que o modelo claramente não é significativamente diferente do modelo teórico). PFProteína hepática; LF- Lipídeo hepático; GF- Glicogênio hepático.

Resultados: O modelo testado mostrou relações significativas diretas entre estágio reprodutivo com PF, GF e IHS, e indireta com LF via IHS. É importante ressaltar que este modelo testou duas unidades distintas, concentração de substratos, dadas em $\mathrm{mg} / \mathrm{g}$ de tecido e a massa do tecido integral em relação à massa total do animal (IHS). Observou- se, como no modelo anterior, relação negativa direta entre o estágio reprodutivo e proteínas hepáticas. As demais relações observadas são positivas, como entre estágio reprodutivo e glicogênio hepático, reflexo possível da capacidade de realização de gliconeogênese deste tecido e das altas concentrações deste substrato durante a gravidez. Adicionalmente, o estágio reprodutivo influenciou lipídeos hepáticos somente via IHS, não sendo observada, entretanto, ligação direta entre estágio reprodutivo e lipídeos hepáticos, mostrando que o estágio reprodutivo afeta este substrato indiretamente, via IHS, enquanto os outros substratos do mesmo tecido não são influenciados por este índice. 
Modelo 3: Mobilização de substratos hepáticos para tecidos reprodutivos.

Predição: O tecido hepático, via ação do estradiol, recruta substratos metabólicos e os organiza, formando a macromolécula vitelogenina (VTG), que é alocada ao tecido ovariano. Adicionalmente, existe alocação de substratos hepáticos ao útero, durante o desenvolvimento do trofonema e histotrofia.

\section{Modelo testado:}

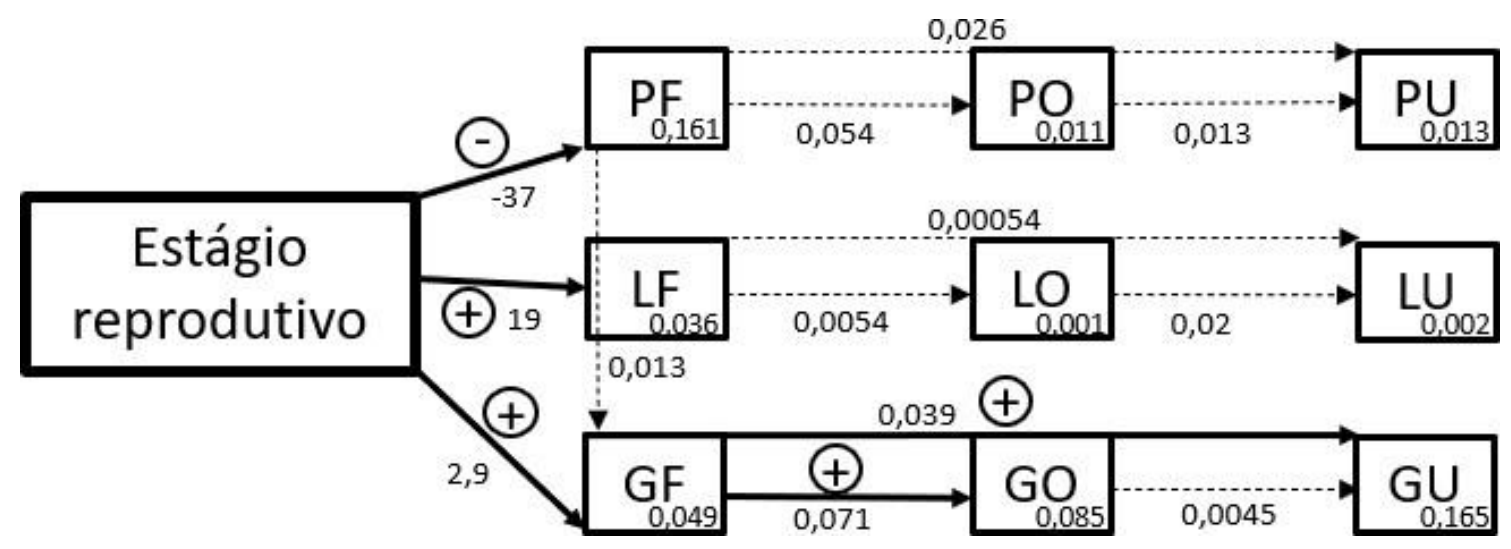

Figura 17. Modelo de equação estrutural (SEM) mostrando conexões diretas entre o estágio reprodutivo, substratos hepáticos, ovarianos e uterinos e indiretas entre estágio reprodutivo e substratos ovarianos e uterinos via substratos hepáticos. Os números associados às relações entre as variáveis são coeficientes apresentados como valores padronizados pelos desviospadrão das variáveis. Os números dentro das caixas são os valores de $R^{2}$ de cada uma das variáveis de saída do modelo. Setas sólidas mostram conexões significativas $(\mathrm{P}<0,05)$, setas tracejadas mostram conexões não significativas $(\mathrm{P}>0,05)$. Qualidade do ajuste do SEM: $\mathrm{P}\left(\chi^{2}\right)$ = 0,128 (um bom ajuste do modelo indicando que o modelo claramente não é significativamente diferente do modelo teórico). PF- Proteína hepática; LF- Lipídeo hepático; GF- Glicogênio hepático; POProteína ovariana; LO- Lipídeo ovariano; GF- Glicogênio ovariano; PU- Proteína uterina; LF- Lipídeo uterino; GF- Glicogênio uterino.

Resultados: Houve relação significativa entre o estágio reprodutivo e os três substratos hepáticos, e indireta entre o estágio reprodutivo, GO e GU. Neste modelo, corroborando os anteriores, o estágio reprodutivo afeta negativamente as proteínas no tecido hepático, e positivamente os lipídeos e glicogênio no mesmo tecido. As proteínas hepáticas não influenciam significativamente os dois tecidos reprodutivos, o que é inesperado, já que quimicamente a VTG é composta por 79\% de proteínas e 19\% de lipídeos, um ponto importante, 
observado nos resultados apresentados anteriormente, é a aparente estabilidade dos ovários e útero na concentração de proteínas totais, enquanto há claramente reflexo direto do ciclo na concentração hepática (instabilidade das concentrações)- a constância do tecido gonadal que pode ter mascarado o padrão de alocação. A não alocação de substratos lipídicos corrobora a incapacidade ou ineficiência de transporte de lipídeos em elasmobrânquios, como consequência da ausência de albumina, e como reflexo na baixa concentração de ácidos graxos livres plasmáticos. O estágio reprodutivo influenciou de modo indireto o glicogênio nos dois tecidos gonadais testados, o que deve ser investigado. 


\section{Conclusões}

O presente estudo permite concluir que:

- A arraia P. amandae apresenta estágio de repouso ocorrendo entre os meses de fevereiro a maio, vitelogênese nos meses de maio a novembro e gravidez entre os meses de novembro a março;

- Foi observada correlação positiva entre os dois índices analisados, o que inviabiliza a hipótese de alocação entre o tecido hepático e gonadal (massa específico) no ciclo reprodutivo;

- A queda dos valores de IHS, IGS e proteínas ovarianas no mês de abril marca o final do período de parto e o começo de um novo ciclo reprodutivo para esta espécie;

- As proteínas hepáticas mostraram padrão de alocação tecidual, com aumento durante a vitelogênese e diminuição durante o período de gravidez, com útero e ovário mantendo concentrações estáveis deste substrato. Julho parece ser um mês de prejuízo deste substrato, com menores valores para fígado, músculo e ovários, aparentemente fruto da escassez de recursos;

- P. amandae, assim como outros elasmobrânquios, apresenta altas concentrações de lipídeos hepáticos; enquanto o tecido muscular apresenta valores ínfimos deste substrato, fruto da ausência de oxidação muscular deste combustível;

- A histotrofia lipídica foi demostrada pelas maiores concentrações de lipídeos nos meses correspondentes ao período de gravidez no tecido uterino, além das maiores porcentagens de SAT e MUFA neste período;

- Nos meses de gravidez cerca de $90 \%$ da composição do tecido uterino (reflexo para a composição do leite uterino) são representados por SAT e MUFA;

- A gliconeogênese e armazenamento de glicogênio parecem ocorrer nos tecidos hepático e ovariano, enquanto o tecido muscular aparentemente realiza glicólise mais ativamente. 


\section{Referências bibliográficas}

ACHENBACH, G. M.; ACHENBACH S. V. M. Notas acerca de algunas especies de raya fluvial (Batoidei, Potamotrygonidae) que frecuentan el sistema hidrográfico del Paraná medio en el Departamento La Capital (Santa Fe- Argentina). Comunicaciones del Museo Provincial de Ciencias Naturales ussi ARAÚJO, M. L. G. Biologia Reprodutiva e Pesca de Potamotrygon sp. (Chondrichthyes - Potamotrygonidae), no Médio Rio Negro, Amazonas. Masters Degree Dissertation, Instituto Nacional de Pesquisas da Amazônia e Universidade do Amazonas, Manaus, 1998, 171 p.

AHMED-SOROUR, H.; BAILEY, C.J. Role of ovarian hormones in the long-therm control of glucose homeostasis glycogen formation and gluconeogenesis. Annals of Nutrition and Metabolism, 25, 208- 212,1981.

AMAZONAS, M.G.F.M. Fisiologia das fêmeas de Potamotrygon wallacei Carvalho, Rosa e Araújo (2016): gonadotrofinas, hormônios esteroides, condição corporal e perfil bioquímico. Dissertação (Mestrado), Universidade Federal do Amazonas, Manaus, 2019, 45 p. AMESBURY, E.L.; BUHI, W.C.; CRAINE, D.; ANDREW, G.L.J.; EVANS, D.H. Uterine fluid and serum protein composition and serum steroid hormone concentrations during gestation in the aplacental viviparous Atlantic stingray, Dasyatis sabina. Palestra no American Elasmobranch Society Annual Meeting, 1999. State College, Pensilvania.

AMESBURY, E.; WYFFELS, j.; WOURMS, J.P., SNELSON, JR. F. F.; BODINE, A. B.

Morphology of the uterus during the annual reproductive cycle of the aplacental viviparous Atlantic stingray, Dasyatis sabina. Palestra no American Elasmobranch Society Annual Meeting, 1999. State College, Pensilvania.

ARAÚJO, M. L. G.; CHARVET-ALMEIDA, P.; ALMEIDA, M. P.; PEREIRA, H..

Freshwater Stingrays (Potamotrygonidae): status, conservation and management challenges. AC20 iNF. 8, 20, 1-6, 2004.

ARISTIZABAL, E. O. Energy investment in the annual reproduction cycle of female red porgy, Pagrus pagrus (L.). Marine Biology, v. 152, n. 3, p. 713-724, 2007. 
ARTS, M. T., BRETT, M. T., KAINZ, M. Lipids in aquatic ecosystems. Springer Science \& Business Media. 394 p., 2009.

BALLANTYNE, J. S.; MOON, T. W. Solute e Vects on mitochondria from an elasmobranch (Raja erinacea) and teleost (Pseudopleuronec-tes americanus). Journal of Experimental Zoology, 239, 319-328, 1986.

BALLANTYNE, J.S. Jaws: the inside story. The metabolism of elasmobranch fishes. Comparative Biochemistry and Physiology B, 118, 703-742, 1997.

BALLANTYNE, J.S.; ROBINSON, J.W. Freshwater elasmobranchs: A review of their physiology and biochemistry. Journal of Comparative Physiology B: Biochemical, Systemic, and Environmental Physiology, 180, 475-493, 2010.

BALLANTYNE, J. S. JAWS II: metabolism of elasmobranchs. In: Shadwick, R.E., Farrell, A.P., Brauner, C.J. (eds) Physiology of elasmobranch fishes: internal processes, 1 st edn. Academic Press, United States, 34, 395-456, 2016.

BECKMANN, C. L.; MITCHELL, J. G.; STONE, D. A.; HUVENEERS, C. Inter-Tissue Differences in Fatty Acid Incorporation as a Result of Dietary Oil Manipulation in Port Jackson Sharks (Heterodontus portusjacksoni). Lipids, 49: 577-590, 2014.

BECKMANN, C. L.; MITCHELL, J. G.; STONE, D. A.; HUVENEERS, C. A controlled feeding experiment investigating the effects of a dietary switch on muscle and liver fatty acid profiles in Port Jackson sharks Heterodontus portusjacksoni. Journal of Experimental marine Biology and Ecology, 448: 10-18, 2013.

BELL HENDERSON, R. J. AND SARGENT J. R., M. V. The role of polyunsaturated fatty acids in fish. Comparative Biochemisthy and Physiology., v. 83B, n. 4, p. 711-719, 1986.

BIDINOTTO, P. M.; MORAES, G.; SOUZA, R. Hepatic glycogen and glucose in eight tropical freshwater teleost fish: A procedure for field determinations of microsamples. Boletim Técnico do CEPTA, 10, 53-60, 1997.

CARRIER J.C.; PRATT, H.L. JR; CASTRO, J.I. 2004. Reproductive biology of elasmobranchs. In: Carrier JC, Musick JA, Heithaus MR, editors. Biology of sharks and their relatives. Boca Raton: CRC Press,269-286, 2004. 
CARVALHO, M. R. de. Description of two extraordinary new species of freshwater stingrays of the genus Potamotrygon endemic to the Rio Tapajós basin, Brazil (Chondrichthyes: Potamotrygonidae), with notes on other Tapajós stingrays. Zootaxa, 4167, 1-63, 2016.

CARVALHO, M. R.; RAGNO, M. P. An unusual, dwarf species of neotropical freshwater stingray, Plesiotrygon nana sp. nov., from the upper and mid Amazon basin: the second species of Plesiotrygon (Chondrichthyes: Potamotrygonidae). Papéis Avulsos de Zoologia, 51, 101-138, 2011.

CARVALHO, M. R.; LOVEJOY, N. R. Morphology and phylogenetic relationships of a remarkable new genus and two new species of Neotropical freshwater stingrays from the Amazon basin (Chondrichthyes: Potamotrygonidae), Zootaxa, 277, 13-48, 2011.

CARVALHO, M. R.; LOVEJOY, N. R.; ROSA, R. S. Family Potamotrygonidae (river stingrays). In: REIS, R.; KULLANDER, S. O.; CJ, F. J. (Eds.). Check List of the Freshwater Fishes of South and Central America, 22-28, 2003.

CARVAlHO, C. C. C. R.; CARAMUJO, M. J. The Various Roles of Fatty Acids. Molecules, 23, 2583, 2018.

CASTEX, M.N.; MACIEL, I. Notas Sobre la Familia Potamotrygonidae Garman 1913. Dirección General de Recursos Naturales, Publicacion Tecnica, 14, 1- 23, 1965.

CASTEX, M. N. Observaciones sobre la raya de rio Potamotrygon motoro (Muller y Henle). Comunicaciones del Museo Argentino de Ciencias Naturales "Bernadino Rivadavia" e Instituto Nacional de Investigacion de Las Ciencias Naturales, Hidrobiologia, 1, 7-14, 1963.

CHAMBERLIN, M. E; GLEMET, H. C.; BALLANTYNE, J. S.1991. Glutamine metabolism in a holostean fish (Amia calva) and a teleost (Salvelinus namaycush). American Journal of Physiology, 206, 159-166, 1991.

CHARVET-ALMEIDA, P. Ocorrência, Biologia e Uso das Arraias de Água Doce na Baía de Marajó (Pará, Brasil), com Ênfase na Biologia de Plesiotrygon iwamae (Chondrichthyes: Potamotrygonidae). Dissertação (Mestrado), Universidade Federal do Pará e Museu Paraense Emílio Goeldi, Belém, 2001, 213 p.

CHARVET-ALMEIDA, P.; GÓES DE ARAÚJO, M. L.; DE ALMEIDA, M. P. Reproductive 
aspects of freshwater stingrays (Chondrichthyes: Patamotrygonidae) in the Brazilian Amazon Basin. Journal of Northwest Atlantic Fishery Science, 35, 165-171, 2005.

CHARVET-ALMEIDA, P. História natural e conservação das arraias de água doce (Chondrichthyes: Potamotrygonidae), no Médio Rio Xingu, área de influência do projeto hidrelétrico de Belo Monte (Pará, Brasil). Tese (Doutorado). Universidade Federal da Paraíba. João Pessoa. 2006.

COMPAGNO, L. J. V.; COOK, S. F. Theexploitation and conservation of freshwater elasmobranchs: status of taxa and prospects for the future. In The biology of freshwater elasmobranchs. A symposium to honor Thomas B. Thorson (ed. M.I. Oetinger and G.D. Zorzi). Journal of Aquaculture and Aquatic Sciences, 7, 62-90, 1995.

CONRATH, C.L.; MUSICK, J.A. Reproductive Biology of Elasmobranchs. In: Carrier, J.C.; Musick, J.A. \& Heithaus, M.R. (eds) Biology of Sharks and their Relatives, Edition 2. CRC Press, Boca Raton, Florida: 291-312, 2012.

CPTEC - Centro de Previsão de Tempo e Estudos Climáticos, INPE - Instituto Nacional de Pesquisas Espaciais. Últimas ocorrências, em http://enos.cptec.inpe.br/. Acesso em 15 de maio de 2021.

DAVIDSON, B.C.; NEL, W.; RAIS, A. NAMDARIZANDI, V.; VIZARRA, S.; CLIFF, G. Comparison of total lipids and fatty acids from liver, heart and abdominal muscle of scalloped (Sphyrna lewini) and smooth (Sphyrna zygaena) hammerhead sharks. SpringerPlus, 521, 1-8, 2014.

DAVIDSON, B.; CLIFF, G. The liver lipid fatty acid profiles of seven Indian Ocean shark species. Fish Physiology and Biochemistry, 26, 171-175, 2002.

DUBOIS, M.; GILLES, K.A.; HAMILTON, J.K.; REBERS, P.A.; SMITH, F. Colorimetric method for determination of sugars and related substances. Analytical Chemistry, 28, 350-356, 1956.

DUNCAN, W. L. P. Habitat, morfologia branquial e osmorregulação das arraias de água doce da bacia amazônica (Elasmobranchii: Potamotrygonidae). Tese (Doutorado) Curso de Ciências: Ecologia e Recursos Naturais. Universidade Federal de São Carlos, 2008, 198 p.

DRIEDZIC, W. R.; HART, T. Relationship between exogenous fuel availability and 
performance by teleosts and elasmobranch hearts. Journal of Comparative Physiology B. 154, 593- 599, 1984.

EVERY, S. L., PETHYBRIDGE, H. R., CROOK, D. A., KYNE, P. M., FULTON CJ. Tropical shark trophic niches. Comparison of fin and muscle tissues for analysis of signature fatty acids in tropical euryhaline sharks. Journal of Experimental Marine Biology Ecology, 479: 46-53, 2016.

FOLCH, J.; LEES, M.; SLOANE STANLEY, G. H. A simple method for the isolation and purification of total lipides from animal tissues. The Journal of biological chemistry, 226, 497-509, 1957.

FONTENELLE, J.P.; CARVALHO, M.R. Systematic revision of the Potamotrygon scobina Garman, 1913 species-complex (Chondrichthyes: Myliobatiformes: Potamotrygonidae), with the description of three new freshwater stingray species From Brazil and comments on their distribution and biogeography. Zootaxa, 1, 001-063, 2017.

FRINGS, C. S. FENDLEY, T.W.; DUNN, R.T.; QUEEN, C.A. Improved determination of total serum lipids by the sulfo-phospho-vanillin reaction. Clinical chemistry, 18, 6734, 1972.

GAllagher, A. J., SKUBEL, R. A., PETHYBRIDGE, H. R., HAMMERSCHLAG, N. Energy metabolism in mobile, wild-sampled sharks inferred by plasma lipids. Conservation Physiology, 5: 1-10, 2017.

GALlAGHER, A. J., WAGNER, D. N., IRSCHICK, D. J., HAMMERSCHLAG, N. Body condition predicts energy stores in apex predatory sharks. Conservation Physiology, 2: cou022, 2014.

GAMA, C. de S. Diversidade e ecologia das arraias de água doce (Chondrichthyes:

Potamotrygonidae) da reserva biológica do Parazinho, ap. Tese (Doutorado) - Curso de Ciências Biológicas: Zoologia. Universidade Federal da Paraíba, 2013, 227 p.

GARRONE NETO, D.; SAZIMA, I. The more stirring the better: cichlid fishes associate with foraging potamotrygonid rays. Neotropical Ichthyology, 7, 499-501, 2009.

GARRONE NETO, D. Considerações sobre a reprodução de duas espécies de arraias 
(Myliobatiformes, Potamotrygonidae) na região do Alto Rio Paraná, Sudeste do Brasil. Pan-american Journal Of Aquatic Sciences, Botucatu, 1, 101-111, 2010.

GARRONE NETO, D.; HADDAD, JR., V.; VILELA, L. J. A.; UIEDA, V. S. Registro de ocorrência de duas espécies de potamotrigonídeos na região do Alto Rio Paraná e algumas considerações sobre sua biologia. Biota Neotropica, 7, 205-208, 2007.

GOMES, A.D.; VIEIRA, V.A.R.O.; TABATA, Y.A.; TAKAHASHI, N.S.; MOREIRA, R.G.; RIBEIRO, C.S. Ploidy influences on metabolic substrate deposition of rainbow trout. Acta Scientiarium Animal Sciences, 42, e44580, 2020.

GRIFFITH, R. W.; PANG, P. K. T.; SRIVASTAVA, K.; PICKFORD, G. E. Serum composition of freshwater stringrays (Potamotrygonidae) adapted to freshwater and dilute seawater. The Biological Bulletin, 144, 304-320, 1973.

HAMLETT, W. C.; EULITT, A. M.; JARRELL, R. L.; KELLY, M. A. Uterogestation and placentation in elasmobranchs. Journal of Experimental Zoology India, 266, 347367, 1993.

HAMLETT, W. C.; MUSICK, J.A.; EULITT, A.M.; JARRELL, R.L.; KELLY, M.A. Ultrastructure of uterine trophonemata, accommodation for uterolactation, and gas exchange in the southern stingray, Dasyatis americana. Canadian Journal of Zoology, 74, 1417-1430, 1996.

HAMLETT, W.; HYSELL, M.K. Uterine specializations in elasmobranchs. Journal of Experimental Zoology,282, 438-459, 1998.

HAMLETT, W.C.; JARREL, R.L.; SPIELER, R. Ultrastructural analysis of folliculogenesis in the ovary of the yellow spotted stingray, Urolophus jamaicensis. Annals of Anatomy Anatomischer Anzeiger, 181, 159-172, 1999.

JALABERT, B. Particularities of reproduction and oogenesis in teleost fish compared to mammals. Reproduction, nutrition, development, 45, 261-79, 2005.

JENNI-EIERMANN, S., JENNI, L., PIERSMA, T. Plasma metabolites reflect seasonally changing metabolic processes in a long-distance migrant shorebird (Calidris canutus). Zoology, 105(3): 239-246, 2002.

KEBIR, M.V.O.E.; BARNATHAN, G.; SIAU, Y.; MIRALLES, J.; GAYDOU, E.M. 
Fatty acids distribution in muscle, liver, and gonads of rays (Dasyatis marmorata, Rhinobatos cemiculus, and Rhinoptera marginata) from the east tropical Atlantic Ocean. Journal of Agricultural and Food Chemistry, 51, 1942-1947, 2003.

KIRCHHEIM, P. D.; SANCHES E. A.; NEUMANN G.; TESSARO L.; ADAMES M. S.;

BOMBARDELLI R. A. Relações morfométricas, rendimento e composição centesimal de cortes da carne de arraias capturadas no reservatório de Itaipu. Arquivos de Ciências Veterinárias e Zoologia da UNIPAR, 16, 35-40, 2013.

LAFFEL, L. Ketone bodies: a review of physiology, pathophysiology and application of monitoring to diabetes. Diabetes Metabolism Research, 15, 412-426, 1999.

LANGEANI, F. Diversidade da ictiofauna do Alto Rio Paraná: composição atual e perspectivas. Biota Neotropica, 7, 181-197, 2007.

LASSO, C.A.; ROSA, R.S.; SÁNCHEZ-DUARTE, P.; MORALES-BETANCOURT, M.A.; AGUDELO- CÓRDOBA, E. (eds) (2013a) IX. Rayas de agua dulce (Potamotrygonidae) de Suramérica. Parte I. Colombia, Venezuela, Ecuador, Perú, Brasil, Guyana, Surinam y Guayana Francesa: diversidad, bioecología, uso y conservación. Instituto de Investigación de Recursos Biológicos Alexander von Humboldt. Bogotá, 2014, 370 p.

LASSO, C. A.; ROSA, R.; MORALES- BETNACOURT, M. A.; GARRONE-NETO, D.; CARVALHO, M. R. XV. Rayas de água dulce (Potamotrygonidae) de Suramérica. Parte II. Colombia, Brasil, Perú, Bolivia, Paraguay, Uruguay y Argentina. Instituto de Investigación de Recursos Biológicos Alexander von Humboldt. Bogotá, 2016, 220 p.

LASSO, C. A.; RIAL, A. B.; LASSO-ALCALÁ, O. Notes on the biology of the freshwater stingrays Paratrygon aiereba (Müller and Henle, 1841) and Potamotrygon orbignyi (Castelnau, 1855) (Chondrichthyes: Potamotrygonidae) in the Venezuelan llanos.

Journal of Ichthyology and Aquatic Biology, 2, 39-52, 1996.

LEBLANC, P. J., BALLANTYNE, J. S. $\beta$-hydroxybutyrate dehydrogenase in teleost fish. Journal of Experimental Zoology, 267, 356-358, 1993.

LESSA, R.; SANTANA, F. M.; RINCÓN, G.; GADIG, O. B. F.; EL-DEIR, A. C. A. Biodiversidade de elasmobrânquios do Brasil. Ministério do Meio Ambiente (MMA) Projeto de Conservação e Utilização Sustentável da Diversidade Biológica Brasileira, 1-154, 1999. 
LOBODA, T. S.; CARVALHO, M. R. DE. Systematic revision of the Potamotrygon motoro (Müller \& Henle, 1841) species complex in the Paraná-Paraguay basin, with description of two new ocellated species (Chondrichthyes: Myliobatiformes: Potamotrygonidae). Neotropical Ichthyology, 11, 693-737, 2013.

LONARDONI, A. P., OLIVEIRA, E. F., ABELHA, M. C., GOULART, E. Hábitos alimentares e sobreposição trófica das arraias Potamotrygon falkneri e Potamotrygon motoro (Chondrichthyes: Potamotrygonidae) na planície alagável do alto rio Paraná; Brasil. Acta Scientiarum Biological Sciences, 28, 195-202, 2006.

LONARDONI, A., OLIVEIRA, P.E.F.; GOULART, E. Trophic ecomorphology of Potamotrygon falkneri and Potamotrygon motoro (Chondrichthyes Potamotrygonidae) on the upper Paraná river floodplain, Brazil. Pan-American Journal of Aquatic Sciences, 4, 436-445, 2009.

LOVEJOY, N. R. Systematics of myliobatoid elasmobranchs: with emphasis on the phylogeny and historical biogeography of neotropical freshwater stingrays (Potamotrygonidae: Rajiformes). Zoological Journal of the Linnean Society, 117, 207-257, 1996.

LOWRY, O. H.; ROSEBROUGH, N. J.; FARR, A. L.; RANDALL, R. J. Protein measurement with the Folin phenol reagent. The Journal of biological chemistry, 193, 265-75, 1951.

LUCIFORA, L O.; CARVALHO, M. R. de; KYNE, P. M.; WHITE, W. T. Freshwater sharks and rays. Current Biology, 25, 971-973, 2015.

\section{MACEDO, M.G.F. Fisiologia reprodutiva das fêmeas de Potamotrygon wallacei} Carvalho, Rosa e Araújo (2016): gonadotrofinas, hormônios esteroides, condição corporal e perfil bioquímico. Dissertação (Mestrado)- Curso Ciências Pesqueiras Nos Trópicos, Universidade Federal do Amazonas, 2019.

MCMEANS, B. C., ARTS, M. T., FISK, A. T. Similarity between predator and prey fatty acid profiles is tissue dependent in Greenland sharks (Somniosus microcephalus): Implications for diet reconstruction. Journal of Experimental Marine Biology and Ecology, 429:55-63, 2012. 
MCWILliAMS, S. R., GUGLIELMO, C., PIERCE, B., KLAASSEN, M. Flying, fasting, and feeding in birds during migration: a nutritional and physiological ecology perspective. Journal of Avian Biology, 35(5): 377-393, 2004.

MARUSKA, K. P.; GELSLEICHTER, J. Hormones and Reproduction in Chondrichthyan Fishes. Elsevier, 1, 209-237, 2011.

MAUÉS, R. C. S. Aspectos da Biologia Reprodutiva e Padrões de Coloração da Raia de Água Doce Potamotrygon orbignyi (Chondrichthyes: Potamotrygonidae) na Baía de Marajó - Pará - Brasil. Monografia de Conclusão de Curso de Licenciatura em Ciências Biológicas. Belém, Universidade Federal do Pará, 2002, 41 p.

MELLO, P. H. Alterações metabólicas ao longo da ontogenia das larvas de cachara (Pseudoplatystoma reticulatum Siluriforme, Pimelodidae, Linnaeus, 1776) e do híbrido. Dissertação (Mestrado)- Curso de Ciências Biológicas, Instituto de Biociências, Universidade de São Paulo, 2010, 223 p.

MILLIGAN, C. L.; GIRARD, S. S. Lactate metabolism in rainbow trout. Journal of Experimental Biology, 180, 175-193, 1993.

MORO, G.; CHARVET, P.; ROSA, R.S. Insectivory in Potamotrygon signata (Chondrichthyes: Potamotrygonidae), an endemic freshwater stingray from the Parnaíba River basin, northeastern Brazil. Brazilian Journal of Biology, 72, 885-891, 2012.

MOYES, C. D.; BUCK, L. T.; HOCHACHKA, P. W.; SUAREZ, R. K. Oxidative properties of carp red and white muscle. The Journal of Experimental Biology. 143, 321-331, 1989.

NARVÁEZ, M.; FREITES, L.; GUEVARA, M.; MENDOZA, J.; GUDERLEY, H.; LODEIROS, CJ. Food availability and reproduction affects lipid and fatty acid composition of the brown mussel, Perna perna, raised in suspension culture. Comparative biochemistry and physiology. Part B, Biochemistry \& molecular biology, v. 149, n. 2, p. 293-302, 2008.

NELSON, J. Fishes of the World. John Wiley and Sons Inc. 4th Edition, 2006, 601 p.

NELSON, D. L.; COX, M. M. Princípios de bioquímica de Lehninger. 3a Edition ed. [s.1.] W.H. FREEMAN AND COMPANY, New York, New York and Basingstoke Copyright 2000 by Worth Publtshers, Inc., 2011. 
NELSON, D. L., COX, M. M. Princípios de bioquímica de Lehninger. Artmed Editora, 2014.

ÖZYILMAZ, A.; OÖZY, A. Determination of the biochemical properties of liver oil from selected cartilaginous fish living in the northeastern mediterranean. The Jornal of animal and Plant Sciences, 25, 160-167, 2015.

OLIVEIRA, A. T. Parâmetros hematológicos, aspectos citoquímicos e ultraestruturais das células sanguíneas de três espécies de arraias (Chondrichthyes: Potamotrygonidae) do Médio Rio Negro, Amazonas, Brasil. Tese (Doutorado) Curso de Ciências Biológicas, Universidade Federal do Amazonas, Manaus, 2013, 203 p.

PAGLIARINI, C. D.; RIBEIRO, C. S.; SPADA, L.; DELARIVA, R. L.; CHAGAS, J.M.A.; ANJOS, L.A.; RAMOS, I. P. Trophic ecology and metabolism of two species of nonnative freshwater stingray (Chondrichthyes: Potamotrygonidae). Hydrobiologia, 47, 2895-2908, 2020.

PALACIN, M.; LASUNCIÓN, M.A.; HERRERA, E. Lactate production and absence of gluconeogenesis from placental transferred substrates in fetuses from fed and $48-\mathrm{H}$ starved rats. Pediatrian Research, 22, 6-10, 1987.

PARRISH, C. C. Determination of total lipid, lipid classes and fatty acids in aquatic samples. In: WAINMAN, M. T. A.; WAINMANN, B. C. (Ed.). Lipids in Freshwater Ecosystems, 4-12, 1999. PETERS, T. Jr. All about Albumin. Biochemistry, Genetics, and Medical Applications. San Diego: Academic Press. 1996, 415 p.

PATIÑO, R.; SULLIVAN, C. V. Ovarian follicle growth, maturation, and ovulation in teleost fish. Fish Physiology and Biochemistry, n. 1986, p. 57-70, 2003.

PETHYBRIDGE, H. R.; PARRISH, C. C.; BRUCE, B. D.; YOUNG J. W.; NICHOLS, P. D. Lipid, fatty acid and energy density profiles of white sharks: Insights into the feeding ecology and ecophysiology of a complex top predator. Plos One, 9, 1-10, 2014.

PETHYBRIDGE, H., DALEY, R., VIRTUE, P., NICHOLS, P. Lipid composition and partitioning of deepwater chondrichthyans: inferences of feeding ecology and distribution. Marine Biology, 157: 1367-1384, 2010.

POLAKOF, S.; MOMMSEN, T.P.; SOENGAS, J.L. Glucosensing and glucose homeostatis: 
From fish to mammals. Comparative Biochemistry and Physiology:B, 160, 123149, 2011.

POUGH, F. H.; HEISER, J. B.; JANIS, C. M. A vida dos vertebrados. 4a Edição ed. São Paulo: Atheneu, 2008, 750 p.

PRATT, H. L.Elasmobranch gonad structure: a description and survey. Copeia, 3, 719-729, 1988.

RASCHI, W.; MACKANOS, L.A. The structure of the ampullae of lorenzini in Dasyatis garouaensis and its implications on the evolution of freshwater electroreceptive systems. The Journal of Experimental Zoology Supplement. 2, 101-111, 1989.

RANGEL, B. S. Lipídios e isótopos estáveis como indicadores de investimento materno e estratégias nutricionais neonatais em arraias vivíparas histotróficas. Dissertação (Mestrado) - Curso de Ciências: Fisiologia Geral. Universidade de São Paulo, 2018, 73 p.

RANGEL, B.S.; HUSSEY, N.E.; NIELLA, Y.; MARTINELLI, L.A.; GOMES, A.D.;

MOREIRA, R.G. Neonatal nutritional strategy of a viviparous elasmobranch with extremely low reproductive output. Marine Ecology Progress Series, 638, 107121,2020 .

RANGEL, B.S.; RIBEIRO, D.C.; CHAGAS, J.M.A.; SPADA, L.; MOREIRA, R.G.; RIBEIRO, C.S. Effects of biological traits on capture-induced parturition in a freshwater stingray and perspectives for species management. Journal of Fish Biology, 97, 546-551.

RAMOS, H. A. C. Commercial species of freshwater stingrays in Brazil, 2017. 33 p.

RÊGO, M.G. Aspectos morfológicos do aparelho reprodutor de tubarões capturados no nordeste brasileiro. Tese (Doutorado) - Curso de Biociência Animal, Universidade Federal Rural de Pernambuco, Recife, 2014, 97p.

RIBEIRO, C. S.; MOREIRA, R. G.; A CANTELMO, O.; ESPOSITO, E. The use of Kluyveromyces marxianus in the diet of Red-Stirling tilapia (Oreochromis niloticus,Linnaeus) exposed to natural climatic variation: effects on growth performance, fatty acids, and protein deposition. Aquaculture Research, 45, 812-827, 2014. 
RICHTER, M.; VIANA, M. S. S.; MALABARBA, M. C. S. L. Agnatos e Peixes. In:

CARVALHO, I.S. (Ed). Paleontologia. Rio de Janeiro: Interciência. cap 28, 497-524, 2000 .

RINCON FILHO, G. Aspectos taxonômicos, alimentação e reprodução da raia de água doce Potamotrygon orbignyi (Castelnau) (Elasmobranchii: Potamotrygonidae) no Rio Paranã-Tocantins. Tese (Doutorado) - Curso de Ciências Biológicas, Universidade Estadual Paulista "Julio de Mesquita Filho", Rio Claro, 2006, 145 p.

ROSA, R.S. A systematic revision of the South American freshwater stingrays

(Chondrichthyes: Potamotrygonidae). Tese (Doutorado). Williamsburg College of William and Mary, 1985, $523 \mathrm{p}$.

SCHOMBURGK, R. H. Fishes of British Guiana. In: Naturalist's Library. W. Jardine. Vol. 40(2). Edinburgh, W. H. Lizars, 1843, 212 p.

SIDELL, B.D., DRIEDZIC, W.R., STOWE, D.B., JOHNSTON, I.A. Biochemical correlations of power development and metabolic fuel preferenda in fish hearts. Physiological and Biochemical Zoology, 221- 232, 1987.

SHADWICK, R.E.; FARRELL, A.E.; BRAUNER, C.J. Physiology of elasmobranch fishes: Structure and interaction with environment. Academic Press, 2015, 442p.

SHAHJAHAN, M.; KITAHASHI, T.; PARHAR, I. S. Central pathways integrating metabolism and reproduction in teleosts. Frontiers in Endocrinology, 5, 1-17, 2014.

SHERIDAN, M. A. Regulation of lipid metabolism in poikilothermic vertebrates. Comparative Biochemistry and Physiology B, 107: 495-508, 1994.

SIDELL, B. D.; DRIEDZIC, W. R.; STOWE, D. B.; JOHNSTON, I. A. Biochemical correlations of power development and metabolic fuel preferenda in fish hearts. Physiological Zoology, 60, 221-232, 1987.

SILVA, M.I.; OLIVEIRA, O.T.F.C.; DUNCAN, W.P. Morphology and morphometry of the ovaries and uteri of the Amazonian Freshwater Stingrays (Potamotrygonidae: Elasmobranchii), The anatomical record, 300, 265-276, 2017. 
SPADA, L; RIBEIRO, D. de C.; CHAGAS, J. M. A.; HOROIWA, A. Y.; SOARES, A. S.; RIBEIRO, C. da S. Metabolismo lipídico da raia vivípara Potamotrygon falkneri Castex \& Maciel, 1963 durante a reprodução. Revista Ibero-Americana de Ciências Ambientais, [S.L.], v. 11, n. 5, p. 186-197, 5 jun. 2020.

SPEAKE, B.K., THOMPSON, M.B. Lipids of the eggs and neonates of oviparous and viviparous lizards. Comparative and Biochemistry Physiology A. 127(4):453-467, 2000.

SPEERS-ROESCH, B., I., Y. K., BALLANTYNE, J. S. Metabolic organization of freshwater, euryhaline, and marine elasmobranchs: implications for the evolution of energy metabolism in sharks and rays. Journal of experimental biology, 209, 24952508, 2006.

SPEERS-ROESCH, B.; TREBERG, J. R. The unusual energy metabolism of elasmobranch fishes. Comparative Biochemistry and Physiology - A Molecular and Integrative Physiology, 155, 417-434, 2010.

TESHIMA, K.; TAKESHITA K. 1992. Reproduction of the freshwater stingray, Potamotrygon magdalenae taken from the Magdalena River System in Colombia, South America. Seikai National Fisheries Research Instute, 70, 11-27, 1992.

THORSON, T. B.; LANGHAMMER, J. K.; OETINGER M. I. Reproduction and development of the South American freshwater stingrays, Potamotrygon circularis and Potamotrygon motoro. Environmental Biology of Fishes, 9, 3-24, 1983.

THORSON, T. B.; BROOKS, D. R. The evolution of freshwater adaptation in stingrays. National Geographic, 15, 663-694, 1983.

TOBERGTE, D. R.; CURTIS, S. Uterine fluid and serum protein composition and serum steroid hormone concentrations during gestation in the aplacental viviparous Atlantic stingray, Dasyatis sabina. Journal of Chemical Information and Modeling, 53, 16891699, 2013.

TOCHER, D. R. Metabolism and Functions of Lipids and Fatty Acids in Teleost Fish. Reviews in Fisheries Science, v. 11, n. 2, p. 107-184, 2003.

TOLUSSI, C. E.; GOMES, A. D.; RIBEIRO, C. da S.; CANEPPELE, D.; MOREIRA, R. G.; 
HONJI, R. M. Mobilization of energetic substrates in the endangered catfish Steindachneridion parahybae (Siluriformes: Pimelodidae). Neotropical Ichthyology, $16,1-8,2018$.

TREBERG, J. R.; SPEERS-ROESCH, B.; PIERMARINI, P. M.; IP, Y. K.; BALLANTYNE, J. S.; DRIEDZIC, W. R. The accumulation of methylamine counteracting solutes in elasmobranchs with differing levels of urea: a comparison of marine and freshwater species. Journal of Experimental Biology, 209, 860-870, 2006.

TRICAS, T. C.; MARUSKA, K. P.; RASMUSSEN, L. E. Annual cycles of steroid hormone production, gonad development, and reproductive behavior in the Atlantic stingray. General and comparative endocrinology, 118, 209-25, 2000.

VALlS, E., NAVARRO, J., BARRÍA, C., COLL, M., FERNÁNDEZ-BORRÀS, J., ROTLLANT, G. Seasonal, ontogenetic and sexual changes in lipid metabolism of the small-spotted catshark (Scyliorhinus canicula) in deep-sea free-living conditions. Journal of Experimental Marine Biology and Ecology, 483: 59-63, 2016.

YANCEY, P. H., CLARK, M. E., HAND, S. C., BOWLUS, R. D.; SOMERO, G. N. Living with water stress: evolution of osmolyte systems. Science 217, 1214-1222, 1982.

WALSH, P.J., KAJIMURA, M., MOMMSEN, T.P., WOOD, C.M. Metabolic organization and effects of feeding on enzyme activities of the dogfish shark (Squalus acanthias) rectal gland. The Journal of Experimental Biology, 209, 2929-2938, 2006.

WETLAUFER, D. B., MALIK, S. K., STOLLER, L. and COFFIN, R. L. Nonpolar group participation in the denaturation of proteins by urea and guanidinium salts. Model compound studies. Journal of the American Chemical Society, 86, 508-514, 1964.

WHITNEY, K. D.; GABLER, C. A. Rapid evolution in introduced species, “invasive traits" and recipient communities: Challenges for predicting invasive potential. Diversity and Distributions, 14, 569-580, 2008.

WILLIAMS, M.J., SUTHERLAND, W.H., MCCORMICK, M.P., de JONG, S.A., WALKER, R.J., WILKINS, G.T. Impaired endothelial function following a meal rich in used cooking fat. Journal of the American College of Cardiology, 33: 1050-1055, 1999. 


\section{Apêndices}

Apêndice 1. Dados dos substratos metabólicos (proteínas, lipídeos e glicogênio) em fêmeas de Potamotrygon amandae coletadas noAlto Rio Paraná (reservatório de Jupiá, Ilha Solteira/SP) (Média \pm Desvio padrão).

\begin{tabular}{|c|c|c|c|c|c|c|c|c|c|c|c|c|}
\hline & Janeiro & Fevereiro & Março & Abril & Maio & Junho & Julho & Agosto & Setembro & Outubro & Novembro & Dezembro \\
\hline \multicolumn{13}{|l|}{ Fígado } \\
\hline Proteínas & $122,5 \pm 12,30^{\mathrm{e}}$ & $60,3 \pm 20,58^{\mathrm{cd}}$ & $151,7 \pm 9,62^{\mathrm{f}}$ & $171,0 \pm 62,22^{\text {befg }}$ & $175,0 \pm 36,72^{\mathrm{g}}$ & $168,3 \pm 11,46 \mathrm{~h}^{\mathrm{g}}$ & $109,9 \pm 14,62^{\text {be }}$ & $162,2 \pm 27,17^{\mathrm{fg}}$ & $159,1 \pm 13,90^{\mathrm{f}}$ & $23,7 \pm 4,06^{\mathrm{d}}$ & $26,2 \pm 22,24^{a}$ & $48,8 \pm 12,93^{\mathrm{c}}$ \\
\hline Lipídeos & $330,4 \pm 78,13^{\text {ace }}$ & $307,0 \pm 50,05^{\text {ae }}$ & $316,3 \pm 47,50^{\mathrm{a}}$ & $314,1 \pm 62,29^{\text {acf }}$ & $264,1 \pm 69,69^{\text {bef }}$ & $309,6 \pm 58,66^{\text {acf }}$ & $269,7 \pm 63,89^{\text {acf }}$ & $261,4 \pm 80,30^{\text {bef }}$ & $304,4 \pm 58,40^{\text {acf }}$ & $244,3 \pm 45,29^{\text {bcf }}$ & $253,9 \pm 70,29^{\text {bef }}$ & $320,2 \pm 62,03^{\text {acf }}$ \\
\hline Glicogênio & $12,2 \pm 6,03^{\mathrm{a}}$ & $5,4 \pm 4,75^{\text {bc }}$ & $4,9 \pm 4,20^{\text {bed }}$ & $6,9 \pm 10,30^{\text {ace }}$ & $5,6 \pm 2,82^{\text {bdd }}$ & $3,2 \pm 1,73^{\mathrm{dfg}}$ & $2,8 \pm 1,28^{\mathrm{df}}$ & $2,7 \pm 1,39^{\mathrm{f}}$ & $4,3 \pm 2,48^{\mathrm{df}}$ & $2,2 \pm 0,52^{\mathrm{f}}$ & $4,1 \pm 2,37^{\text {bfg }}$ & $5,1 \pm 2,60^{\mathrm{bcgh}}$ \\
\hline Músculo & Janeiro & Fevereiro & Março & Abril & Maio & Junho & Julho & Agosto & Setembro & Outubro & Novembro & Dezembro \\
\hline Proteínas & $40,1 \pm 22,52^{\mathrm{b}}$ & $125,0 \pm 14,09^{b}$ & $150,2 \pm 15,80^{c}$ & $120,2 \pm 18,44^{\mathrm{bc}}$ & $114,9 \pm 17,30^{\mathrm{b}}$ & $129,3 \pm 21,74^{\mathrm{bc}}$ & $76,0 \pm 16,59^{c}$ & $125,7 \pm 31,30^{\text {bc }}$ & $174,2 \pm 20,48^{\mathrm{a}}$ & $141,3 \pm 27,59^{\mathrm{bc}}$ & $148,9 \pm 29,38^{\mathrm{c}}$ & $147,5 \pm 30,70^{\mathrm{ac}}$ \\
\hline Glicogênio & $0,7 \pm 5,86^{\mathrm{acd}}$ & $1,0 \pm 2,66^{\mathrm{bdf}}$ & $0,6 \pm 1,62^{\mathrm{ab}}$ & $0,5 \pm 0,72^{\mathrm{a}}$ & $1,1 \pm 2,20^{\mathrm{bc}}$ & $0,6 \pm 0,8^{\text {ad }}$ & $4,3 \pm 3,55^{\text {bde }}$ & $0,4 \pm 1,59^{\mathrm{acd}}$ & $0,5 \pm 1,08^{\mathrm{ae}}$ & $1,2 \pm 2,01^{\mathrm{acd}}$ & $0,6 \pm 0,86^{\text {acf }}$ & $1,4 \pm 6,32^{\mathrm{acd}}$ \\
\hline Ovários & Janeiro & Fevereiro & Março & Abril & Maio & Junho & Julho & Agosto & Setembro & Outubro & Novembro & Dezembro \\
\hline Proteínas & $84,2 \pm 24,46^{\mathrm{cg}}$ & $90,6 \pm 26,26^{\mathrm{cg}}$ & $121,1 \pm 15,74^{\mathrm{b}}$ & $55,9 \pm 16,98^{\mathrm{a}}$ & $119,9 \pm 13,04^{\text {bd }}$ & $83,9 \pm 31,82^{\mathrm{ac}}$ & $69,6 \pm 21,10^{\mathrm{afg}}$ & $108,5 \pm 17,99^{\text {bd }}$ & $126,0 \pm 23,89^{\text {bd }}$ & $110,9 \pm 6,43^{\text {bed }}$ & $88,3 \pm 39,37^{\text {ace }}$ & $103,4 \pm 16,61^{\text {cd }}$ \\
\hline Lipídeos & $17,3 \pm 9,77^{\mathrm{bd}}$ & $15,6 \pm 4,58^{\mathrm{cd}}$ & $15,5 \pm 1,61^{\mathrm{cd}}$ & $15,8 \pm 11,62^{\mathrm{bd}}$ & $14,2 \pm 9,64^{\text {bd }}$ & $13,9 \pm 4,08^{\mathrm{cd}}$ & $22,7 \pm 5,31^{\mathrm{b}}$ & $15,7 \pm 6,15^{\mathrm{cd}}$ & $15,3 \pm 1,30^{c}$ & $4,1 \pm 3,50^{a}$ & $13,2 \pm 14,48^{\mathrm{bd}}$ & $19,5 \pm 12,43^{\text {bd }}$ \\
\hline Glicogênio & $4,8 \pm 1,99^{\text {bd }}$ & $4,4 \pm 2,54^{b}$ & $3,7 \pm 1,27^{\text {bd }}$ & $5,0 \pm 1,26^{\mathrm{b}}$ & $4,2 \pm 1,75^{\mathrm{bc}}$ & $2,5 \pm 1,20^{\mathrm{ac}}$ & $1,6 \pm 0,66^{\mathrm{a}}$ & $3,5 \pm 1,51^{\mathrm{bc}}$ & $3,3 \pm 0,51^{\mathrm{cd}}$ & $3,6 \pm 1,02^{\mathrm{bc}}$ & $4,0 \pm 2,57^{\text {bd }}$ & $3,6 \pm 3,06^{\mathrm{abd}}$ \\
\hline Proteínas & $40,1 \pm 36,38^{\mathrm{a}}$ & $125,0 \pm 100,72^{\text {ace }}$ & $51,3 \pm 21,28^{\mathrm{a}}$ & $116,6 \pm 32,26^{\text {bce }}$ & $96,5 \pm 16,25^{\text {bce }}$ & $88,3 \pm 14,66^{\mathrm{e}}$ & $76,0 \pm 52,04^{\text {ace }}$ & $93,5 \pm 22,15^{\text {bce }}$ & $105,2 \pm 14,55^{\mathrm{bc}}$ & $97,7 \pm 7,91^{\text {bce }}$ & $88,9 \pm 28,27^{\text {bce }}$ & $90,0 \pm 2,20^{\text {bce }}$ \\
\hline Lipídeos & $8,6 \pm 3,90^{\mathrm{ac}}$ & $8,6 \pm 2,14^{\mathrm{ac}}$ & $7,7 \pm 5,20^{\mathrm{acd}}$ & $8,2 \pm 2,67^{\mathrm{bc}}$ & $7,5 \pm 2,26^{\mathrm{acd}}$ & $9,0 \pm 4,26^{\mathrm{acd}}$ & $8,9 \pm 4,45^{\mathrm{bc}}$ & $5,9 \pm 3,71^{\mathrm{bc}}$ & $6,4 \pm 3,14^{\mathrm{bc}}$ & $5,7 \pm 4,16^{\text {bd }}$ & $7,2 \pm 3,27^{\mathrm{bc}}$ & $10,5 \pm 2,68^{\mathrm{a}}$ \\
\hline Glicogênio & $0,3 \pm 0,07^{\text {be }}$ & $0,3 \pm 0,06^{\text {be }}$ & $0,2 \pm 0,10^{\mathrm{ae}}$ & $0,2 \pm 0,08^{\mathrm{ce}}$ & $0,3 \pm 0,06^{\text {bef }}$ & $0,2 \pm 0,10^{\text {acf }}$ & $0,2 \pm 0,10^{\mathrm{ae}}$ & $0,1 \pm 0,10^{\mathrm{ac}}$ & $0,2 \pm 0,06^{\text {ad }}$ & $0,3 \pm 0,07^{\text {ae }}$ & $0,2 \pm 0,09^{\text {bdef }}$ & $0,3 \pm 0,07^{\text {bef }}$ \\
\hline
\end{tabular}

${ }^{\mathrm{a}, \mathrm{b}}$ mostram diferença estatística significativa $(\mathrm{P}<0,05)$ entre os meses de coleta, One Way ANOVA. 
Apêndice 2. Perfil de ácidos graxos (\%) do tecido hepático de fêmeas de Potamotrygon amandae coletadas no Alto Rio Paraná (reservatório de Jupiá, IlhaSolteira/SP) ao longo do ciclo reprodutivo (Média \pm EPM).

\begin{tabular}{|c|c|c|c|c|c|c|c|c|c|c|c|c|}
\hline & Jan/18 & Fev/18 & Mar/18 & Abr/18 & Mai/18 & Jun/18 & Jul/18 & Ago/18 & Set/18 & Out/18 & Nov/18 & Dez/18 \\
\hline C14:0 & $2,26 \pm 0,18$ & $2,29 \pm 0,38$ & $1,99 \pm 0,81$ & $0,69 \pm 0,31$ & $2,21 \pm 0,97$ & $3,09 \pm 0,66$ & $1,93 \pm 0,81$ & $2,14 \pm 0,90$ & $2,17 \pm 0,20$ & $0,98 \pm 0,19$ & $1,92 \pm 0,66$ & $1,78 \pm 0,53$ \\
\hline C14:1 & $4,99 \pm 0,69$ & $4,40 \pm 1,24$ & $3,10 \pm 1,89$ & $2,92 \pm 1,70$ & $5,07 \pm 1,58$ & $3,96 \pm 0,99$ & $4,51 \pm 1,39$ & $4,52 \pm 2,58$ & $4,91 \pm 0,82$ & $3,44 \pm 0,52$ & $6,76 \pm 1,89$ & $5,56 \pm 1,73$ \\
\hline C15:0 & $1,97 \pm 0,23$ & $1,83 \pm 0,23$ & $1,68 \pm 0,54$ & $2,80 \pm 1,39$ & $2,12 \pm 0,33$ & $2,02 \pm 0,33$ & $1,86 \pm 0,23$ & $2,28 \pm 0,72$ & $2,06 \pm 0,26$ & $2,30 \pm 0,54$ & $1,87 \pm 0,40$ & $1,75 \pm 0,32$ \\
\hline C15:1 & $1,60 \pm 0,19$ & $1,50 \pm 0,20$ & $1,31 \pm 0,55$ & $0,57 \pm 0,37$ & $1,65 \pm 0,18$ & $1,62 \pm 0,24$ & $1,59 \pm 0,63$ & $1,82 \pm 0,67$ & $1,61 \pm 0,23$ & $0,42 \pm 0,10$ & $1,71 \pm 0,27$ & $1,48 \pm 0,46$ \\
\hline C16:0 & $30,89 \pm 3,81$ & $27,99 \pm 1,45$ & $29,35 \pm 1,81$ & $28,87 \pm 7,85$ & $26,58 \pm 2,74$ & $25,39 \pm 2,02$ & $26,55 \pm 1,91$ & $25,84 \pm 4,18$ & $26,86 \pm 1,88$ & $28,98 \pm 2,75$ & $22,51 \pm 3,50$ & $27,10 \pm 1,50$ \\
\hline C16:1 & $13,27 \pm 1,41$ & $9,94 \pm 2,04$ & $11,90 \pm 2,32$ & $8,61 \pm 4,32$ & $9,02 \pm 2,87$ & $8,84 \pm 2,43$ & $11,56 \pm 1,35$ & $10,16 \pm 3,21$ & $13,46 \pm 3,39$ & $11,88 \pm 1,76$ & $6,56 \pm 4,94$ & $10,82 \pm 4,66$ \\
\hline C17:0 & $2,66 \pm 0,39$ & $3,54 \pm 0,29$ & $2,96 \pm 0,23$ & $3,76 \pm 1,65$ & $3,34 \pm 0,62$ & $3,02 \pm 0,61$ & $3,13 \pm 0,48$ & $3,46 \pm 2,25$ & $3,10 \pm 0,56$ & $3,30 \pm 0,34$ & $3,89 \pm 0,84$ & $2,91 \pm 0,31$ \\
\hline $\mathrm{C} 17: 1$ & $1,02 \pm 0,11$ & $1,16 \pm 0,26$ & $1,02 \pm 0,24$ & $0,79 \pm 0,56$ & $0,97 \pm 0,48$ & $1,08 \pm 0,12$ & $1,01 \pm 0,20$ & $1,30 \pm 0,38$ & $1,10 \pm 0,23$ & $0,55 \pm 0,44$ & $0,95 \pm 0,19$ & $1,08 \pm 0,36$ \\
\hline C18:0 & $4,62 \pm 0,63$ & $5,88 \pm 0,44$ & $5,44 \pm 0,90$ & $6,24 \pm 1,34$ & $5,62 \pm 1,51$ & $5,91 \pm 0,84$ & $5,28 \pm 0,40$ & $5,57 \pm 3,06$ & $5,17 \pm 0,64$ & $5,50 \pm 0,77$ & $6,56 \pm 1,58$ & $5,29 \pm 1,40$ \\
\hline C18:1 & $17,57 \pm 0,95$ & $16,19 \pm 1,38$ & $16,94 \pm 0,49$ & $15,04 \pm 3,53$ & $15,27 \pm 3,30$ & $15,86 \pm 0,71$ & $17,19 \pm 1,14$ & $17,59 \pm 1,20$ & $16,43 \pm 1,26$ & $15,73 \pm 1,36$ & $16,86 \pm 3,71$ & $17,67 \pm 1,70$ \\
\hline C18:2n6 & $2,14 \pm 0,27$ & $2,44 \pm 0,75$ & $2,43 \pm 0,38$ & $2,11 \pm 1,77$ & $2,25 \pm 1,03$ & $3,37 \pm 1,01$ & $2,64 \pm 0,56$ & $3,29 \pm 0,55$ & $2,54 \pm 0,55$ & $2,67 \pm 1,34$ & $2,22 \pm 0,71$ & $2,28 \pm 0,54$ \\
\hline C18:3n3 & $0,81 \pm 0,28$ & $1,78 \pm 0,79$ & $0,95 \pm 0,69$ & $1,55 \pm 0,98$ & $0,58 \pm 0,87$ & $1,86 \pm 0,42$ & $1,43 \pm 0,84$ & $1,86 \pm 1,80$ & $1,80 \pm 0,86$ & $1,80 \pm 0,95$ & $0,98 \pm 0,55$ & $0,96 \pm 0,51$ \\
\hline $\mathrm{C} 20: 2 \mathrm{n} 6$ & $1,26 \pm 0,18$ & $1,46 \pm 0,46$ & $1,35 \pm 0,53$ & $0,57 \pm 0,42$ & $1,76 \pm 0,25$ & $1,53 \pm 0,34$ & $1,37 \pm 0,17$ & $0,96 \pm 0,53$ & $0,97 \pm 0,48$ & $1,28 \pm 0,39$ & $1,26 \pm 0,27$ & $1,10 \pm 0,37$ \\
\hline $\mathrm{C} 20: 3 \mathrm{n} 6$ & $0,95 \pm 0,22$ & $1,08 \pm 0,38$ & $1,29 \pm 0,29$ & $1,91 \pm 0,56$ & $1,55 \pm 0,20$ & $1,33 \pm 0,25$ & $1,32 \pm 0,21$ & $1,02 \pm 0,31$ & $1,23 \pm 0,41$ & $1,25 \pm 0,21$ & $1,01 \pm 0,44$ & $0,88 \pm 0,30$ \\
\hline C20:4n6 & $6,82 \pm 0,90$ & $8,58 \pm 1,48$ & $7,26 \pm 3,85$ & $1,86 \pm 4,13$ & $10,25 \pm 3,65$ & $8,33 \pm 1,10$ & $9,55 \pm 1,20$ & $7,44 \pm 0,42$ & $6,51 \pm 3,34$ & $7,78 \pm 1,35$ & $8,81 \pm 1,69$ & $7,01 \pm 1,43$ \\
\hline $\mathrm{C} 20: 3 \mathrm{n} 3$ & $0,18 \pm 0,05$ & $0,28 \pm 0,14$ & $0,47 \pm 4,50$ & $0,34 \pm 5,46$ & $0,19 \pm 0,10$ & $0,41 \pm 0,06$ & $0,29 \pm 0,16$ & $0,25 \pm 0,31$ & $0,27 \pm 3,17$ & $0,36 \pm 0,10$ & $0,21 \pm 0,14$ & $0,13 \pm 0,12$ \\
\hline $\mathrm{C} 20: 4 \mathrm{n} 3$ & $0,11 \pm 0,04$ & $0,27 \pm 0,08$ & $0,25 \pm 0,07$ & $0,13 \pm 0,57$ & $0,32 \pm 0,40$ & $0,35 \pm 0,05$ & $0,16 \pm 0,13$ & $0,16 \pm 0,09$ & $0,13 \pm 0,17$ & $0,26 \pm 0,16$ & $0,18 \pm 0,11$ & $0,15 \pm 0,06$ \\
\hline$C 20: 5 n 3$ & $2,55 \pm 0,65$ & $4,30 \pm 1,75$ & $2,75 \pm 2,47$ & $1,95 \pm 0,96$ & $3,19 \pm 1,60$ & $3,79 \pm 2,35$ & $4,94 \pm 1,72$ & $4,87 \pm 4,10$ & $4,99 \pm 1,65$ & $5,82 \pm 1,36$ & $4,42 \pm 3,58$ & $4,13 \pm 2,10$ \\
\hline C22:0 & $0,34 \pm 0,16$ & $0,63 \pm 0,16$ & $0,54 \pm 1,63$ & $0,99 \pm 8,53$ & $0,83 \pm 0,58$ & $0,79 \pm 0,19$ & $0,56 \pm 0,22$ & $0,52 \pm 0,26$ & $0,51 \pm 0,31$ & $0,71 \pm 0,18$ & $0,75 \pm 0,36$ & $0,29 \pm 0,35$ \\
\hline $\mathrm{C} 22: 2 \mathrm{n} 6$ & $0,93 \pm 0,11$ & $1,00 \pm 0,12$ & $0,53 \pm 0,35$ & $0,16 \pm 1,52$ & $0,45 \pm 0,20$ & $0,20 \pm 0,12$ & $0,80 \pm 0,27$ & $0,79 \pm 0,31$ & $0,19 \pm 0,11$ & $0,26 \pm 0,13$ & $0,68 \pm 0,28$ & $0,86 \pm 0,10$ \\
\hline C23:0 & $0,34 \pm 0,97$ & $0,31 \pm 0,04$ & $0,45 \pm 0,39$ & $0,33 \pm 0,19$ & $0,32 \pm 0,22$ & $0,08 \pm 0,04$ & $0,35 \pm 0,14$ & $0,27 \pm 0,59$ & $0,05 \pm 0,07$ & $0,17 \pm 0,05$ & $0,47 \pm 0,16$ & $0,28 \pm 0,13$ \\
\hline C22:5n6 & $1,40 \pm 0,25$ & $2,21 \pm 0,39$ & $1,99 \pm 0,84$ & $2,79 \pm 1,44$ & $2,91 \pm 1,45$ & $2,47 \pm 1,58$ & $2,38 \pm 0,67$ & $1,91 \pm 0,48$ & $2,77 \pm 0,50$ & $2,64 \pm 0,64$ & $3,13 \pm 1,34$ & $2,37 \pm 0,44$ \\
\hline$C 22: 5 n 3$ & $0,07 \pm 0,03$ & $0,12 \pm 0,06$ & $0,14 \pm 0,07$ & $0,34 \pm 8,49$ & $0,30 \pm 0,39$ & $0,20 \pm 0,03$ & $0,19 \pm 0,25$ & $0,01 \pm 0,02$ & $0,16 \pm 0,06$ & $0,34 \pm 0,13$ & $0,27 \pm 0,33$ & $0,02 \pm 0,02$ \\
\hline C22:6n3 & $0,22 \pm 0,31$ & $0,38 \pm 0,07$ & $0,55 \pm 0,68$ & $0,49 \pm 0,82$ & $0,98 \pm 0,87$ & $0,53 \pm 3,72$ & $0,46 \pm 0,32$ & $0,22 \pm 1,31$ & $0,61 \pm 0,23$ & $0,57 \pm 0,59$ & $1,58 \pm 0,65$ & $1,33 \pm 2,32$ \\
\hline SAT & $43,98 \pm 2,81^{\mathrm{ac}}$ & $42,03 \pm 1,22^{\mathrm{b}}$ & $43,68 \pm 4,18^{\mathrm{ab}}$ & $46,47 \pm 2,98^{\mathrm{a}}$ & $40,43 \pm 2,42^{\mathrm{bcd}}$ & $39,68 \pm 1,79^{\text {bd }}$ & $40,10 \pm 1,74^{\mathrm{d}}$ & $43,54 \pm 4,04^{\text {abcd }}$ & $39,17 \pm 0,89^{d}$ & $41,91 \pm 2,87^{\mathrm{bcd}}$ & $38,22 \pm 4,60^{\mathrm{bcd}}$ & $40,44 \pm 1,88^{\text {bd }}$ \\
\hline MUFA & $37,92 \pm 1,38^{\mathrm{a}}$ & $33,04 \pm 2,84^{\mathrm{bc}}$ & $34,82 \pm 3,12^{\mathrm{acd}}$ & $29,74 \pm 8,31^{b}$ & $31,99 \pm 5,98^{\mathrm{ab}}$ & $31,44 \pm 3,28^{\mathrm{bc}}$ & $34,81 \pm 1,96^{\mathrm{ac}}$ & $35,46 \pm 3,82^{\mathrm{bc}}$ & $38,63 \pm 4,04^{\mathrm{acd}}$ & $32,24 \pm 1,70^{\mathrm{bd}}$ & $32,85 \pm 6,63^{\mathrm{ab}}$ & $37,27 \pm 5,28^{\mathrm{ab}}$ \\
\hline PUFA & $17,81 \pm 2,64^{\mathrm{a}}$ & $24,95 \pm 2,65^{\mathrm{bc}}$ & $21,16 \pm 2,88^{\mathrm{ac}}$ & $24,35 \pm 6,16^{\mathrm{bc}}$ & $28,41 \pm 6,23^{\mathrm{bc}}$ & $29,00 \pm 4,62^{\mathrm{bc}}$ & $24,95 \pm 3,58^{\mathrm{bc}}$ & $20,95 \pm 7,37^{\mathrm{bc}}$ & $22,36 \pm 4,59^{\mathrm{ab}}$ & $25,19 \pm 3,65^{b}$ & $25,50 \pm 4,45^{\mathrm{bc}}$ & $22,68 \pm 5,11^{\mathrm{ab}}$ \\
\hline PUFA n3 & $4,71 \pm 1,03^{\mathrm{a}}$ & $6,73 \pm 2,46^{\mathrm{ab}}$ & $9,67 \pm 3,53^{b}$ & $12,63 \pm 8,27^{\mathrm{b}}$ & $6,37 \pm 2,30^{\mathrm{ab}}$ & $9,92 \pm 3,20^{\mathrm{b}}$ & $7,59 \pm 2,27^{b}$ & $6,62 \pm 6,96^{b}$ & $8,41 \pm 5,39^{\mathrm{b}}$ & $9,54 \pm 1,47^{\mathrm{b}}$ & $8,54 \pm 4,27^{\mathrm{ab}}$ & $6,62 \pm 3,97^{\mathrm{ab}}$ \\
\hline PUFA n6 & $13,10 \pm 1,67^{\mathrm{a}}$ & $17,11 \pm 2,37^{\mathrm{bd}}$ & $14,82 \pm 5,09^{\text {ade }}$ & $12,17 \pm 2,47^{\mathrm{ac}}$ & $20,12 \pm 4,71^{\text {be }}$ & $19,08 \pm 1,75^{\text {be }}$ & $17,87 \pm 2,05^{\text {be }}$ & $14,32 \pm 0,69^{\text {ad }}$ & $13,15 \pm 4,40^{\text {ade }}$ & $15,95 \pm 2,87^{\text {bce }}$ & $16,96 \pm 3,02^{\mathrm{b}}$ & $14,88 \pm 2,62^{\text {ade }}$ \\
\hline C18 n3 & $0,81 \pm 0,28^{\mathrm{a}}$ & $1,78 \pm 0,79^{\mathrm{bc}}$ & $0,95 \pm 0,69^{\mathrm{ab}}$ & $1,55 \pm 0,98^{\mathrm{ab}}$ & $0,58 \pm 0,87^{\mathrm{ab}}$ & $1,86 \pm 0,42^{\mathrm{b}}$ & $1,43 \pm 0,84^{\mathrm{ab}}$ & $1,86 \pm 1,80^{\mathrm{ab}}$ & $1,80 \pm 0,86^{\mathrm{ab}}$ & $1,80 \pm 0,95^{\mathrm{ab}}$ & $0,98 \pm 0,55^{\mathrm{ac}}$ & $0,96 \pm 0,51^{\mathrm{ab}}$ \\
\hline C20-22 n3 & $3,80 \pm 0,79^{\mathrm{a}}$ & $5,11 \pm 1,76^{\mathrm{ab}}$ & $7,24 \pm 3,16^{\mathrm{b}}$ & $10,15 \pm 8,54^{b}$ & $4,95 \pm 1,93^{\mathrm{ab}}$ & $7,71 \pm 3,24^{\mathrm{b}}$ & $6,16 \pm 1,99^{b}$ & $5,89 \pm 5,55^{\mathrm{b}}$ & $6,61 \pm 4,62^{\mathrm{b}}$ & $8,20 \pm 1,75^{\mathrm{b}}$ & $7,40 \pm 3,83^{\mathrm{ab}}$ & $5,66 \pm 3,49^{b}$ \\
\hline
\end{tabular}


C18 n6

C20-22 n6
$2,14 \pm 0,27^{\mathrm{a}} \quad 2,44 \pm 0,75^{\mathrm{ab}}$

$11,13 \pm 1,42^{\text {ad }} \quad 13,81 \pm 2,48^{\text {bd }} \quad 12,38 \pm 4,92^{\text {ade }}$

C18n6, C20-22n6, PUFAn3, C18n3 e C20-22n3, são as somatórias dos ácidos graxos saturados, monoinsaturados, polinsaturados n6, cadeias curtas de polinsaturados n6, cadeias longas de polinsaturados n6, polinsaturados n3, cadeias curtas de polinsaturados n3, cadeias longas de polinsaturados n3. 
Apêndice 3. Perfil de ácidos graxos (\%) do tecido muscular de fêmeas de Potamotrygon amandae coletadas no Alto Rio Paraná (reservatório de Jupiá, IlhaSolteira/SP) ao longo do ciclo reprodutivo (Média \pm EPM).

\begin{tabular}{|c|c|c|c|c|c|c|c|c|c|c|c|c|}
\hline & Jan/18 & Fev/18 & Mar/18 & Abr/18 & Mai/18 & Jun/18 & $\mathrm{Jul} / \mathbf{1 8}$ & Ago/18 & Set/18 & Out/18 & Nov/18 & Dez/18 \\
\hline C14:0 & $0,69 \pm 0,22$ & $1,19 \pm 0,45$ & $0,63 \pm 0,16$ & $0,36 \pm 0,22$ & $0,90 \pm 0,31$ & $0,76 \pm 0,53$ & $1,07 \pm 0,26$ & $1,62 \pm 0,22$ & $0,82 \pm 0,40$ & $0,40 \pm 0,47$ & $0,74 \pm 0,26$ & $0,74 \pm 0,26$ \\
\hline C14:1 & $1,03 \pm 0,68$ & $1,33 \pm 0,63$ & $1,20 \pm 0,24$ & $1,02 \pm 0,61$ & $1,34 \pm 0,46$ & $1,44 \pm 0,34$ & $1,47 \pm 0,32$ & $2,60 \pm 0,23$ & $1,26 \pm 0,70$ & $1,34 \pm 0,60$ & $1,92 \pm 0,44$ & $1,92 \pm 0,44$ \\
\hline C15:0 & $0,50 \pm 0,29$ & $0,78 \pm 0,37$ & $0,75 \pm 13,13$ & $0,96 \pm 0,96$ & $0,66 \pm 0,17$ & $1,11 \pm 0,36$ & $0,73 \pm 0,19$ & $1,05 \pm 0,70$ & $0,61 \pm 0,12$ & $1,06 \pm 0,37$ & $0,47 \pm 0,25$ & $0,47 \pm 0,25$ \\
\hline $\mathrm{C} 16: 0$ & $25,48 \pm 5,12$ & $34,00 \pm 5,22$ & $34,82 \pm 12,52$ & $27,40 \pm 2,26$ & $31,22 \pm 7,28$ & $33,99 \pm 5,67$ & $31,53 \pm 4,48$ & $29,24 \pm 2,8$ & $30,76 \pm 4,40$ & $27,34 \pm 1,50$ & $28,17 \pm 6,16$ & $28,17 \pm 6,16$ \\
\hline C16:1 & $6,28 \pm 2,23$ & $8,27 \pm 1,72$ & $6,47 \pm 2,24$ & $2,66 \pm 1,43$ & $4,47 \pm 1,29$ & $6,44 \pm 0,97$ & $5,55 \pm 2,37$ & $8,88 \pm 1,56$ & $9,58 \pm 2,20$ & $7,05 \pm 1,19$ & $4,76 \pm 2,87$ & $4,76 \pm 2,87$ \\
\hline C17:0 & $1,50 \pm 0,53$ & $2,55 \pm 0,88$ & $1,90 \pm 0,31$ & $1,48 \pm 0,51$ & $1,60 \pm 0,61$ & $1,75 \pm 0,49$ & $1,98 \pm 0,46$ & $2,31 \pm 0,33$ & $1,64 \pm 0,54$ & $1,51 \pm 0,72$ & $1,86 \pm 0,29$ & $1,86 \pm 0,29$ \\
\hline C18:0 & $14,65 \pm 1,81$ & $15,77 \pm 2,27$ & $15,13 \pm 2,92$ & $14,46 \pm 1,90$ & $16,51 \pm 3,54$ & $14,26 \pm 2,29$ & $12,58 \pm 2,19$ & $15,09 \pm 2,8$ & $12,99 \pm 2,92$ & $12,23 \pm 0,56$ & $16,18 \pm 3,03$ & $16,18 \pm 3,03$ \\
\hline C18:1 & $13,42 \pm 2,64$ & $18,16 \pm 1,90$ & $16,31 \pm 3,08$ & $10,81 \pm 2,18$ & $15,45 \pm 2,60$ & $15,46 \pm 1,15$ & $14,48 \pm 2,95$ & $17,17 \pm 2,1$ & $16,43 \pm 2,48$ & $16,47 \pm 2,23$ & $13,99 \pm 3,77$ & $13,99 \pm 3,77$ \\
\hline C18:2n6 & $0,92 \pm 0,46$ & $1,98 \pm 0,57$ & $1,17 \pm 0,24$ & $1,19 \pm 0,63$ & $1,09 \pm 0,79$ & $1,92 \pm 0,47$ & $1,63 \pm 0,61$ & $1,32 \pm 0,89$ & $1,31 \pm 0,49$ & $1,39 \pm 1,12$ & $1,68 \pm 0,51$ & $1,68 \pm 0,51$ \\
\hline C18:3n6 & $0,49 \pm 0,14$ & $0,47 \pm 0,11$ & $0,13 \pm 0,17$ & $0,24 \pm 0,24$ & $0,35 \pm 0,23$ & $0,33 \pm 0,20$ & $0,47 \pm 0,05$ & $0,45 \pm 0,14$ & $0,31 \pm 0,24$ & $0,36 \pm 0,86$ & $0,41 \pm 0,18$ & $0,41 \pm 0,18$ \\
\hline C20:0 & $0,38 \pm 0,25$ & $0,51 \pm 0,23$ & $0,61 \pm 0,37$ & $0,49 \pm 0,40$ & $0,60 \pm 0,27$ & $0,33 \pm 0,28$ & $1,48 \pm 0,41$ & $1,65 \pm 0,45$ & $0,97 \pm 0,56$ & $0,33 \pm 0,48$ & $1,03 \pm 0,39$ & $1,03 \pm 0,39$ \\
\hline C20:1 & $0,15 \pm 0,15$ & $0,21 \pm 0,14$ & $0,14 \pm 0,22$ & $0,31 \pm 0,52$ & $0,09 \pm 0,07$ & $1,13 \pm 0,61$ & $0,13 \pm 0,17$ & $0,33 \pm 0,12$ & $0,56 \pm 0,27$ & $0,58 \pm 0,38$ & $0,14 \pm 0,19$ & $0,14 \pm 0,19$ \\
\hline $\mathrm{C} 20: 2 \mathrm{n} 6$ & $0,67 \pm 0,32$ & $0,68 \pm 0,32$ & $0,90 \pm 0,32$ & $0,26 \pm 6,00$ & $0,78 \pm 0,53$ & $0,78 \pm 0,38$ & $0,89 \pm 0,30$ & $0,64 \pm 0,43$ & $0,64 \pm 0,33$ & $0,52 \pm 0,43$ & $0,60 \pm 0,39$ & $0,60 \pm 0,39$ \\
\hline C20:3n6 & $1,43 \pm 0,44$ & $0,74 \pm 0,43$ & $1,37 \pm 0,29$ & $0,72 \pm 0,51$ & $0,88 \pm 0,68$ & $1,28 \pm 0,46$ & $1,50 \pm 0,20$ & $0,93 \pm 0,56$ & $1,11 \pm 0,44$ & $1,56 \pm 0,36$ & $0,90 \pm 0,41$ & $0,90 \pm 0,41$ \\
\hline C20:4n6 & $23,28 \pm 7,28$ & $6,29 \pm 6,21$ & $10,86 \pm 8,63$ & $16,85 \pm 9,06$ & $12,62 \pm 9,44$ & $11,36 \pm 6,36$ & $11,45 \pm 7,17$ & $7,03 \pm 4,48$ & $14,05 \pm 6,84$ & $16,59 \pm 6,28$ & $19,01 \pm 9,12$ & $19,01 \pm 9,17$ \\
\hline $\mathrm{C} 20: 5 \mathrm{n} 3$ & $1,82 \pm 1,12$ & $0,75 \pm 1,60$ & $1,59 \pm 0,72$ & $1,37 \pm 0,40$ & $1,24 \pm 2,09$ & $1,30 \pm 1,14$ & $1,75 \pm 0,96$ & $0,91 \pm 097$ & $1,52 \pm 1,65$ & $2,05 \pm 0,85$ & $1,77 \pm 1,43$ & $1,77 \pm 1,43$ \\
\hline $\mathrm{C} 22: \ln 9$ & $0,43 \pm 0,21$ & $0,24 \pm 1,26$ & $0,48 \pm 0,26$ & $1,18 \pm 1,13$ & $0,65 \pm 0,22$ & $0,48 \pm 0,39$ & $0,35 \pm 0,17$ & $0,47 \pm 0,05$ & $0,36 \pm 0,14$ & $0,23 \pm 0,25$ & $0,53 \pm 0,18$ & $0,53 \pm 0,18$ \\
\hline $\mathrm{C} 22: 2 \mathrm{n} 6$ & $1,22 \pm 0,18$ & $1,33 \pm 0,11$ & $1,04 \pm 0,41$ & $3,26 \pm 1,68$ & $1,07 \pm 0,87$ & $0,71 \pm 0,58$ & $1,06 \pm 0,34$ & $1,29 \pm 0,43$ & $0,66 \pm 0,29$ & $1,15 \pm 0,94$ & $0,84 \pm 0,66$ & $0,84 \pm 0,66$ \\
\hline $\mathrm{C} 22: 5 \mathrm{n} 6$ & $2,01 \pm 1,38$ & $0,67 \pm 1,79$ & $1,48 \pm 0,98$ & $1,08 \pm 0,97$ & $2,16 \pm 3,01$ & $1,22 \pm 1,91$ & $1,90 \pm 1,55$ & $0,94 \pm 0,96$ & $0,95 \pm 2,10$ & $1,34 \pm 1,33$ & $1,52 \pm 2,01$ & $1,52 \pm 2,01$ \\
\hline $\mathrm{C} 22: 5 \mathrm{n} 3$ & $0,27 \pm 0,33$ & $0,44 \pm 0,77$ & $0,22 \pm 0,09$ & $1,86 \pm 0,89$ & $0,27 \pm 0,23$ & $0,62 \pm 0,27$ & $0,35 \pm 0,12$ & $0,56 \pm 0,31$ & $0,29 \pm 1,42$ & $2,36 \pm 1,15$ & $0,31 \pm 0,18$ & $0,31 \pm 0,18$ \\
\hline $\mathrm{C} 22: 6 \mathrm{n} 3$ & $2,39 \pm 1,34$ & $0,73 \pm 1,68$ & $0,84 \pm 1,32$ & $3,38 \pm 0,97$ & $0,92 \pm 1,25$ & $1,73 \pm 0,84$ & $0,64 \pm 0,96$ & $0,52 \pm 0,54$ & $0,53 \pm 1,00$ & $1,17 \pm 0,89$ & $1,88 \pm 2,43$ & $1,88 \pm 2,43$ \\
\hline $\mathrm{C} 24: 0$ & $0,34 \pm 0,22$ & $0,17 \pm 0,61$ & $0,56 \pm 0,39$ & $1,35 \pm 0,79$ & $1,00 \pm 0,43$ & $0,69 \pm 0,44$ & $0,54 \pm 0,16$ & $0,23 \pm 0,30$ & $0,75 \pm 0,89$ & $0,45 \pm 0,17$ & $0,73 \pm 0,29$ & $0,73 \pm 0,29$ \\
\hline SAT & $43,90 \pm 6,24$ & $55,55 \pm 7,64$ & $55,56 \pm 6,78^{\mathrm{ab}}$ & $44,72 \pm 5,09$ & $52,12 \pm 11,05^{\mathrm{a}}$ & $53,33 \pm 7,89$ & $51,16 \pm 6,54^{\mathrm{ab}}$ & $50,00 \pm 5,6$ & $48,94 \pm 7,39^{\mathrm{ab}}$ & $43,71 \pm 2,35$ & $51,00 \pm 9,24^{\mathrm{ab}}$ & $51,00 \pm 9,24^{\mathrm{ab}}$ \\
\hline MUFA & $20,96 \pm 5,45$ & $29,17 \pm 4,53$ & $24,30 \pm 4,90^{\mathrm{b}}$ & $17,60 \pm 4,89$ & $22,26 \pm 4,16^{\mathrm{b}}$ & $25,23 \pm 2,29$ & $22,25 \pm 5,43^{\mathrm{ab}}$ & $29,26 \pm 2,9$ & $27,09 \pm 4,24^{\mathrm{ac}}$ & $26,71 \pm 3,20$ & $20,74 \pm 6,89^{\mathrm{ab}}$ & $20,74 \pm 6,89^{\mathrm{ab}}$ \\
\hline PUFA & $37,74 \pm 11,2$ & $14,10 \pm 10,6$ & $19,57 \pm 11,32$ & $38,93 \pm 9,63$ & $25,62 \pm 15,02^{\mathrm{a}}$ & $20,23 \pm 9,40$ & $18,98 \pm 10,25$ & $20,19 \pm 6,1$ & $22,49 \pm 10,62$ & $30,44 \pm 4,74$ & $28,26 \pm 14,85$ & $28,26 \pm 14,85$ \\
\hline PUFA & $4,83 \pm 2,33^{\mathrm{a}}$ & $2,84 \pm 2,19^{\mathrm{a}}$ & $2,34 \pm 2,02^{\mathrm{ab}}$ & $6,20 \pm 0,94^{\mathrm{a}}$ & $2,99 \pm 2,75^{\mathrm{ab}}$ & $3,67 \pm 1,24^{\mathrm{b}}$ & $2,55 \pm 1,82^{\mathrm{b}}$ & $2,83 \pm 0,94^{\mathrm{b}}$ & $2,70 \pm 2,92^{\mathrm{ab}}$ & $5,85 \pm 1,97^{\mathrm{a}}$ & $3,58 \pm 3,70^{\mathrm{ab}}$ & $3,58 \pm 3,70^{\mathrm{ab}}$ \\
\hline PUFA & $32,05 \pm 9,23$ & $12,59 \pm 8,97$ & $17,23 \pm 9,34^{\mathrm{ab}}$ & $32,88 \pm 9,50$ & $22,63 \pm 12,47^{a}$ & $17,59 \pm 8,34$ & $17,30 \pm 8,48^{\mathrm{ab}}$ & $16,69 \pm 5,2$ & $19,46 \pm 7,93^{\mathrm{ab}}$ & $24,59 \pm 3,63$ & $24,68 \pm 11,57$ & $24,68 \pm 11,57$ \\
\hline C20-22 & $4,83 \pm 2,33^{\mathrm{a}}$ & $2,84 \pm 2,19^{a}$ & $2,34 \pm 2,02^{\mathrm{ab}}$ & $6,20 \pm 0,94^{\mathrm{a}}$ & $2,99 \pm 2,75^{\mathrm{ab}}$ & $3,67 \pm 1,24^{b}$ & $2,55 \pm 1,82^{\mathrm{b}}$ & $2,83 \pm 0,94^{\mathrm{b}}$ & $2,70 \pm 2,92^{\mathrm{ab}}$ & $5,85 \pm 1,97^{\mathrm{a}}$ & $3,58 \pm 3,70^{\mathrm{ab}}$ & $3,58 \pm 3,70^{\mathrm{ab}}$ \\
\hline C18 n6 & $1,41 \pm 0,59^{b}$ & $2,60 \pm 0,59^{\mathrm{a}}$ & $1,44 \pm 0,18^{b}$ & $1,48 \pm 0,55^{\mathrm{b}}$ & $1,37 \pm 0,98^{\mathrm{ab}}$ & $2,08 \pm 0,58^{\mathrm{a}}$ & $1,98 \pm 0,61^{\mathrm{ab}}$ & $1,69 \pm 0,89^{\mathrm{a}}$ & $1,61 \pm 0,62^{\mathrm{ab}}$ & $1,73 \pm 1,90^{\mathrm{a}}$ & $2,17 \pm 0,62^{\mathrm{ab}}$ & $2,17 \pm 0,62^{\mathrm{ab}}$ \\
\hline C20-22 & $30,64 \pm 9,01$ & $9,60 \pm 8,71^{\mathrm{a}}$ & $15,81 \pm 9,46^{\mathrm{ab}}$ & $31,29 \pm 9,07$ & $19,39 \pm 12,65^{\mathrm{a}}$ & $15,36 \pm 8,33$ & $15,32 \pm 8,60^{\mathrm{ab}}$ & $13,72 \pm 5,3$ & $17,97 \pm 8,13^{\mathrm{ab}}$ & $21,32 \pm 4,94$ & $22,50 \pm 11,41$ & $22,50 \pm 11,41$ \\
\hline
\end{tabular}

${ }^{\mathrm{ab}}$ Letras diferentes mostram diferenças estatísticas $(\mathrm{P}<0,05)$ ao longo do ciclo anual para fêmeas. Valores abaixo de 0.1 não foram considerados. SFA, MUFA, PUFA, PUFAn6,

C18n6, C20-22n6, PUFAn3, C18n3 e C20-22n3, são as somatórias dos ácidos graxos saturados, monoinsaturados, polinsaturados n6, cadeias curtas de polinsaturados n6, cadeias longas de polinsaturados n6, polinsaturados n3, cadeias curtas de polinsaturados n3, cadeias longas de polinsaturados n3. 
Apêndice 4. Perfil de ácidos graxos (\%) do tecido ovariano de fêmeas de Potamotrygon amandae coletadas no Alto Rio Paraná (reservatório de Jupiá, IlhaSolteira/SP) ao longo do ciclo reprodutivo (Média \pm EPM).

\begin{tabular}{|c|c|c|c|c|c|c|c|c|c|c|c|c|}
\hline & Jan/18 & Fev/18 & Mar/18 & Abr/18 & Mai/18 & Jun/18 & Jul/18 & Ago/18 & Set/18 & Out/18 & Nov/18 & Dez/18 \\
\hline C14:0 & $0,96 \pm 0,47$ & $1,62 \pm 0,55$ & $1,24 \pm 0,32$ & $0,18 \pm 0,67$ & $2,04 \pm 0,43$ & $1,67 \pm 0,44$ & $1,19 \pm 0,40$ & $1,75 \pm 0,53$ & $2,59 \pm 0,64$ & $0,20 \pm 1,03$ & $1,65 \pm 0,49$ & $1,40 \pm 0,51$ \\
\hline C14:1 & $4,08 \pm 1,28$ & $3,44 \pm 0,85$ & $4,00 \pm 0,86$ & $2,60 \pm 1,56$ & $4,03 \pm 0,36$ & $3,93 \pm 0,50$ & $3,75 \pm 1,02$ & $4,29 \pm 1,09$ & $4,57 \pm 0,78$ & $1,92 \pm 1,03$ & $4,29 \pm 1,13$ & $4,32 \pm 0,68$ \\
\hline C15:0 & $1,11 \pm 0,34$ & $1,45 \pm 1,12$ & $1,42 \pm 0,29$ & $2,56 \pm 1,06$ & $1,58 \pm 0,20$ & $1,43 \pm 0,21$ & $1,18 \pm 0,33$ & $1,55 \pm 0,34$ & $1,88 \pm 0,45$ & $3,14 \pm 1,09$ & $1,22 \pm 0,25$ & $1,07 \pm 0,35$ \\
\hline $\mathrm{C} 15: 1$ & $0,91 \pm 0,36$ & $1,16 \pm 0,25$ & $1,18 \pm 0,28$ & $1,50 \pm 0,46$ & $1,11 \pm 0,12$ & $1,21 \pm 0,16$ & $1,38 \pm 0,84$ & $1,41 \pm 0,13$ & $1,46 \pm 0,51$ & $1,33 \pm 0,32$ & $1,04 \pm 0,29$ & $1,05 \pm 0,26$ \\
\hline C16:0 & $23,36 \pm 5,92$ & $25,02 \pm 2,23$ & $26,50 \pm 4,52$ & $23,80 \pm 5,79$ & $24,00 \pm 1,70$ & $23,22 \pm 0,67$ & $23,62 \pm 4,04$ & $25,94 \pm 4,29$ & $26,62 \pm 2,96$ & $27,19 \pm 4,63$ & $22,89 \pm 4,40$ & $26,69 \pm 7,08$ \\
\hline C16:1 & $6,48 \pm 1,49$ & $6,16 \pm 1,07$ & $6,35 \pm 1,77$ & $4,72 \pm 0,99$ & $7,72 \pm 0,68$ & $6,08 \pm 0,79$ & $7,29 \pm 1,11$ & $9,33 \pm 1,11$ & $7,47 \pm 0,94$ & $8,18 \pm 1,25$ & $6,53 \pm 1,63$ & $5,70 \pm 1,22$ \\
\hline $\mathrm{C} 17: 0$ & $2,19 \pm 0,72$ & $2,94 \pm 0,74$ & $2,20 \pm 0,59$ & $3,12 \pm 1,47$ & $2,65 \pm 0,46$ & $3,36 \pm 0,36$ & $2,64 \pm 0,75$ & $2,99 \pm 0,73$ & $2,97 \pm 0,75$ & $2,79 \pm 0,59$ & $2,43 \pm 0,68$ & $2,69 \pm 0,99$ \\
\hline C18:0 & $10,42 \pm 5,83$ & $16,28 \pm 1,51$ & $14,80 \pm 2,90$ & $14,99 \pm 7,17$ & $14,57 \pm 0,47$ & $12,73 \pm 3,70$ & $10,94 \pm 1,32$ & $11,04 \pm 2,50$ & $15,27 \pm 3,01$ & $15,10 \pm 3,65$ & $11,68 \pm 2,46$ & $14,03 \pm 5,79$ \\
\hline C18:1 & $17,28 \pm 3,62$ & $14,90 \pm 1,54$ & $15,30 \pm 2,98$ & $15,26 \pm 1,90$ & $13,94 \pm 1,67$ & $13,80 \pm 1,69$ & $14,52 \pm 3,72$ & $15,60 \pm 2,58$ & $15,75 \pm 1,71$ & $14,45 \pm 4,29$ & $14,99 \pm 2,71$ & $15,57 \pm 2,11$ \\
\hline C18:2n6 & $1,49 \pm 0,24$ & $2,38 \pm 0,76$ & $1,83 \pm 0,36$ & $2,30 \pm 7,36$ & $2,08 \pm 0,48$ & $3,13 \pm 5,08$ & $2,00 \pm 0,41$ & $1,84 \pm 0,34$ & $1,93 \pm 0,35$ & $1,27 \pm 0,51$ & $1,87 \pm 0,47$ & $1,49 \pm 0,48$ \\
\hline C18:3n6 & $0,44 \pm 0,22$ & $0,58 \pm 0,15$ & $0,53 \pm 0,20$ & $0,57 \pm 0,58$ & $0,37 \pm 0,15$ & $0,53 \pm 0,82$ & $0,41 \pm 0,08$ & $0,48 \pm 0,07$ & $0,37 \pm 0,13$ & $0,41 \pm 0,25$ & $0,33 \pm 0,12$ & $0,49 \pm 0,33$ \\
\hline C20:0 & $0,27 \pm 0,21$ & $0,61 \pm 0,32$ & $0,31 \pm 0,19$ & $0,26 \pm 0,10$ & $0,54 \pm 0,22$ & $0,36 \pm 0,21$ & $0,29 \pm 0,10$ & $0,31 \pm 0,23$ & $0,36 \pm 0,40$ & $0,32 \pm 1,56$ & $0,37 \pm 0,08$ & $0,38 \pm 0,18$ \\
\hline C20:1 & $0,41 \pm 0,17$ & $0,42 \pm 0,19$ & $0,05 \pm 0,15$ & $1,28 \pm 1,37$ & $1,35 \pm 0,79$ & $0,36 \pm 0,23$ & $0,56 \pm 0,93$ & $0,46 \pm 0,09$ & $0,55 \pm 0,14$ & $1,28 \pm 1,01$ & $0,50 \pm 0,23$ & $0,34 \pm 0,19$ \\
\hline C20:2n6 & $1,15 \pm 0,43$ & $0,84 \pm 0,17$ & $0,50 \pm 0,14$ & $0,64 \pm 0,30$ & $0,60 \pm 0,21$ & $0,89 \pm 0,27$ & $1,14 \pm 0,18$ & $1,08 \pm 0,16$ & $0,87 \pm 0,59$ & $0,43 \pm 0,38$ & $0,72 \pm 0,19$ & $1,14 \pm 0,44$ \\
\hline $\mathrm{C} 20: 3 \mathrm{n} 6$ & $0,96 \pm 0,38$ & $0,60 \pm 0,08$ & $0,55 \pm 0,35$ & $0,54 \pm 0,11$ & $0,71 \pm 0,30$ & $0,98 \pm 0,31$ & $1,06 \pm 0,23$ & $1,08 \pm 0,18$ & $0,71 \pm 0,46$ & $0,99 \pm 1,38$ & $0,78 \pm 0,10$ & $0,74 \pm 0,50$ \\
\hline C20:4n6 & $17,91 \pm 11,19$ & $7,38 \pm 6,65$ & $10,22 \pm 7,64$ & $10,92 \pm 6,54$ & $12,58 \pm 2,56$ & $12,37 \pm 6,83$ & $13,01 \pm 2,76$ & $8,58 \pm 2,65$ & $4,42 \pm 4,68$ & $3,47 \pm 6,45$ & $14,30 \pm 8,34$ & $8,23 \pm 9,59$ \\
\hline C20:5n3 & $1,99 \pm 1,77$ & $0,56 \pm 0,86$ & $0,59 \pm 2,08$ & $1,55 \pm 1,21$ & $1,63 \pm 0,70$ & $2,18 \pm 3,71$ & $2,71 \pm 3,81$ & $3,88 \pm 2,50$ & $1,67 \pm 0,61$ & $1,82 \pm 2,60$ & $3,45 \pm 1,10$ & $1,59 \pm 2,35$ \\
\hline $\mathrm{C} 22: 0$ & $0,67 \pm 0,36$ & $1,30 \pm 0,21$ & $1,03 \pm 0,29$ & $1,29 \pm 0,38$ & $0,97 \pm 0,16$ & $0,82 \pm 0,54$ & $0,64 \pm 0,05$ & $0,55 \pm 0,05$ & $0,69 \pm 0,19$ & $0,46 \pm 0,24$ & $0,85 \pm 0,14$ & $0,78 \pm 0,37$ \\
\hline $\mathrm{C} 22: \ln 9$ & $0,68 \pm 1,07$ & $3,49 \pm 0,79$ & $2,54 \pm 1,33$ & $2,73 \pm 1,16$ & $2,98 \pm 0,29$ & $2,13 \pm 0,96$ & $1,06 \pm 0,64$ & $1,37 \pm 0,89$ & $2,30 \pm 1,11$ & $1,32 \pm 0,78$ & $1,54 \pm 0,60$ & $1,68 \pm 0,75$ \\
\hline $\mathrm{C} 22: 2 \mathrm{n} 6$ & $1,12 \pm 0,16$ & $1,02 \pm 0,22$ & $0,32 \pm 0,16$ & $0,53 \pm 0,53$ & $0,81 \pm 0,18$ & $0,37 \pm 0,32$ & $0,90 \pm 0,27$ & $1,38 \pm 0,32$ & $0,38 \pm 0,45$ & $1,05 \pm 1,97$ & $0,87 \pm 0,22$ & $0,85 \pm 0,07$ \\
\hline C23:0 & $0,62 \pm 0,22$ & $0,71 \pm 0,16$ & $0,83 \pm 0,27$ & $1,09 \pm 0,36$ & $0,75 \pm 0,14$ & $0,66 \pm 0,21$ & $0,77 \pm 0,05$ & $0,32 \pm 1,02$ & $0,46 \pm 0,26$ & $0,79 \pm 2,99$ & $0,70 \pm 0,11$ & $0,48 \pm 0,24$ \\
\hline C22:5n6 & $3,28 \pm 5,41$ & $0,86 \pm 0,36$ & $0,98 \pm 3,60$ & $1,02 \pm 3,64$ & $0,94 \pm 0,29$ & $1,32 \pm 1,40$ & $2,38 \pm 2,16$ & $2,74 \pm 1,56$ & $1,05 \pm 1,10$ & $0,84 \pm 1,96$ & $2,34 \pm 2,02$ & $1,15 \pm 3,45$ \\
\hline $\mathrm{C} 22: 5 \mathrm{n} 3$ & $0,35 \pm 0,38$ & $1,22 \pm 0,19$ & $1,48 \pm 0,69$ & $1,63 \pm 0,35$ & $1,23 \pm 0,16$ & $1,13 \pm 0,19$ & $0,81 \pm 0,34$ & $0,98 \pm 0,29$ & $1,00 \pm 0,56$ & $1,07 \pm 0,45$ & $0,97 \pm 0,32$ & $1,03 \pm 1,14$ \\
\hline C22:6n3 & $1,88 \pm 2,31$ & $1,71 \pm 0,37$ & $2,53 \pm 0,83$ & $1,69 \pm 1,41$ & $1,46 \pm 0,05$ & $1,86 \pm 1,05$ & $0,91 \pm 0,84$ & $0,58 \pm 0,27$ & $1,41 \pm 0,93$ & $1,30 \pm 0,96$ & $1,62 \pm 0,91$ & $2,54 \pm 4,08$ \\
\hline C24:0 & $0,54 \pm 0,50$ & $1,11 \pm 0,41$ & $1,12 \pm 0,74$ & $1,42 \pm 0,69$ & $1,39 \pm 0,14$ & $0,80 \pm 0,51$ & $0,44 \pm 0,29$ & $0,57 \pm 0,41$ & $1,42 \pm 0,64$ & $0,93 \pm 0,19$ & $1,07 \pm 0,44$ & $0,73 \pm 0,42$ \\
\hline SAT & $39,43 \pm 13,91^{\mathrm{ab}}$ & $52,01 \pm 4,96^{\mathrm{ab}}$ & $49,99 \pm 8,82^{\mathrm{ab}}$ & $48,82 \pm 11,11^{\mathrm{ab}}$ & $48,59 \pm 1,88^{\mathrm{a}}$ & $45,89 \pm 4,84^{\mathrm{ab}}$ & $43,16 \pm 5,73^{b}$ & $43,45 \pm 6,68^{a b}$ & $52,60 \pm 5,56^{\mathrm{a}}$ & $51,82 \pm 5,68^{\mathrm{ab}}$ & $45,69 \pm 7,27^{b}$ & $50,68 \pm 14,75^{\mathrm{ab}}$ \\
\hline MUFA & $30,11 \pm 6,87^{\mathrm{ab}}$ & $30,63 \pm 1,74^{\mathrm{ab}}$ & $31,37 \pm 5,40^{\mathrm{ab}}$ & $28,15 \pm 2,75^{\mathrm{b}}$ & $29,58 \pm 2,48^{\mathrm{ab}}$ & $27,44 \pm 2,42^{b}$ & $31,19 \pm 4,53^{\mathrm{ab}}$ & $32,11 \pm 2,13^{\mathrm{ab}}$ & $31,93 \pm 1,86^{\mathrm{a}}$ & $30,26 \pm 5,94^{\mathrm{ab}}$ & $30,22 \pm 4,04^{\mathrm{ab}}$ & $27,05 \pm 4,34^{\mathrm{ab}}$ \\
\hline PUFA & $30,47 \pm 20,52^{\mathrm{ab}}$ & $16,64 \pm 6,06^{\mathrm{ab}}$ & $17,45 \pm 13,94^{\mathrm{ab}}$ & $23,87 \pm 11,57^{\mathrm{ab}}$ & $21,83 \pm 3,83^{\mathrm{ab}}$ & $26,67 \pm 6,91^{\mathrm{b}}$ & $25,14 \pm 9,95^{\mathrm{ab}}$ & $22,47 \pm 6,12^{\mathrm{ab}}$ & $14,25 \pm 6,32^{a}$ & $17,92 \pm 11,36^{\mathrm{ab}}$ & $24,22 \pm 10,03^{\mathrm{ab}}$ & $20,19 \pm 18,64^{\mathrm{ab}}$ \\
\hline PUFA n3 & $4,12 \pm 3,72$ & $3,52 \pm 0,77$ & $3,99 \pm 2,57$ & $4,54 \pm 2,54$ & $4,35 \pm 0,63$ & $5,83 \pm 4,04$ & $4,48 \pm 4,73$ & $5,07 \pm 2,31$ & $3,85 \pm 0,93$ & $3,70 \pm 3,34$ & $6,59 \pm 1,78$ & $7,06 \pm 4,86$ \\
\hline PUFA n6 & $26,35 \pm 16,88$ & $13,16 \pm 6,39$ & $13,82 \pm 11,50$ & $19,34 \pm 9,99$ & $18,11 \pm 3,39$ & $20,60 \pm 4,38$ & $20,65 \pm 5,29$ & $17,40 \pm 3,92$ & $9,97 \pm 6,74$ & $14,22 \pm 8,08$ & $21,03 \pm 8,90$ & $14,01 \pm 14,29$ \\
\hline C20-22 n3 & $4,12 \pm 3,72$ & $3,52 \pm 0,77$ & $3,99 \pm 2,57$ & $4,54 \pm 2,54$ & $4,35 \pm 0,63$ & $5,83 \pm 4,04$ & $4,48 \pm 4,73$ & $5,07 \pm 2,31$ & $3,85 \pm 0,93$ & $3,70 \pm 3,34$ & $6,59 \pm 1,78$ & $7,06 \pm 4,86$ \\
\hline
\end{tabular}




\begin{tabular}{|c|c|c|c|c|c|c|c|c|c|c|c|c|}
\hline $18 \mathrm{ng}$ & $1,96 \pm 0,32^{\mathrm{b}}$ & $2,86 \pm 0,70^{\mathrm{ab}}$ & $2,45 \pm 0,46^{\mathrm{ab}}$ & $2,87 \pm 7,92^{\mathrm{a}}$ & $2,35 \pm 0,44^{\mathrm{ac}}$ & $3,41 \pm 5,88^{\mathrm{ad}}$ & $2,41 \pm 0,40^{\mathrm{ab}}$ & $2,37 \pm 0,35^{\mathrm{ab}}$ & $2,29 \pm 0,45^{\text {bcd }}$ & $1,69 \pm 0,37^{\mathrm{bc}}$ & $2,13 \pm 0,49^{\mathrm{abc}}$ & \\
\hline & & & $12,04 \pm 11,44$ & $13,94 \pm 10,30$ & $15,60 \pm 3,23$ & $17,20 \pm 8,12$ & $18,37 \pm 5,04$ & $15,22 \pm 4,10$ & $7,48 \pm 6,53$ & $12,06 \pm 7,81$ & $18,89 \pm 8,88$ & \\
\hline
\end{tabular}

abLetras diferentes significam diferenças estatísticas $(\mathrm{P}<0,05)$ ao longo do ciclo anual para fêmeas. Valores abaixo de 0.1 não foram considerados. SFA, MUFA, PUFA, PUFAn6, C18n6, C20-22n6, PUFAn3, C18n3 e C20-22n3, são as somatórias dos ácidos graxos saturados, monoinsaturados, polinsaturados n6, cadeias curtas de polinsaturados n6, cadeias longas de polinsaturados n6, polinsaturados $\mathrm{n} 3$, cadeias curtas de polinsaturados $\mathrm{n} 3$, cadeias longas de polinsaturados $\mathrm{n} 3$. 
Apêndice 5. Perfil de ácidos graxos (\%) do tecido uterino de fêmeas de Potamotrygon amandae coletadas no Alto Rio Paraná (reservatório de Jupiá, IlhaSolteira/SP) ao longo do ciclo reprodutivo (Média \pm EPM).

\begin{tabular}{|c|c|c|c|c|c|c|c|c|c|c|c|c|}
\hline & Jan/18 & Fev/18 & Mar/18 & Abr/18 & Mai/18 & Jun/18 & Jul/18 & Ago/18 & Set/18 & Out/18 & Nov/18 & Dez/18 \\
\hline C14:0 & $1,59 \pm 0,51$ & $1,03 \pm 0,41$ & $1,30 \pm 0,36$ & $1,21 \pm 0,67$ & $0,97 \pm 0,25$ & $1,82 \pm 0,48$ & $1,35 \pm 0,28$ & $1,92 \pm 0,53$ & $1,68 \pm 0,33$ & $1,87 \pm 0,64$ & $1,08 \pm 0,47$ & $1,80 \pm 0,22$ \\
\hline C14:1 & $3,09 \pm 1,51$ & $2,15 \pm 0,68$ & $2,75 \pm 0,69$ & $3,65 \pm 1,41$ & $2,42 \pm 0,38$ & $3,30 \pm 0,19$ & $3,16 \pm 1,41$ & $2,74 \pm 0,72$ & $3,13 \pm 0,50$ & $3,44 \pm 0,84$ & $2,11 \pm 0,64$ & $4,26 \pm 0,88$ \\
\hline C15:0 & $1,28 \pm 0,56$ & $0,99 \pm 0,31$ & $1,29 \pm 0,29$ & $1,47 \pm 0,40$ & $1,33 \pm 0,26$ & $1,49 \pm 0,28$ & $1,19 \pm 0,46$ & $1,50 \pm 0,21$ & $1,56 \pm 0,19$ & $1,53 \pm 0,62$ & $1,02 \pm 0,17$ & $1,67 \pm 0,43$ \\
\hline C15:1 & $1,02 \pm 0,35$ & $0,87 \pm 0,21$ & $0,93 \pm 0,24$ & $1,54 \pm 1,43$ & $1,11 \pm 0,23$ & $1,28 \pm 0,24$ & $1,07 \pm 0,44$ & $0,81 \pm 0,19$ & $1,13 \pm 0,09$ & $1,20 \pm 0,50$ & $0,57 \pm 0,36$ & $1,12 \pm 0,23$ \\
\hline C16:0 & $31,01 \pm 1,21$ & $26,69 \pm 2,89$ & $28,74 \pm 2,17$ & $24,45 \pm 3,51$ & $25,00 \pm 2,19$ & $26,05 \pm 1,28$ & $27,89 \pm 1,53$ & $28,47 \pm 1,66$ & $27,85 \pm 1,37$ & $26,97 \pm 3,39$ & $26,66 \pm 2,59$ & $28,88 \pm 1,65$ \\
\hline C16:1 & $10,60 \pm 1,14$ & $6,66 \pm 0,89$ & $7,20 \pm 1,20$ & $5,18 \pm 1,64$ & $5,78 \pm 0,41$ & $6,57 \pm 1,05$ & $8,51 \pm 0,67$ & $8,40 \pm 1,18$ & $9,12 \pm 1,89$ & $8,59 \pm 1,65$ & $9,04 \pm 1,34$ & $9,51 \pm 1,53$ \\
\hline C17:0 & $2,47 \pm 0,33$ & $2,95 \pm 0,67$ & $3,14 \pm 0,50$ & $2,17 \pm 0,91$ & $3,06 \pm 0,65$ & $2,82 \pm 0,79$ & $2,92 \pm 1,15$ & $2,57 \pm 0,61$ & $2,88 \pm 0,18$ & $2,42 \pm 0,74$ & $2,07 \pm 0,45$ & $2,86 \pm 0,46$ \\
\hline C18:0 & $16,27 \pm 3,20$ & $15,18 \pm 2,60$ & $15,18 \pm 2,57$ & $13,55 \pm 1,76$ & $14,98 \pm 1,60$ & $14,26 \pm 1,09$ & $17,70 \pm 3,02$ & $17,17 \pm 0,95$ & $14,77 \pm 1,19$ & $13,71 \pm 2,08$ & $15,17 \pm 1,27$ & $12,79 \pm 1,24$ \\
\hline C18:1 & $22,14 \pm 2,34$ & $20,41 \pm 2,14$ & $23,20 \pm 2,41$ & $22,33 \pm 3,78$ & $22,85 \pm 2,68$ & $24,46 \pm 1,44$ & $22,59 \pm 2,35$ & $24,51 \pm 2,14$ & $22,29 \pm 1,32$ & $20,67 \pm 4,61$ & $24,00 \pm 3,66$ & $24,80 \pm 1,74$ \\
\hline C18:2n6 & $1,27 \pm 0,56$ & $1,35 \pm 0,46$ & $1,53 \pm 0,55$ & $1,49 \pm 0,79$ & $1,45 \pm 0,33$ & $1,51 \pm 0,43$ & $0,96 \pm 0,51$ & $0,79 \pm 0,35$ & $1,40 \pm 0,38$ & $1,48 \pm 0,84$ & $1,05 \pm 0,30$ & $1,43 \pm 0,34$ \\
\hline C18:3n6 & $0,35 \pm 0,17$ & $0,44 \pm 0,13$ & $0,27 \pm 0,13$ & $1,87 \pm 1,10$ & $0,12 \pm 0,18$ & $0,63 \pm 0,33$ & $0,38 \pm 0,18$ & $0,36 \pm 0,09$ & $0,26 \pm 0,26$ & $0,64 \pm 0,50$ & $0,37 \pm 0,23$ & $0,40 \pm 0,07$ \\
\hline C18:4n3 & $0,05 \pm 0,12$ & $0,20 \pm 0,12$ & $0,15 \pm 0,20$ & $0,14 \pm 0,19$ & $0,70 \pm 0,31$ & $0,58 \pm 0,24$ & $0,10 \pm 0,15$ & $0,08 \pm 0,06$ & $0,39 \pm 0,17$ & $0,15 \pm 0,18$ & $0,30 \pm 0,41$ & $0,08 \pm 0,02$ \\
\hline C20:0 & $0,24 \pm 0,20$ & $0,55 \pm 0,24$ & $0,36 \pm 0,34$ & $0,30 \pm 0,42$ & $0,56 \pm 0,19$ & $0,77 \pm 0,11$ & $0,54 \pm 0,12$ & $0,52 \pm 0,11$ & $0,78 \pm 0,27$ & $0,30 \pm 0,19$ & $0,45 \pm 0,17$ & $0,40 \pm 0,16$ \\
\hline C20:1 & $0,26 \pm 0,16$ & $0,41 \pm 0,06$ & $0,32 \pm 0,10$ & $0,60 \pm 0,32$ & $0,33 \pm 0,10$ & $0,54 \pm 0,64$ & $0,30 \pm 0,08$ & $0,32 \pm 0,11$ & $0,40 \pm 0,23$ & $0,33 \pm 0,32$ & $0,39 \pm 0,07$ & $0,26 \pm 0,13$ \\
\hline $\mathrm{C} 20: 2 \mathrm{n} 6$ & $0,56 \pm 0,27$ & $0,91 \pm 0,48$ & $0,43 \pm 0,21$ & $1,10 \pm 0,66$ & $0,53 \pm 0,20$ & $0,44 \pm 0,60$ & $0,80 \pm 0,52$ & $0,72 \pm 0,24$ & $0,67 \pm 0,47$ & $0,58 \pm 0,96$ & $1,04 \pm 0,94$ & $0,77 \pm 0,12$ \\
\hline C20:3n6 & $0,57 \pm 0,59$ & $0,27 \pm 0,12$ & $0,68 \pm 1,19$ & $0,41 \pm 3,44$ & $0,84 \pm 0,38$ & $0,21 \pm 0,18$ & $0,18 \pm 0,17$ & $0,19 \pm 0,16$ & $0,28 \pm 0,39$ & $0,41 \pm 0,37$ & $0,34 \pm 0,44$ & $0,27 \pm 0,12$ \\
\hline C20:4n6 & $1,99 \pm 1,13$ & $6,46 \pm 6,30$ & $4,58 \pm 4,34$ & $2,82 \pm 2,84$ & $7,80 \pm 4,17$ & & $2,81 \pm 2,14$ & & & & & \\
\hline $\mathrm{C} 20: 3 \mathrm{n} 3$ & $0,09 \pm 0,06$ & $0,21 \pm 0,07$ & $0,08 \pm 0,04$ & $0,57 \pm 0,61$ & $0,10 \pm 0,03$ & $0,29 \pm 0,31$ & $0,10 \pm 0,12$ & $0,24 \pm 0,20$ & $0,11 \pm 0,08$ & $0,11 \pm 0,11$ & $0,06 \pm 0,13$ & $0,22 \pm 0,20$ \\
\hline $\mathrm{C} 20: 5 \mathrm{n} 3$ & $0,26 \pm 0,14$ & $0,89 \pm 0,40$ & $0,63 \pm 0,45$ & $1,23 \pm 1,52$ & $0,78 \pm 0,52$ & $0,74 \pm 0,37$ & $0,06 \pm 0,19$ & $0,32 \pm 0,29$ & $0,81 \pm 0,25$ & $1,33 \pm 0,99$ & $1,18 \pm 0,46$ & $0,77 \pm 0,24$ \\
\hline $\mathrm{C} 22: 0$ & $0,54 \pm 0,18$ & $0,78 \pm 0,37$ & $1,02 \pm 0,25$ & $1,21 \pm 1,12$ & $1,05 \pm 0,18$ & $1,28 \pm 0,26$ & $0,95 \pm 0,42$ & $0,67 \pm 0,33$ & $0,92 \pm 0,25$ & $1,07 \pm 0,54$ & $0,89 \pm 0,20$ & $0,55 \pm 0,17$ \\
\hline $\mathrm{C} 22: \ln 9$ & $1,06 \pm 0,65$ & $0,75 \pm 0,35$ & $0,52 \pm 0,53$ & $1,67 \pm 1,80$ & $1,03 \pm 0,25$ & $0,91 \pm 0,24$ & $0,78 \pm 0,49$ & $0,91 \pm 0,30$ & $0,69 \pm 0,28$ & $0,55 \pm 0,30$ & $0,59 \pm 0,26$ & $0,62 \pm 0,24$ \\
\hline $\mathrm{C} 22: 2 \mathrm{n} 6$ & $1,10 \pm 0,78$ & $1,56 \pm 0,51$ & $1,20 \pm 0,31$ & $1,85 \pm 0,76$ & $1,05 \pm 0,77$ & $0,77 \pm 0,53$ & $1,40 \pm 0,44$ & $0,68 \pm 0,94$ & $0,93 \pm 0,24$ & $2,24 \pm 1,06$ & $1,33 \pm 0,14$ & $0,89 \pm 0,10$ \\
\hline C23:0 & $0,51 \pm 0,33$ & $0,84 \pm 0,32$ & $0,63 \pm 2,44$ & $2,04 \pm 1,25$ & $0,90 \pm 0,23$ & $1,44 \pm 0,90$ & $0,89 \pm 1,10$ & $0,45 \pm 0,29$ & $0,64 \pm 0,21$ & $0,85 \pm 0,42$ & $0,56 \pm 0,23$ & $0,36 \pm 0,29$ \\
\hline $\mathrm{C} 22: 5 \mathrm{n} 6$ & $0,50 \pm 0,32$ & $1,55 \pm 0,98$ & $1,01 \pm 0,55$ & $2,39 \pm 0,87$ & $0,61 \pm 0,42$ & $1,40 \pm 0,61$ & $0,92 \pm 0,39$ & $0,56 \pm 0,41$ & $0,59 \pm 0,59$ & $1,14 \pm 0,75$ & $0,49 \pm 0,81$ & $1,08 \pm 0,61$ \\
\hline $\mathrm{C} 22: 5 \mathrm{n} 3$ & $0,64 \pm 0,33$ & $0,86 \pm 0,28$ & $0,98 \pm 0,41$ & $1,32 \pm 0,68$ & $1,23 \pm 0,36$ & $0,83 \pm 0,54$ & $1,36 \pm 3,24$ & $1,41 \pm 0,34$ & $0,91 \pm 0,27$ & $0,94 \pm 0,23$ & $0,70 \pm 0,30$ & $0,65 \pm 0,17$ \\
\hline $\mathrm{C} 22: 6 \mathrm{n} 3$ & $0,53 \pm 0,40$ & $0,73 \pm 0,36$ & $0,73 \pm 0,22$ & $1,16 \pm 0,65$ & $1,22 \pm 0,18$ & $0,73 \pm 0,18$ & $0,97 \pm 0,56$ & $0,50 \pm 0,15$ & $0,42 \pm 0,35$ & $0,52 \pm 0,30$ & $1,06 \pm 0,36$ & $0,39 \pm 0,20$ \\
\hline SAT & $52,70 \pm 1,55^{\mathrm{ac}}$ & $52,46 \pm 5,49^{\mathrm{ab}}$ & $51,99 \pm 2,98^{\mathrm{ab}}$ & $46,25 \pm 3,81^{b c}$ & $48,42 \pm 3,60^{\mathrm{b}}$ & $50,51 \pm 1,60^{\mathrm{bc}}$ & $54,32 \pm 3,16^{\mathrm{ab}}$ & $54,28 \pm 1,42^{\mathrm{a}}$ & $51,51 \pm 0,87^{\mathrm{ac}}$ & $49,34 \pm 3,45^{\mathrm{ab}}$ & $48,71 \pm 3,81^{b}$ & $50,64 \pm 1,92^{\mathrm{bc}}$ \\
\hline MUFA & $39,25 \pm 2,80^{b f}$ & $33,11 \pm 2,72^{\mathrm{a}}$ & $34,67 \pm 2,42^{\text {af }}$ & $33,56 \pm 1,21^{\mathrm{ac}}$ & $35,37 \pm 3,00^{\text {aef }}$ & $37,79 \pm 0,90^{\text {be }}$ & $36,75 \pm 4,61^{\text {adef }}$ & $37,62 \pm 1,99^{b f}$ & $36,91 \pm 2,72^{\mathrm{bcf}}$ & $33,44 \pm 5,64^{\text {adef }}$ & $36,05 \pm 3,98^{\mathrm{bcf}}$ & $40,27 \pm 2,33^{\mathrm{bd}}$ \\
\hline PUFA & $7,33 \pm 2,82^{\mathrm{b}}$ & $14,43 \pm 8,20^{\mathrm{ac}}$ & $11,47 \pm 4,55^{\mathrm{ab}}$ & $18,99 \pm 4,25^{\mathrm{a}}$ & $16,21 \pm 6,29^{\mathrm{ac}}$ & $12,29 \pm 2,02^{b c}$ & $10,25 \pm 4,63^{\mathrm{ab}}$ & $9,87 \pm 2,24^{\mathrm{b}}$ & $12,08 \pm 2,94^{\mathrm{bc}}$ & $19,34 \pm 8,01^{\mathrm{ab}}$ & $15,30 \pm 6,84^{\mathrm{ab}}$ & $10,07 \pm 2,15^{b}$ \\
\hline PUFA n3 & $1,42 \pm 0,80^{\mathrm{ac}}$ & $3,15 \pm 0,82^{\mathrm{ab}}$ & $2,98 \pm 0,49^{\mathrm{bcd}}$ & $3,77 \pm 1,87^{\text {bd }}$ & $4,58 \pm 0,94^{\mathrm{b}}$ & $3,44 \pm 0,50^{\mathrm{bd}}$ & $3,35 \pm 3,24^{\mathrm{ab}}$ & $2,61 \pm 0,62^{\mathrm{ad}}$ & $2,97 \pm 0,77^{\mathrm{ab}}$ & $3,32 \pm 0,99^{\mathrm{bcd}}$ & $4,05 \pm 1,24^{\mathrm{ab}}$ & $1,91 \pm 0,27^{\mathrm{a}}$ \\
\hline PUFA n6 & $5,90 \pm 2,13^{\mathrm{b}}$ & $11,74 \pm 7,75^{\mathrm{ac}}$ & $8,84 \pm 4,14^{\mathrm{ab}}$ & $13,13 \pm 4,28^{\mathrm{a}}$ & $12,83 \pm 5,68^{\mathrm{acd}}$ & $8,91 \pm 1,84^{b c}$ & $8,14 \pm 1,79^{\text {bd }}$ & $7,13 \pm 1,65^{\mathrm{b}}$ & $9,20 \pm 2,20^{\mathrm{bc}}$ & $15,90 \pm 7,09^{\mathrm{ab}}$ & $11,25 \pm 5,89^{\mathrm{ab}}$ & $8,15 \pm 2,07^{b c}$ \\
\hline C18 n3 & $0,05 \pm 0,12^{\text {be }}$ & $0,20 \pm 0,12^{\mathrm{ab}}$ & $0,15 \pm 0,20^{\mathrm{ab}}$ & $0,14 \pm 0,19^{b c}$ & $0,70 \pm 0,31^{\mathrm{a}}$ & $0,58 \pm 0,24^{\mathrm{ac}}$ & $0,10 \pm 0,15^{\mathrm{ad}}$ & $0,08 \pm 0,06^{\mathrm{bd}}$ & $0,39 \pm 0,17^{\text {ace }}$ & $0,15 \pm 0,18^{\mathrm{ab}}$ & $0,30 \pm 0,41^{\mathrm{ab}}$ & $0,08 \pm 0,02^{\text {bd }}$ \\
\hline C20-22 n3 & $1,38 \pm 0,69^{\mathrm{ac}}$ & $2,86 \pm 0,77^{\mathrm{bcd}}$ & $2,95 \pm 0,65^{\mathrm{bcd}}$ & $3,24 \pm 1,92^{\text {bd }}$ & $3,88 \pm 0,65^{\mathrm{b}}$ & $3,01 \pm 0,43^{\mathrm{bd}}$ & $2,99 \pm 3,23^{\mathrm{ab}}$ & $2,59 \pm 0,58^{\mathrm{ad}}$ & $2,76 \pm 0,67^{\mathrm{ab}}$ & $2,88 \pm 0,98^{\mathrm{bcd}}$ & $3,04 \pm 1,02^{\mathrm{ab}}$ & $1,80 \pm 0,28^{\mathrm{a}}$ \\
\hline
\end{tabular}




\begin{tabular}{|c|c|c|c|c|c|c|c|c|c|c|c|c|}
\hline C18 n6 & $1,62 \pm 0,39^{\mathrm{bc}}$ & $1,84 \pm 0,44^{\mathrm{bc}}$ & $1,74 \pm 0,44^{\text {bc }}$ & $3,13 \pm 1,12^{\mathrm{a}}$ & $1,77 \pm 0,39^{\mathrm{bc}}$ & $2,14 \pm 0,50^{\mathrm{b}}$ & $1,34 \pm 0,67^{\mathrm{bc}}$ & $1,14 \pm 0,44^{\mathrm{c}}$ & $1,65 \pm 0,32^{\mathrm{bc}}$ & $1,90 \pm 1,03^{\mathrm{abc}}$ & $1,54 \pm 0,43^{\mathrm{bc}}$ & $1,79 \pm 0,39^{\mathrm{bc}}$ \\
\hline C20-22 n6 & $4,28 \pm 1,74^{\mathrm{a}}$ & $9,41 \pm 7,76^{\mathrm{bc}}$ & $6,55 \pm 4,17^{\mathrm{ab}}$ & $8,01 \pm 3,85^{\mathrm{bc}}$ & $10,43 \pm 5,56^{b}$ & $6,65 \pm 1,48^{\mathrm{ac}}$ & $6,13 \pm 2,24^{\mathrm{ab}}$ & $5,28 \pm 1,44^{\text {ad }}$ & $7,30 \pm 2,14^{\mathrm{ab}}$ & $14,26 \pm 6,31^{\mathrm{ab}}$ & $9,34 \pm 6,09^{\mathrm{bcd}}$ & $2,13^{\mathrm{ab}}$ \\
\hline
\end{tabular}

${ }^{a b}$ Letras diferentes significam diferenças estatísticas $(\mathrm{P}<0,05)$ ao longo do ciclo anual para fêmeas. Valores abaixo de 0.1 não foram considerados. SFA, MUFA, PUFA,

PUFAn6, C18n6, C20-22n6, PUFAn3, C18n3 e C20-22n3, são as somatórias dos ácidos graxos saturados, monoinsaturados, polinsaturados n6, cadeias curtas de

polinsaturados n6, cadeias longas de polinsaturados n6, polinsaturados n3, cadeias curtas de polinsaturados n3, cadeias longas de polinsaturados n3. 
